\title{
Die gelöschte Limited mit Restvermögen
}

\section{in Deutschland}

Diplomarbeit

von

Herrn Kay Müller

Technische Fachhochschule Wildau

Fachbereich Wirtschaft, Verwaltung und Recht

Eingereicht am: 22. Mai 2009

Erstbetreuer: Herr Prof. Dr. Jörg Peter

Zweitbetreuer: Herr RA Ulf Claus 


\section{Inhaltsverzeichnis}

Inhaltsverzeichnis..................................................................................................................................II

Abkürzungsverzeichnis ............................................................................................................... IV

1. Einleitung ................................................................................................................................................1

2. Die englische Limited ................................................................................................................5

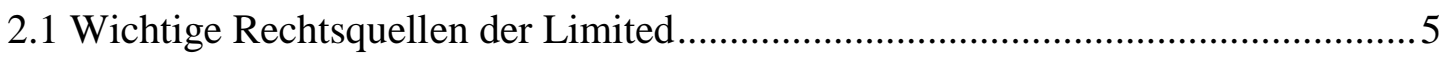

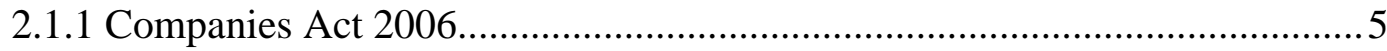

2.1.2 Company Directors Disqualification Act 1986 .........................................

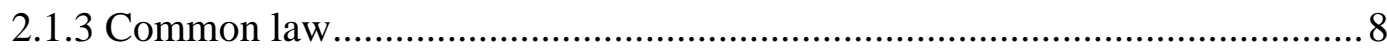

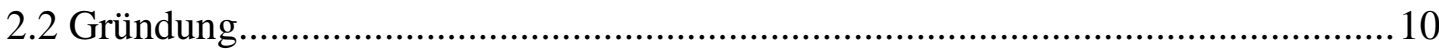

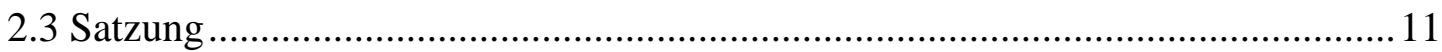

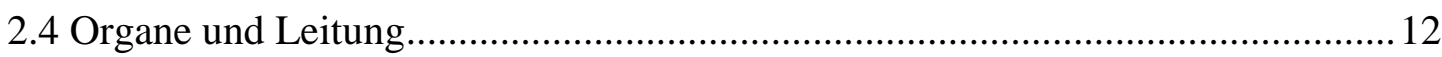

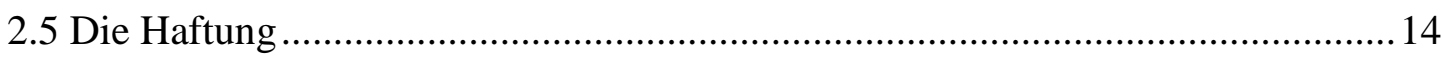

2.6 Die Rechnungslegungs- und Publizitätsvorschriften ......................................... 14

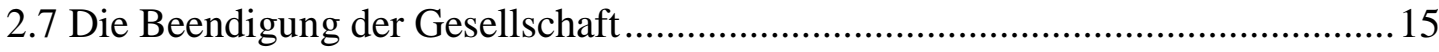

3. Internationales Privat- und Europarecht..........................................................16

3.1 Grundstruktur des Internationalen Privatrechts ............................................... 16

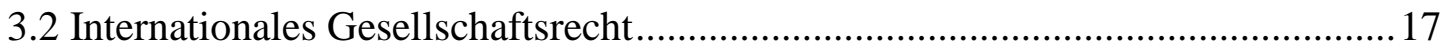

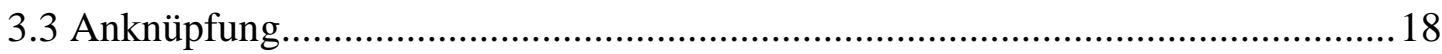

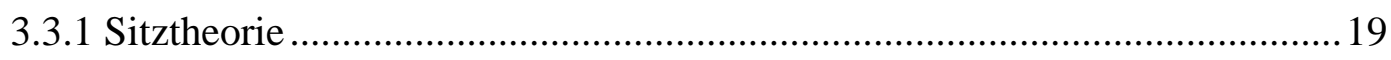

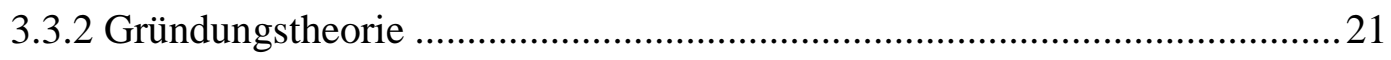

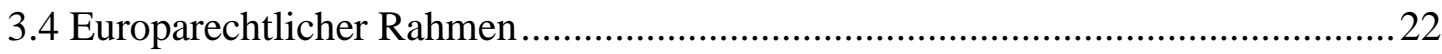

3.4.1 Europäische Niederlassungsfreiheit........................................................2 22

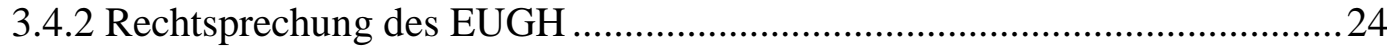

3.5 Folgen für das deutsche Internationale Gesellschaftsrecht ................................26

3.6 Richtlinien und Verordnungen (Sekundärrecht) ............................................26

4. Die Rechtsfolgen der Löschung für das in Deutschland belegene Vermögen.....28

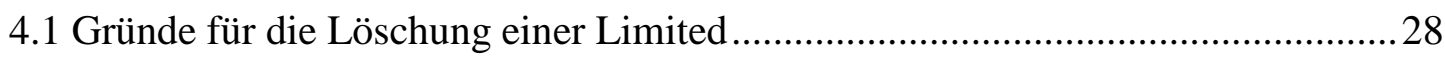

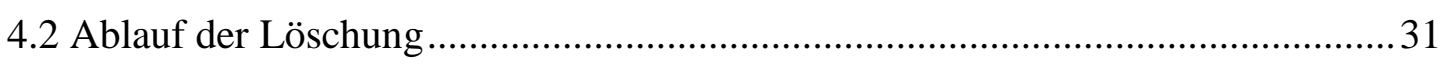

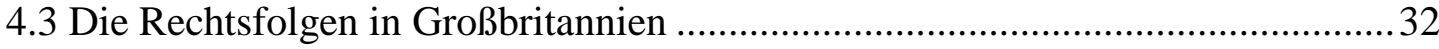




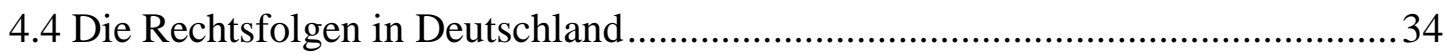

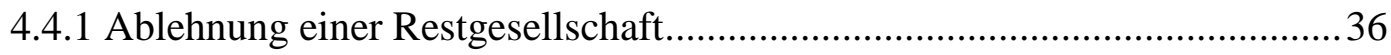

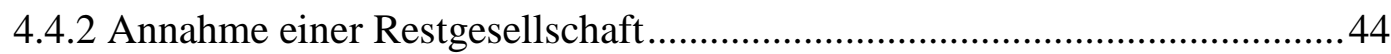

4.4.2.1 Die Lehre der Rest- und Spaltgesellschaft ..................................... 46

4.4.2.2 Anwendbarkeit der Restgesellschaft für die Rest-Limited................ 47

4.4.3 Gesellschaftsstatut der Rest-Limited ...................................................... 49

4.4.4 Rechts- und Parteifähigkeit der Rest-Limited ...........................................5 54

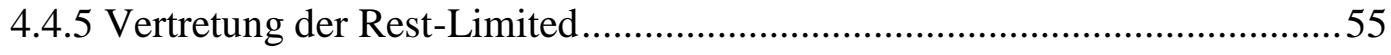

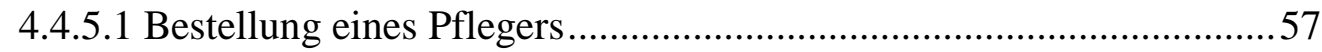

4.4.5.2 Bestellung eines Nachtragsliquidators...........................................57

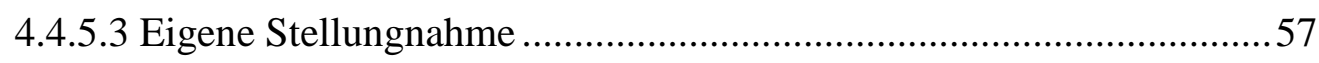

4.4.6 Die Liquidation der Rest-Limited ..........................................................59

4.4.7 Haftung der Vertreter der Rest-Limited ................................................. 60

4.4.8 Haftung der Gesellschafter der Rest-Limited ............................................ 61

4.4.9 Insolvenzfähigkeit der Rest-Limited ......................................................61

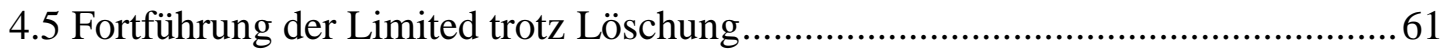

4.6 Die Möglichkeit der Wiedereintragung im register of companies....................... 62

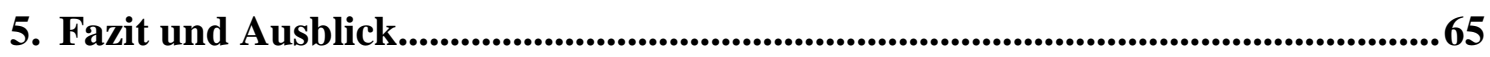

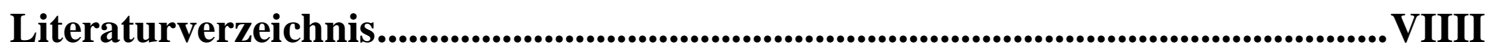

Internetquellenverzeichnis ......................................................................................XII

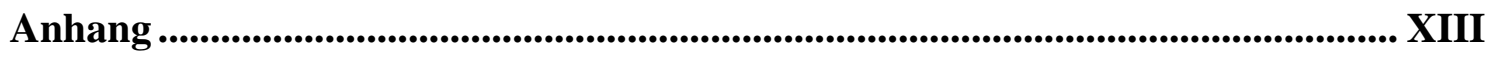

Anhang 1: Table of Commencement Dates ....................................................... XIII

\section{Selbständigkeitserklärung}




\section{Abkürzungsverzeichnis}

ABl. EG Amtsblatt der Europäischen Gemeinschaft

AktG Aktiengesetz

BayObLG Bayerische Oberste Landesgericht

BB Betriebsberater

BERR Department for Business, Enterprise and Regulatory Reform

BGBl. Bundesgesetzblatt

BGH Bundesgerichtshof

BGHZ Entscheidungssammlung des Bundesgerichtshof in Zivilsachen

BMJ Bundesministerium der Justiz

BT-Drucks. Bundestagsdrucksache

BV Besloten Vennootschap met beperkte aansprakelijkheid

(Eine Kapitalgesellschaft des niederländischen Rechts, vergleichbar mit der GmbH in Deutschland)

CA Companies Act

CDDA Companies Directors Disqualification Act

COMI center of main interest

DTI Department for Trade and Industry

EG Europäische Gemeinschaft

EGBGB Einführungsgesetz zum Bürgerlichen Gesetzbuch

EGV Vertrag zur Gründung der Europäischen Gemeinschaft

EHUG Gesetz über elektronische Handelsregister und Genossenschaftsregister sowie das Unternehmensregister

EU Europäische Union

EuGH Europäischer Gerichtshof

EuGVVO Verordnung des Rates über die gerichtliche Zuständigkeit und die Anerkennung und Vollstreckung von Entscheidungen in Zivil- und Handelssachen

EuInsVO Europäische Insolvenzordnung

EWR Europäischer Wirtschaftsraum

Fn. $\quad$ Fußnote 


$\begin{array}{ll}\text { GBP } & \text { Great Britain Pound } \\ \text { GbR } & \text { Gesellschaft bürgerlichen Rechts } \\ \text { GewO } & \text { Gewerbeordnung } \\ \text { GmbHG } & \text { GmbH-Gesetz } \\ \text { GmbHR } & \text { GmbH-Rundschau } \\ \text { h. M. } & \text { herrschende Meinung } \\ \text { Halbs. } & \text { Halbsatz } \\ \text { Hrsg. } & \text { Herausgeber } \\ \text { i. V. m. } & \text { in Verbindung mit } \\ \text { IA } & \text { Insolvency Act } \\ \text { IPR } & \text { Internationales Privatrecht } \\ \text { IPRax } & \text { Praxis des Internationalen Privat- und Verfahrensrechts } \\ \text { IZVR } & \text { Internationales Zivilverfahrensrecht } \\ \text { KostO } & \text { Gesetz über die Kosten in Angelegenheiten der freiwilligen } \\ \text { l. r. s. } & \text { Gerichtsbarkeit (Kostenordnung) } \\ \text { lat. } & \text { lex rei sitae } \\ \text { Limited } & \text { private company limited by shares } \\ \text { Ltd, Ltd. } & \text { Limited } \\ \text { m. w. N. } & \text { mit weiteren Nachweisen } \\ & \end{array}$

MoMiG Gesetz zur Modernisierung des GmbH-Rechts und zur Bekämpfung von Missbräuchen

NJW Neue Juristische Wochenschrift

NZG Neue Zeitschrift für Gesellschaftsrecht

OHG Offene Handelsgesellschaft

OLG Oberlandesgericht

RG Reichsgericht

RGZ Entscheidungssammlung des Reichsgerichts in Zivilsachen

Rn. Randnummer

Slg. Sammlung der Rechtsprechung des Gerichtshof der Europäischen Gemeinschaft 
TSol Treasury Solicitor's Department

Tz. Textziffer

UG Unternehmergesellschaft

ZGR Zeitschrift für Gesellschaftsrecht

ZInsO Zeitschrift für das gesamte Insolvenzrecht

ZIP Zeitschrift für Wirtschaftsrecht

ZPO Zivilprozessordnung

ZustErgG Zuständigkeitsergänzungsgesetz 


\section{Einleitung}

In den vergangenen Jahren gab es einen Ansturm deutscher Unternehmensgründer auf die englische ${ }^{1}$ private company limited by shares (im Folgenden kurz: Limited oder Ltd.), welche das englische Pendant zur deutschen $\mathrm{GmbH}$ bildet. $^{2}$

Gemäß der Becht-Studie wurden allein bis Ende 2006 mehr als 40.000 Ltds. mit Verwaltungssitz in Deutschland gegründet. ${ }^{3}$ Davon allein 9.038 im Jahr 2004, 12.777 im Jahr 2005 und 15.633 im Jahr 2006. ${ }^{4}$ Diese Zahlen machen deutlich, dass Limiteds mit Verwaltungssitz in Deutschland einen nicht unerheblichen Anteil der haftungsbeschränkten Unternehmen in Deutschland ausmachen.

Der Grund für diesen enormen Anstieg ${ }^{5}$ an Neugründungen waren die wegweisenden Entscheidungen des EuGH in den Sachen „Centros“66, „Überseering ${ }^{667}$ und „Inspire Art $^{6 / 8}$. Diese ermöglichen es Gesellschaften, die nach dem Recht eines Mitgliedsstaates in zulässiger Weise gegründet wurden, ihren Verwaltungssitz ${ }^{9}$ in einem anderen Staat

${ }^{1}$ Wenn in dieser Arbeit von der englischen Limited bzw. vom englischen Recht gesprochen wird, dann ist zu beachten, dass dieses Recht nicht nur in England, sondern ebenfalls in Wales gilt.

2 Buchmann, T. (2007), Die Insolvenz der englischen Limited in Deutschland. De lege lata sowie im Gefüge der Modernisierung des europäischen Gesellschaftsrechts, Baden-Baden, S. 25. Ausführlich zur Unternehmensform private company limited by shares in Kapitel 2.

${ }^{3}$ Becht, M. u. a. (2008), Where do firms incorporate? Deregulation and the cost of entry, in: Journal of Corporate Finance, S. 248.

${ }^{4}$ Selbst Niemeier, der sich kontinuierlich sehr skeptisch über veröffentlichte Daten und Studien zur möglichen Anzahl neu gegründeter Limiteds mit Verwaltungssitz in Deutschland äußert, hält diese Zahlen für realistisch. Niemeier, W. (2007), Die "Mini-GmbH" (UG) trotz Marktwende bei der Limited?, in: ZIP, S. 1794 ff.; zuvor sehr ausführlich: Niemeier, W. (2006), GmbH und Limited im Markt der Unternehmensrechtsträger, in: ZIP, S. 2237 ff. Westhoff geht von mehr als 46.000 bis zum 1.11.2006 aus. Siehe hierzu Westhoff, O. (2007), Die Verbreitung der englischen Limited mit Verwaltungssitz in Deutschland, in: GmbHR, S. 478.Man kann diese Zahlen also als unterste Grenze für die Anzahl an Gründungen ansehen.

${ }^{5}$ Zum Vergleich: laut Becht-Studie waren es 2002 gerade einmal 420.

${ }^{6}$ EuGH vom 9.3.1999, GmbHR 1999, S. 474 ff.

${ }^{7}$ EuGH vom 5.11.2002, GmbHR 2002, S. 1137 ff.

${ }^{8}$ EuGH vom 30.9.2003, GmbHR 2003, S. 1260 ff.

${ }^{9}$ Dabei versteht man unter dem Verwaltungssitz den Ort, an dem die grundlegenden Entscheidungen der Unternehmensleitung effektiv in laufende Geschäftsführungsakte umgesetzt werden. Vgl. hierzu BGH vom 21.3.1986, BGHZ 97, S. 269 ff. (272). 
der $\mathrm{EU}^{10}$ einzunehmen, ohne nachhaltig in ihrer rechtlichen Organisation berührt zu werden. ${ }^{11}$

Der Konkurrenzkampf der europäischen Gesellschaftsformen war damit eröffnet. Die englische Limited hat sich dabei zur beliebtesten Alternative zur GmbH in Deutschland entwickelt. Grund hierfür ist vor allem die Haftungsbeschränkung ihrer Gesellschafter für die Verbindlichkeiten der Gesellschaft, das fehlende gesetzliche Erfordernis eines bestimmten Mindestkapitals und die Schnelligkeit, mit der diese errichtet werden kann. ${ }^{12}$ Mittlerweile gibt es viele Anbieter, die potenzielle Gründer bei der Errichtung einer Ltd. unterstützen bzw. dies komplett übernehmen. Diese LimitedVermarktungsunternehmen werben mit den o. g. Vorteilen der Limited und bieten die Gründung einer solchen Gesellschaft zu sehr niedrigen Preisen an. ${ }^{13}$ Hinzu kommt, dass durch den Companies Act 2006 (CA 2006) die Limited noch wettbewerbsfähiger gemacht und im internationalen Vergleich gestärkt werden soll, in dem zahlreiche Vereinfachungen für diese Unternehmensform eingeführt wurden. ${ }^{14}$

Doch auch der deutsche Gesetzgeber war nicht untätig und hat mit dem Gesetz zur Modernisierung des GmbH-Rechts und zur Bekämpfung von Missbräuchen (MoMiG) ein Gesetz verabschiedet, das nicht nur den Missbrauch der GmbH bekämpfen, sondern diese, vor allem auch im Vergleich zur Limited, attraktiver machen soll. ${ }^{15}$

Ob sich durch die Vereinfachungen und Änderungen, die das MoMiG ins deutsche Gesellschaftsrecht eingeführt hat, in Zukunft wirklich weniger deutsche Unternehmensgründer für die englische Limited entscheiden werden, ist nicht abzusehen. Dagegen scheint zu sprechen, dass sich in der Vergangenheit anscheinend besonders viele Unternehmensgründer für diese Gesellschaftsform entschieden haben,

${ }^{10} \mathrm{Zu}$ beachten ist, dass dies ebenfalls für Mitgliedsstaaten des EWR, also Liechtenstein, Island und Norwegen gilt.

${ }^{11}$ Vgl. hierzu Kapitel 3.4.2.

${ }^{12}$ Vgl. hierzu Just, C. (2008a), Die englische Limited in der Praxis, 3. Aufl., München, Rn. 211.

${ }^{13}$ Z. B. $185 €$ für die „Auftragsregistrierung Limited” bei Limited4you, Vgl. hierzu L4You Ltd. (Hrsg.) (2009), http://www.limited4you.de/preise/einzelpreise-2.html, 10.3.2009.

14 Vgl. weiterführend hierzu Just, C. (Hrsg.) (2008b), Englisches Gesellschaftsrecht. Companies Act 2006, Limited Liability Partnerships Act 2000, München, S. 1.

${ }^{15}$ Vgl. Bundesministerim der Justiz (Hrsg.) (2008), Pressemitteilung des BMJ vom 30.10.2008, http://www.bmj.bund.de/enid/5c1d0f0cc7d08ec98ad9dc52965ce39e,a57133636f6e5f6964092d0935343 637093a095f7472636964092d0932303736/Pressestelle/Pressemitteilungen_58.html, 12.3.2009. 
die entweder kein Interesse an einer seriösen Tätigkeit haben, oder mit der Führung eines Unternehmens überfordert sind und hoffen, so unter den Schirm des vermeintlich weniger strengen, englischen Gesellschaftsrechts fliehen zu können. ${ }^{16}$ Hinzu kommt, dass viele Unternehmer mangels fehlenden Eigenkapitals nicht in der Lage sind, die erforderliche Mindeststammkapitaleinzahlung einer deutschen $\mathrm{GmbH} \mathrm{zu}$ erbringen. Diese Vermutung ergibt sich bei Betrachtung der hohen Insolvenzquote der Limiteds mit Verwaltungssitz in Deutschland. In 2007 wurden 552 Insolvenzverfahren für private companies limited by shares beantragt. ${ }^{17}$ Noch dramatischer gestaltet sich die Lage, wenn man beachtet, dass davon nur 183 Verfahren eröffnet wurden und 369 mangels Masse abgewiesen wurden. Die Eröffnungsquote ist damit bei keiner anderen Rechtsform so gering wie bei der Limited.

Doch nicht nur die Insolvenz der Limited mit Verwaltungssitz in Deutschland beschäftigt die deutschen Gerichte. Immer häufiger haben sie es auch mit Limiteds zu tun, die in England aus dem Gesellschaftsregister (register of companies ${ }^{18}$ ) gelöscht wurden und über Vermögen in Deutschland verfügen. ${ }^{19}$ Der Grund für die Löschung (striking off) sind in der Regel die aus deutscher Sicht sehr strengen englischen Publizitätsvorschriften, die in letzter Konsequenz die Löschung und damit Auflösung der Gesellschaft zur Folge haben. ${ }^{20}$ Die Anzahl der davon betroffenen Limiteds wird in den nächsten Monaten voraussichtlich stark ansteigen, da viele von ihnen erstmals zur Erfüllung dieser Pflichten verpflichtet sind.

Wie mit dem in Deutschland belegenen Vermögen einer solchen gelöschten private company limited by shares (kurz: Rest-Limited) sachgerecht zu verfahren ist, bildet den Hauptteil dieser Arbeit (Kapitel 4). Hierbei soll zunächst auf die Gründe und den Ablauf der Löschung einer Limited aus dem register of companies eingegangen werden.

\footnotetext{
${ }^{16}$ Schmittmann, J. M. (2007), Die scheinausländische Gesellschaft, in: NZI, S. VI.

17 Statistisches Bundesamt (Hrsg.) (2008), Statistisches Jahrbuch 2008 Für die Bundesrepublik Deutschland, http://www.destatis.de/jetspeed/portal/cms/Sites/destatis/SharedContent/Oeffentlich/AI/ IC/Publikationen/Jahrbuch/StatistischesJahrbuch,property=file.pdf., S. 502, 10.4.2009.

${ }^{18}$ Ein mit dem deutschen Handelsregister vergleichbares Register das beim Companies House geführt wird und unter http://companieshouse.gov.uk eingesehen werden kann. Hier sind alle englischen haftungsbeschränkten Gesellschaften registriert.

${ }^{19}$ Vgl. OLG Jena vom 22.8.2007, in: ZIP 2007, S. 1709 ff. (1710); OLG Nürnberg vom 10.8.2007, in: GmbHR 2008, S. 41 ff. (42); jüngst AG Charlottenburg vom 7.11.2008, in: GmbHR 2009, S. 321 ff.

${ }^{20}$ Ausführlich dazu in Kapitel 4.1.
} 
Im Anschluss daran sollen die verschiedenen Ansätze zur rechtlichen Qualifikation des in Deutschland belegenen Vermögens betrachtet werden. Nachfolgend werden eingehend die Probleme erläutert, die im Zusammenhang mit der Rest-Limited entstehen und mögliche Lösungswege für diese aufgezeigt. Danach erfolgen in Kapitel 5 eine Zusammenfassung der Arbeit und ein Ausblick auf mögliche zukünftige Entwicklungen. Zuerst werden jedoch in Kapitel 2 die Rechtsgrundlagen sowie die Gründung und Organisation der englischen private company limited by shares betrachtet. Zur Erarbeitung dieser Grundlagen wird von einer Limited ausgegangen, die nicht nur ihren Satzungssitz in England, sondern dort auch ihren Verwaltungssitz inne hat. Im Anschluss daran soll in Kapitel 3 auf das Internationale Privatrecht sowie den europarechtlichen Rahmen dieser Arbeit eingegangen werden. Hier sollen auch die rechtlichen Probleme des Auseinanderfallens von Verwaltungs- und Satzungssitz der Gesellschaft aufgezeigt werden.

In der vorliegenden Arbeit wurden Literatur und veröffentlichte Rechtsprechung bis einschließlich März 2009 berücksichtigt. Um nicht nur eine kurze Momentaufnahme zu thematisieren wird hier bereits die volle Umsetzung des Companies Act $2006 \mathrm{zu}$ Grunde gelegt, auch wenn dieser in vollem Umfang erst zum 1. Oktober 2009 in Kraft tritt. $^{21}$

${ }^{21}$ Für eine Übersicht der Zeitpunkte des Inkrafttretens der verschiedenen Abschnitte des CA 2006 siehe Anhang 1. Bei Unterschieden zwischen aktuellen Regelungen und dem CA 2006 wird in dieser Arbeit darauf hingewiesen. Ausführlich zu den Regelungen gemäß CA 1985 siehe Just, C. (2005), Die englische Limited in der Praxis, München. 


\section{Die englische Limited}

Da die (gelöschte) Limited „Hauptdarstellerin“ dieser Arbeit ist, ist es zunächst notwendig, sich mit ihrer Grundstruktur und dem sie regelnden englischen Gesellschaftsrecht (company law) ${ }^{22}$ auseinanderzusetzen. Dabei soll die Betrachtung in diesem Kapitel jedoch nicht über das hinausgehen, was für die Problemstellung dieser Arbeit relevant ist. ${ }^{23}$

\subsection{Wichtige Rechtsquellen der Limited}

Im Gegensatz zu vielen anderen Rechtsbereichen ist im englischen Gesellschaftsrecht die Regelungstiefe sehr weit fortgeschritten. ${ }^{24}$ Dies liegt vor allem daran, dass zahlreiche europäische Richtlinien in England umgesetzt werden mussten. Das wichtigste Gesetz für englische Kapitalgesellschaften ist der Companies Act 2006. Ergänzend hierzu sind vor allem der Company Directors Disqualification Act 1986 (CDDA 1986), der Insolvency Act $1986^{25}$ (IA 1986), das common law, i. S. d. richterlichen Fallrechts und selbstverständlich die Satzung ${ }^{26}$ der Gesellschaft von Bedeutung. ${ }^{27}$

\subsubsection{Companies Act 2006}

Der Companies Act 2006 bildet die Rechtsgrundlage der private company limited by shares, da er alle englischen Kapitalgesellschaften regelt. ${ }^{28}$ Er unterscheidet zwischen

\footnotetext{
${ }^{22}$ Während nach dem deutschen Rechtsverständnis mit Gesellschaftsrecht sowohl das Kapital- als auch das Personengesellschaftsrecht bezeichnet werden, bezeichnet company law nur das Recht der Kapitalgesellschaften, das Recht der Personengesellschaften heißt abgrenzend dazu partnership law. Vgl. hierzu Just, C. (Hrsg.) (2008b), S. 5 f.

${ }^{23}$ Für einen Überblick über das englische Recht und seine Geschichte siehe Graf von Bernstorff, C. (2006), Einführung in das englische Recht, 3. Aufl., München. Speziell zum Recht der Limited siehe m. w. N. Just, C. (2008a). Ausführlich, in englischer Sprache, zum company law siehe Davies, P. L. (2008), Gower and Davies' Principles of Modern Company Law, 8. Aufl., London.

${ }^{24}$ Just, C. (Hrsg.) (2008b), S. 1 ff.

${ }^{25}$ Da der Insolvency Act 1986 für die vorliegende Arbeit nicht relevant ist, wird auf seine Darstellung verzichtet. Einen guten Einblick liefert: Goode, R. (2005), Principles of Corporate Insolvency Law, 3. Aufl., London.

${ }^{26}$ Vgl. hierzu Kapitel 2.3.

${ }^{27}$ Just, C. (2008a), Rn. 17.

${ }^{28}$ Vgl. Just, C. (Hrsg.) (2008b), S. 6.
} 
private und public companies. ${ }^{29}$ Zwischen diesen beiden Gesellschaftsformen gibt es zwei zentrale Unterscheidungsmerkmale. ${ }^{30}$ Zum einen dürfen die Geschäftsanteile einer private company nicht zum öffentlichen Handel angeboten werden, also nicht an der London Stock Exchange oder dem Alternative Investment Market gehandelt werden. ${ }^{31}$ Zum anderen hat nur die public company ein festgeschriebenes Mindestkapital von GBP $50.000 .^{32}$ Ein weiteres Differenzierungsmerkmal für Kapitalgesellschaften ist im CA 2006 die Art der Haftungsbeschränkung, ${ }^{33}$ entweder durch Anteile (shares), oder eine Garantiesumme (guarantee).$^{34}$

Der Companies Act 2006 ist das Ergebnis eines acht Jahre währenden Reformprozesses des englischen Kapitalgesellschaftsrechts. ${ }^{35}$ Ziel war es, den rechtlichen Rahmen für Kapitalgesellschaften $\mathrm{zu}$ schaffen, der besonders kleineren und mittelgroßen Unternehmen entgegenkommt. Um dies zu erreichen wurde der CA 2006 nach dem sog. „Think small first“ - Prinzip strukturiert. Während der CA 1985 noch von der (größeren) public company als Grundmodell ausging und Sonderregelungen für die (kleinere) private company beinhaltete, wurde dieses Prinzip jetzt umgekehrt. Im CA 2006 bildet jetzt also die private company die Grundlage der Kodifikation, und es gibt zusätzliche Regelungen für die public company. ${ }^{36}$ Dadurch soll das Gesetz für kleinere und mittlere Unternehmen übersichtlicher und einfacher $\mathrm{zu}$ handhaben sein und die Limited im Wettbewerb der europäischen haftungsbeschränkten Gesellschaftsformen noch attraktiver werden.

Nachdem beide Kammern des englischen Parlaments (House of Lords und House of Commons) dem CA 2006 zugestimmt hatten, erhielt dieser am 8. November 2006 den sog. royal assent, also die königliche Genehmigung. Damit ist dieses Gesetz zwar

\footnotetext{
${ }^{29}$ Vgl. section 4 CA 2006.

${ }^{30}$ Section 4 (4) CA 2006.

${ }^{31}$ Section 755 ff. CA 2006.

32 Section 763 CA 2006. Das Kapital der private company limited by shares kann im Falle der „Einpersonen-Limited“ auf einen Penny begrenzt werden, Vgl. sections 633, 630 CA 2006.

33 Es gibt auch noch die unlimited company, section 3 (4) CA 2006, die eben gerade keine Haftungsbeschränkung hat, jedoch ist diese in der Praxis wenig bedeutsam.

${ }^{34}$ Section 3 CA 2006.

${ }^{35}$ Vgl. Just, C. (Hrsg.) (2008b), S. 7.

${ }^{36}$ Lembeck, E. D. (2003), UK Company Law Reform - Ein Überblick, in: NZG, S. 962.
} 
verabschiedet, jedoch erfolgt die Umsetzung in unterschiedlichen Stufen, gem. sog. commencement orders. ${ }^{37}$ Diese bestimmen, wann welcher Abschnitt des CA 2006 in Kraft tritt. ${ }^{38}$ Eigentlich sollte das gesamte Regelwerk bereits zum 1. Oktober 2008 Rechtswirkung erlangen, jedoch hat sich der Zeitpunkt verschoben. Der Grund hierfür ist, dass es beim Companies House länger als erwartet dauert, die Computersysteme und Arbeitsprozesse an die neuen Regelungen anzupassen. ${ }^{39}$ Die letzten Teile des CA 2006 treten jetzt erst am 1. Oktober 2009 in Kraft. Im Folgenden wird bereits von der vollen Umsetzung ausgegangen. Sofern jedoch inhaltliche Unterschiede zum aktuell geltenden Recht bestehen, wird auf diese hingewiesen.

\subsubsection{Company Directors Disqualification Act 1986}

Bereits seit dem Companies Act 1928 kennt das englische Recht die Möglichkeit, Direktoren (directors) ${ }^{40} \mathrm{zu}$ disqualifizieren (disqualification). ${ }^{41}$ Das Institut der Disqualifikation hat sich über die Jahre in mehreren Etappen weiter entwickelt und ist im Zuge der Insolvenzrechtsreform der Jahre 1985/1986 entscheidend verschärft worden. ${ }^{42}$ Kodifiziert wurde es letztendlich im Company Directors Disqualification Act 1986 (CDDA 1986) als Nebengesetz des CA 2006.

Der CDDA 1986 leistet einen wesentlichen Beitrag zum Schutz des Rechtsverkehrs. Insbesondere soll durch seine Regelungen der Missbrauch der Gesellschaftsformen mit beschränkter Haftung im Interesse des Gläubigerschutzes und zum Schutz der Allgemeinheit verhindert werden. ${ }^{43}$ Dies erfolgt einerseits durch die Aufstellung von Mindeststandards für directors und zum anderen durch die Möglichkeit, ungeeignete

37 Hierbei handelt es sich um Rechtsverordnungen, die vom Wirtschaftsministerium, ehemals DTI (Department for Trade and Industry) jetzt BERR (Department for Business, Enterprise and Regulatory Reform) erlassen werden. Das BERR ist der Nachfolger des DTI und wurde im Juni 2007 gegründet.

${ }^{38}$ Für eine Übersicht der Zeitpunkte des Inkrafttretens der verschiedenen Abschnitte des CA 2006 siehe Anhang 1.

39 Vgl. Pressemitteilung des BERR (Hrsg.), vom 13.12.2007, auf http://www.berr.gov.uk/ whatwedo/businesslaw/co-act-2006/whatsnew/page42866.html, 16.3.2009.

${ }^{40}$ Vergleichbar mit dem Geschäftsführer einer deutschen GmbH.

${ }^{41}$ Höfling, B. S. (2002), Das englische internationale Gesellschaftsrecht, Heidelberg, S. 183 ff.

${ }^{42}$ Vgl. m. w. N. Bachner, T. (2007), Die Limited in der Insolvenz, Wien, S. 89.

${ }^{43}$ Vgl. Davies, P. L. (2008), S. 238; m. w. N. Zessel, M. (2008), Durchgriffshaftung gegenüber einer in Deutschland ansässigen Limited?, Baden-Baden, S. 290. 
directors $\mathrm{zu}$ entfernen und $\mathrm{zu}$ disqualifizieren. ${ }^{44}$ Die Disqualifikation, das Tätigkeitsverbot, wirkt zwar nur für die Zukunft, jedoch wird ihr durch ihre abschreckenden Sanktionen auch eine präventive Schutzfunktion zugesprochen. ${ }^{45}$ Britische Juristen sehen die disqualification als Eckpfeiler im verantwortungsvollen Umgang mit beschränkt haftenden Gesellschaften. ${ }^{46}$ Eine Bestätigung für diese Ansicht findet sich unter anderem in der Statistik. Diese weist jährlich über 1.000 Disqualifikationen aus. ${ }^{47}$

\subsubsection{Common law}

Das common law, i. S. d. richterlichen Fallrechts, hat in den vergangenen Jahren, vor allem durch den Beitritt Großbritanniens zur Europäischen Union 1977, an Bedeutung verloren, da europäische Vorgaben in Legislativgesetze umgesetzt werden müssen. Man muss sich jedoch immer bewusst sein, dass neben diesen Kodifikationen das common law, seine volle Gültigkeit behält und zur Rechtsfindung immer heranzuziehen ist. ${ }^{48}$

Der Begriff des common law begegnet jedem, der sich mit dem englischen Recht, dem Recht der Limited, beschäftigt. Da er jedoch verschiedene Bedeutungen haben kann und für das Verständnis des englischen Rechtssystems von überragender Bedeutung ist, soll an dieser Stelle Grundlegendes geklärt werden. Dadurch kann ein Verständnis für die spezifische Herangehensweise bei der Rechtsfindung im englischen Gesellschaftsrecht geschaffen und im weiteren Verlauf der Arbeit auf störende Exkurse verzichtet werden.

Im Bezug auf andere Rechtsordnungen dient der Begriff des common law zunächst einmal der Abgrenzung zum kontinentaleuropäischen, römisch-rechtlich beeinflussten Rechtssystem, dem civil law. ${ }^{49}$ Dabei kommt das common law jedoch nicht nur in England zur Anwendung. Vielmehr bildet es die Grundlage des sog. „englischen

\footnotetext{
${ }^{44}$ Höfling, B. S. (2002), S. 183 ff.

${ }^{45}$ Vgl. m. w. N. Zessel, M. (2008), S. 290.

${ }^{46}$ Bachner, T. (2007), S. 89.

${ }^{47}$ Vgl. Department of Trade and Industry (Hrsg.) (2006), Companies in 2005-2006. Report for the year ended 31. March 2006, London, Tabelle D1, S. 23.

${ }^{48}$ Vgl. Graf von Bernstorff, C. (2006), S. 153.

${ }^{49}$ Just, C. (Hrsg.) (2008b), S. 2 ff.
} 
Rechtskreises“ bzw. der großen „Common-law-Familie“. ${ }^{50}$ Kennzeichnend für dieses Rechtssystem ist, dass das vom Parlament in Gesetzesform gegossene Recht traditionell nur punktuell besteht und oftmals schlicht von den Gerichten entwickelte Rechtssätze aufgreift..$^{51}$

Bei der Rechtsfindung besteht der Unterschied zum civil law darin, dass diese nicht deduktiv, sondern induktiv erfolgt. Grundlage dafür ist, dass über viele Jahre entwickelte richterliche Fallrecht (case law). Ein Gericht muss sich zur Urteilsfindung immer an früheren Entscheidungen (precedents) orientieren. Dabei gilt die bindende Wirkung präjudizieller Entscheidungen (,doctrine of stare decisis"). Diese besagt, dass ein Gericht immer an einzelne Entscheidungen eines im Instanzenzug übergeordneten Gerichts gebunden ist. ${ }^{52}$ Die gilt jedoch nur hinsichtlich der tragenden Entscheidungsgründe (,ratio decidendi“). Es obliegt jedoch dem Gericht zu bestimmen, welche Gründe tragend sind, oder ob es sich nur um etwas nebenbei Gesagtes (,obiter dictum") handelt. Nur das oberste Gericht (House of Lords) behält sich seit 1966 vor, von älteren Entscheidungen abzuweichen.

Die ursprüngliche Bedeutung des Begriffs des common law liegt jedoch in der Bezeichnung des gemeinen Rechts aus dem Mittelalter. Es ersetzte in England und Wales die regionalen Bräuche und Gewohnheitsrechte durch ein gemeinsames Recht (common law). ${ }^{53}$ Dieses basierte auf starren Aktionssystemen (writs). ${ }^{54}$ Dabei handelte es sich um individuelle Formulare, die für bestimmte materiellrechtliche Konstellationen geschaffen wurden. Auf deren Einreichung hin wurden die Gerichte tätig. Wenn das konkrete Begehren jedoch nicht von einem writ erfasst wurde, war die entsprechende Rechtsdurchsetzung nach common law nicht möglich. ${ }^{55}$ Deswegen bildete sich parallel dazu das Billigkeitsrecht (equity) heraus, um etwaige Härten des common law auszugleichen und dieses zu ergänzen. Hierdurch konnten rechtliche

\footnotetext{
${ }^{50}$ Lyall, F. (2002), An Introduction to British Law, 2. Aufl., Baden-Baden, S. 22.

${ }^{51}$ Buchmann, T. (2007), S. 32; Vgl. Redmond, P. W. D./Shears, P. (1990), General Principles of English Law, 6. Aufl., London, S. 29.

52 Just, C. (Hrsg.) (2008b), S. 5.

${ }^{53}$ Redmond, P. W. D./Shears P. (1990), S. 4.

${ }^{54}$ Just, C. (Hrsg.) (2008b), S. 3.

${ }^{55}$ Graf von Bernstorff, C. (2006), S. 2 f.
} 
Begehren, die nach dem common law nicht verfolgbar waren, auf Antrag vom König bzw. dem Chancellor (dem höchsten Verwaltungsbeamten) und später dem Court of Chancery stattgegeben werden, wenn es nach Treu und Glauben recht und billig erschien. ${ }^{56}$ Auch hier bildete sich eine ,doctrine of stare decisis “ heraus. ${ }^{57}$ Bis zum Judiacature Act 1873 fielen common law und equity unterschiedlichen Gerichtsbarkeiten zu. Dieses fasste die verschiedenen Gerichtsbarkeiten zu einem einheitlichen High Court of Justice zusammen. ${ }^{58}$ Seit dem umfasst das richterliche Fallrecht beide Rechtswege.

Heute sowie in der vorliegenden Arbeit wird der Begriff des common law (meist) als Synonym für das richterliche Fallrecht gebraucht, als Abgrenzung zur legislativen Gesetzgebung (statutory law), egal ob es seinen Ursprung im common law oder equity hat. ${ }^{59}$

\subsection{Gründung}

Die Gründung einer private company limited by shares kann auf zwei Arten erfolgen. ${ }^{60}$ Entweder durch eine Neugründung der Gesellschaft, oder durch den Erwerb einer Vorratsgesellschaft (shelf company) von einer darauf spezialisierten Servicegesellschaft. ${ }^{61}$ Diese beschleunigen die Gründung noch einmal erheblich. ${ }^{62}$

Zur Gründung einer Limited mit Satzungssitz in England oder Wales muss diese beim Companies House in Cardiff registriert werden. ${ }^{63}$ Dazu müssen folgende Unterlagen eingereicht werden: das memorandum of association, ein Registrierungsantrag, die articles of association, eine Erklärung hinsichtlich des Kapitals und der ersten Kapitalanteile, eine Liste mit den Angaben $\mathrm{zu}$ den Direktoren und zum

\footnotetext{
${ }^{56}$ Buchmann, T. (2007), S. 34.

${ }^{57}$ Graf von Bernstorff, C. (2006), S. 4 f.

${ }^{58}$ Vgl. Just, C. (Hrsg.) (2008b), S. 4.

59 Vgl. hierzu Just, C. (Hrsg.) (2008b), S. 3; Buchmann, T. (2007), S. 34; Goode, R. (2005), S. 455; Davies, P. L. (2008), S. 53 f.

${ }^{60}$ Just, C. (2008a), Rn. 29.

${ }^{61} \mathrm{Vgl}$. hierzu z. B. www.jordans.co.uk, einem der bekanntesten Anbieter.

${ }^{62}$ Vgl. hierzu Kasolowsky B./Schall A. in: Hirte H./Bücker T. (Hrsg.) (2006), § 4 Rn. 23 ff.

${ }^{63}$ Innerhalb des Companies House ist dafür der Registrator (registrator) des Companies Registration Office zuständig.
} 
Gesellschaftssekretär (company secretary), falls die Gesellschaft einen bestimmt sowie eine Erklärung bzgl. der Einhaltung der gesetzlichen Anforderungen. ${ }^{64}$ Außerdem ist den Unterlagen regelmäßig ein Scheck über GBP 20 beizufügen, um die Registrierungsgebühren zu begleichen. ${ }^{65}$

All diese Dokumente werden vom Registerführer (Registrar of Companies) lediglich formell geprüft, eine materielle Prüfung erfolgt nicht. ${ }^{66}$ Der Registrar stellt daraufhin eine Gründungsurkunde (certificate of incorporation) aus, mit dem die Einhaltung der Eintragungsvoraussetzungen bestätigt wird. Das Ausstellungsdatum auf dieser Bescheinigung ist zugleich das Gründungsdatum der Gesellschaft. ${ }^{67}$ Gleichzeitig erhält die Gesellschaft eine Registernummer (registered number) und kann nunmehr als juristische Person mit einer auf das Gesellschaftsvermögen beschränkten Haftung am Geschäftsverkehr teilnehmen. ${ }^{68}$

\subsection{Satzung}

Die neu eingeführte constitution der Limited besteht nach dem CA 2006 nur noch aus den Regelungen der articles of association sowie bestimmten Gesellschafterbeschlüssen und Vereinbarungen unter den Gesellschaftern (section 17, 29 CA 2006) ${ }^{69}$ Gleichzeitig führt der CA 2006 getrennte Mustersatzungen (Table A) für private companies und public companies ein. Durch die getrennten Mustersatzungen soll die private company dereguliert und von den strengen Vorschriften der public company befreit werden.

Die Bedeutung des memorandum of association wird ab dem 1. Oktober 2009 erheblich vermindert, es entspricht dann eher einer Gründungserklärung und macht nur noch

${ }^{64}$ Just, C. (2008a), Rn. 31. Form 10 und Form 12 werden durch neue Formblätter ersetzt, bis zu deren Einführung dürfen die alten Formblätter jedoch weiter verwendet werden.

${ }^{65}$ Bei einer elektronischen Gründung betragen die Kosten GBP 15 und bei der Eintragung am gleichen Tag GBP 50. Eine aktuelle Übersicht über die Gebühren findet sich auf http://www.companieshouse.gov.uk/infoAndGuide/companyRegistration.shtml, 18.4.2009.

${ }^{66}$ Zum Inhalt der Prüfung vgl. Just, C. (2008a), Rn. 35. Weiterführend zur Firma der Limited vgl. Just, C. (2008a), Rn. 82.

${ }^{67}$ Just, C. (2008a), Rn. 35.

${ }^{68}$ Vgl. section 15 CA 2006. Zur registered number, vgl. section 1066 CA 2006.

${ }^{69}$ Just, C. (2008a), Rn. 77. 
einen kleinen Teil des Gesellschaftsvertrags aus. ${ }^{70}$ Es enthält nach dem CA 2006 nur noch die wesentlichen Informationen, dass die Unterzeichnenden (subscribers) eine Gesellschaft gründen und Gesellschafter dieser Gesellschaft werden möchten sowie zumindest einen Anteil übernehmen werden (Section 8 (1) CA 2006). Die bisherigen Angaben aus dem memorandum of association zur Firma, zum Sitz, zum Unternehmensgegenstand, zur Haftungsbeschränkung und zur Kapitalklausel sind ab dem 1. Oktober 2009 Bestandteil der articles of association der Limited. ${ }^{71}$ Bei der Registrierung der Limited ist anzugeben, ob sich der satzungsmäßige Sitz (registered office) in England und Wales, in Schottland oder in Nordirland befindet. ${ }^{72}$ Dieser wird dann auch im certificate of incorporation ausgewiesen. ${ }^{73}$ Das registered office dient der Entgegennahme von offiziellen Mitteilungen und Zustellungen an die Gesellschaft sowie der Aufbewahrung von veröffentlichungspflichtigen Unterlagen. ${ }^{74}$ Hier müssen keine Geschäftstätigkeiten ausgeübt werden. Das Büro eines Rechtsanwalts oder Buchprüfers reicht aus.

\subsection{Organe und Leitung}

Das wichtigste Organ einer englischen Limited ist die Gesellschafterversammlung (general meeting), bestehend aus den einzelnen Gesellschaftern (members oder shareholders) ${ }^{75}$ Diese sind im Verhältnis ihrer Anteile Eigentümer der Gesellschaft. Wobei es jedoch auch möglich ist, dass es nur einen Gesellschafter gibt. ${ }^{76}$

Da es sich bei der englischen Limited um eine juristische Person handelt, benötigt sie Vertretungsorgane, die für sie im Rechtsverkehr handeln. ${ }^{77}$ Diese Aufgabe übernehmen directors. Sie treffen die wirtschaftlichen Entscheidungen der Gesellschaft und

\footnotetext{
70 Just, C. (2008a), Rn. 76. Zum Inhalt des memorandum gem. CA 1985 vgl. section 2 und Table B CA 1985. Für bestehende Gesellschaften gelten weiterhin die Vorschriften des memorandum gem. CA 1985 nach Inkrafttreten des CA 2006 als Teil der articles der Gesellschaft fort (section 28 CA 2006).

${ }^{71}$ Just, C. (2008a), Rn. 80.

72 Section 9 (2) (b) CA 2006. Bisher erfolgt die Angabe zur vollständigen Postanschrift im gewählten Land gem. section 10 CA 1985 auf Form 10. Das Formblatt gem. CA 2006 ist noch nicht verfügbar.

${ }^{73}$ Section 15 (2) (e) CA 2006.

${ }^{74}$ Section 1139 (1) CA 2006. Eine Übersicht dieser Unterlagen findet sich in section 1136 (2) CA 2006.

${ }^{75}$ Just, C. (2008a), Rn. 97 ff.

${ }^{76}$ Vgl. section 7 (1) CA 2006 bzw. section 1 (3A) CA 1985.

${ }^{77}$ Just, C. (2008a), Rn. 137.
} 
schließen Verträge für diese. Jede private company muss mindestens einen Direktor haben, ${ }^{78}$ und mindestens ein Direktor muss eine natürliche Person sein, die das 16. Lebensjahr vollendet hat. ${ }^{79}$

Der Umfang der Geschäftsführungs- und Vertretungsbefugnisse der Direktoren unterliegt keiner zwingenden gesetzlichen Regelung. ${ }^{80}$ Diese werden in den articles festgelegt, wonach üblicherweise sämtliche Befugnisse vollständig auf den bzw. die Direktor(en) übertragen werden. ${ }^{81}$ Dadurch haben die Gesellschafter in der Regel keinen Einfluss auf die Geschäftsführung der Gesellschaft. ${ }^{82}$ Ihre einzige Einflussnahmemöglichkeit besteht darin, entweder Direktoren abzuwählen, oder die articles zu ändern, um die Befugnisse der Direktoren einzuschränken. ${ }^{83}$

Ein Direktor hat bei der Geschäftsführung einer Gesellschaft vielfältige Pflichten (duties) zu beachten ${ }^{84}$ Er schuldet diese grundsätzlich nur der Gesellschaft und nur ganz ausnahmsweise den Gesellschaftern. ${ }^{85}$ Diese waren bis zum CA 2006 kaum kodifiziert und entsprangen zum größten Teil dem Richterrecht. Die Kodifizierung dieser Pflichten im CA $2006^{86}$ entspricht zum größten Teil den von der Rechtsprechung entwickelten Kategorien. Jedoch ist dieser Katalog nicht abschließend und wird durch die Rechtsprechung ausgelegt und ergänzt werden müssen, wobei die bisherige Rechtsprechung ihre Gültigkeit behält. ${ }^{87}$ Wenn ein director gegen seine gesetzlichen Pflichten verstößt (breach of duties), können die Gesellschafter gegen ihn

\footnotetext{
${ }^{78}$ Section 154 (1) CA 2006.

${ }^{79}$ Section 155 (1) CA 2006 i. V. m. section 157 (1) CA 2006.

${ }^{80}$ Buchmann, T. (2007), S. 43.

81 Rehm, G. in: Eidenmüller, H. (Hrsg.) (2004), § 10 Rn. 57; Just, C. (2008a), Rn. 144. Zu den Einschränkungen der Befugnisse der Direktoren vgl. Just, C. (2008a), Rn. 148 ff; Davies, P. L. (2008), S. $366 \mathrm{ff}$.

${ }^{82}$ Rehm, G. in: Eidenmüller, H. (Hrsg.) (2004), § 10 Rn. 53.

${ }^{83}$ Just, C. (2008a), Rn. 144; Davies, P. L. (2008), S. 371.

${ }^{84}$ Just, C. (2008a), Rn. 157. Die Pflicht des Direktors bezüglich der Übersendung bestimmter Unterlagen an das englische Gesellschaftsregister wird in Kapitel 4.1 dargestellt.

${ }^{85}$ Just, C. (2008a), Rn. 156, vgl. Davies, P. L. (2008), S. 479 ff.

${ }^{86}$ Sections 171 - 177 CA 2006.

${ }^{87}$ Just, C. (2008a), Rn. 157; vgl. Section 174 (4) CA 2006. Ausführlich zu den Pflichten der directors Just, C. (2008a), Rn. 158 ff.; Davies, P. L. (2008), S. 475 ff.
} 
vorgehen ${ }^{88}$ oder durch einen Gesellschafterbeschluss dem Handeln des Direktors nachträglich zustimmen ${ }^{89}$.

Zusätzlich zu den in Kapitel 2.1.2 behandelten Ausschlussgründen gem. CDDA 1986 kann ein Direktor auch gemäß Bestimmungen der articles ausgeschlossen werden. So zum Beispiel im Falle der geistigen Unzurechnungsfähigkeit oder der Insolvenz des Direktors. $^{90}$ Wie bereits oben erwähnt, haben die Gesellschafter jederzeit die Möglichkeit, einen director durch einfachen Gesellschafterbeschluss abzuberufen. ${ }^{91}$

Ein weiteres wichtiges Organ der Limited ist der company secretary (Gesellschaftssekretär). Dieser ist insbesondere dafür verantwortlich, dass die Ltd. ihre Verzeichnisse führt und immer alle nach dem CA 1985 bzw. CA 2006 notwendigen Dokumente, Formulare und Urkunden an das Companies House übermittelt. ${ }^{92}$

\subsection{Die Haftung}

Die Haftung der Gesellschafter einer Limited beschränkt sich grundsätzlich auf ihre Einlage, sie sind durch den Schleier der Rechtspersönlichkeit (veil of incorporation) geschützt. ${ }^{93}$ Allein die juristische Person haftet gegenüber den Gläubigern. ${ }^{94}$ Die Haftungsbeschränkung gilt mit der Erteilung des certificate of incorporation.

\subsection{Die Rechnungslegungs- und Publizitätsvorschriften}

Da die strengen Rechnungslegungs- und Publizitätsvorschriften des englischen Gesellschaftsrechts häufig der Grund für die Löschung einer Limited mit

${ }^{88}$ Es gelten die gleichen Sanktionen wie bisher bei einem Verstoß gegen die richterrechtlich entwickelten Treuepflichten vgl. hierzu Davies, P. L. (2008), S. 576 ff, section 178 CA 2006; Just, C. (2008a) Rn. 166.

${ }^{89}$ Just, C. (2008a), Rn. 166; section 239 CA 2006; Davies, P. L. (2008), S. $581 \mathrm{ff}$.

${ }^{90}$ Just, C. (2008a), Rn. 191.

${ }^{91}$ Vgl. hierzu Just, C. (2008a), Rn. 192 ff.

92 Vgl. hierzu die Darstellung bei Kasolowsky B./Schall A. in: Hirte H./Bücker T. (Hrsg.) (2006), § 4 Rn. 47 ff. Seit dem 06.04.2008 ist eine Limited nicht mehr verpflichtet einen company secretary zu bestellen (section 270 (1) CA 2006). Freiwillig ist dies noch immer möglich.

${ }^{93}$ Just, C. (2008a), Rn 91.

${ }^{94} \mathrm{Zu}$ diesem Grundsatz und seinen Ausnahmen siehe Davies, P. L. (2008) S. 193 ff.; m. w. N. Wilms, T. (2006), Die englische Limited in deutscher Insolvenz. Nach Centros, Überseering und Inspire Art, Baden-Baden, S. 36 ff. 
Verwaltungssitz in Deutschland aus dem register of companies sind, werden diese im entsprechenden Zusammenhang in Kapitel 4.1 dargestellt.

\subsection{Die Beendigung der Gesellschaft}

Die Beendigung der Limited erfolgt nach englischem Recht ausschließlich durch die Löschung im register of companies.$^{95}$ Anders als im deutschen Recht ist hierzu nicht die Vermögenslosigkeit Voraussetzung. Ähnlichkeiten zum deutschen Recht bestehen insofern, dass auch das englische Recht zwischen der Beendigung (dissolution) und der Liquidation (winding up, liquidation) der Gesellschaft unterscheidet. Die Liquidation ist im Insolvency Act 1986 geregelt. Diese kann entweder als freiwillige Auflösung durch die Gesellschafter (voluntary winding up) oder als Auflösung durch ein Gericht erfolgen (compulsary winding up ${ }^{96}$. Die Auflösung durch ein Gericht ist praktisch der Regelfall. Die gerichtliche Auflösung erfordert einen Auflösungsgrund. In der Praxis ist dies meist die Insolvenz der Gesellschaft. ${ }^{97}$

${ }^{95}$ Borges, G. (2005), S. 134 ff. (135).

${ }^{96}$ Section 73 (1) IA 1986.

${ }^{97}$ Ausführlich zu den verschieden Arten der Beendigung einer Gesellschaft in Bähr, R. M. in: Fritz, D. F./Herrmann O. (Hrsg.) (2008), Rn. 302 ff. 


\section{Internationales Privat- und Europarecht}

Im Rahmen der rechtlichen Betrachtung einer in England erloschenen Limited mit Restvermögen in Deutschland, lässt sich die Frage, welche Rechtsgrundlagen in Betracht kommen und welche letztlich einschlägig sind, in mehrfacher Hinsicht stellen. ${ }^{98}$ So kann einerseits englisches, deutsches oder europäisches Recht in Betracht kommen. Andererseits besteht die Möglichkeit der Verortung in verschiedenen Rechtsgebieten. Das folgende Kapitel gibt deshalb einen Überblick über die relevanten Regelungsmaterien. Dabei wird auch auf den Einfluss der dem EG-Vertrag entspringenden Niederlassungsfreiheit und der dazu ergangenen Rechtsprechung des EuGH eingegangen. ${ }^{99}$

\subsection{Grundstruktur des Internationalen Privatrechts}

Das deutsche internationale Privatrecht ist vorrangig in den Art. 3 - 46 EGBG geregelt. Die Aufgabe des internationalen Privatrechts (im Folgenden: IPR) ist es, bei Sachverhalten, die eine Verbindung zum Recht eines ausländischen Staates aufweisen, die anwendbare Rechtsordnung zu bestimmen. ${ }^{100}$ Es gibt in Form von Kollisionsnormen vor, welcher Rechtsordnung das Sachrecht zu entnehmen ist, es enthält also selbst kein materielles Recht. ${ }^{101}$ Das IPR ist Teil des nationalen Rechts, dementsprechend gehen ihm, gemäß Art. 3 II EGBGB, völkerrechtliche Vereinbarungen und Regelungen in Rechtsakten der EG vor.

Das internationale Privatrecht der Mitgliedsstaaten der EU wird zunehmend durch das Europarecht beeinflusst. Das primäre Gemeinschaftsrecht ${ }^{102}$ der EG selbst enthält keine ausdrücklichen Normen des IPR. Jedoch werden über die darin enthaltenen Grundfreiheiten sowie der Rechtsprechung des EuGH bezüglich dieser, Vorgaben und

\footnotetext{
${ }^{98}$ Vgl. Buchmann, T. (2007), S. 80.

${ }^{99}$ Diese sollen jedoch bis Kapitel 3.4 außer Betracht bleiben.

${ }^{100}$ Vgl. Legaldefinition in Art. 3 I EGBGB.

101 Sturm, G. in: Staudinger, J. von (2003), Kommentar zum Bürgerlichen Gesetzbuch mit Einführungsgesetz und Nebengesetzen. EGBGB/IPR, Einleitung zum IPR, Art. 3-6 EGBGB, 13 Aufl., Berlin, Rn. 1 ff.

102 Das primäre Gemeinschaftsrecht umfasst die Gründungsverträge der Europäischen Gemeinschaften (EGV, EGKSV, EAGV) samt deren Änderungen, Anhängen und Protokollen.
} 
Grenzen für das jeweilige nationale IPR der Mitgliedstaaten aufgestellt. Außerdem enthält das breite Spektrum an sekundärem Gemeinschaftsrecht ${ }^{103}$ zahlreiche IPR-Normen. ${ }^{104}$

\subsection{Internationales Gesellschaftsrecht}

Das internationale Gesellschaftsrecht ist ein Teilbereich des IPR. Seine Aufgabe besteht darin, die nationale Rechtsordnung zu bestimmen, die bei gesellschaftsrechtlichen Sachverhalten mit Auslandsbezug zur Anwendung kommen soll. ${ }^{105}$ Gesellschaftsrechtliche Sachverhalte sind solche, die das Innen- und Außenverhältnis einer Gesellschaft bestimmen. Maßgeblich für dieses Recht bei einer juristischen Person wie der Limited, ist das sog. Gesellschaftsstatut, auch als Personalstatut bezeichnet (lex societatis). Es bestimmt, unter welchen Voraussetzungen eine Gesellschaft „entsteht, lebt und vergeht ${ }^{\star 106}$ Das Gesellschaftsstatut umfasst u. a. Errichtung und Auflösung der Gesellschaft, den Umfang der Rechtsfähigkeit, die Partei- und Prozessfähigkeit sowie die Rechtsstellung von Gesellschaftern und Organen. ${ }^{107}$

Jedoch ist es teilweise sehr problematisch, das Rechtsgebiet des Gesellschaftsrechts (das Gesellschaftsstatut) von anderen Rechtsgebieten (Statuten) abzugrenzen. Zur Lösung des Problems muss der Anknüpfungsgegenstand ermittelt werden. ${ }^{108}$ Der Anknüpfungsgegenstand sind die jeweiligen Rechtsgebiete wie etwa das Gesellschaftsrecht, das Schuldrecht oder das Deliktsrecht. Mit Hilfe der sog. Qualifikation wird eine Rechtsfrage unter einen Anknüpfungsgegenstand subsumiert, um zu ermitteln, ob es sich überhaupt um einen gesellschaftsrechtlichen Sachverhalt handelt. Nach h. M. ist dabei nach der lex fori vorzugehen. Die Einordnung und

\footnotetext{
103 Das sekundäre Gemeinschaftsrecht umfasst gemäß Art. 249 EGV die von den Organen der EG erlassenen Rechtsnormen, insbesondere Verordnungen, Richtlinien und Entscheidungen.

${ }^{104}$ Insbesondere in Form von Richtlinien auf dem Gebiet des Gesellschaftsrechts und Verordnungen auf dem Gebiet des Internationalen Zivilverfahrensrecht (IZVR). Vgl. dazu Kapitel 3.6.

105 Herdegen, M. (2005), Internationales Wirtschaftsrecht, 5. Aufl., München, S. 186; Kindler, P. in: Münchener Kommentar zum Bürgerlichen Gesetzbuch (2006), Band 11. EGBGB (Art 50-245). Internationales Handels- und Gesellschaftsrecht, 4. Aufl., München, Rn. 1.

${ }^{106}$ BGH vom 11.7.1957, BGHZ 25, S. 134 ff. (144); Kindler, P. in: MünchKomm (2006), IntGesR, Rn. 6.

${ }^{107}$ Siehe auch Aufzählung in Art. 37 Nr. 2 EGBGB; Hoffmann, B. von/Thorn, K. (2005), Internationales Privatrecht, 8. Aufl., München, $§ 7$ Rn. 23.

${ }^{108}$ Vgl. hierzu ausführlich m. w. N. Fritz, D. F. in: Fritz, D. F./Herrmann O. (2008), Die Private Limited Company in Deutschland, Münster, Rn. 41ff.
} 
Auslegung des Rechtsinstituts richten sich also nach dem Recht des Staates, dessen Gerichte zur Entscheidung berufen sind. ${ }^{109}$

Neben der Frage nach dem einschlägigen Rechtsgebiet ist weiterhin zu klären, welcher (nationalen) Rechtsordnung dieses entspringt. Dies erfolgt durch Anknüpfungsmomente. ${ }^{110}$ Diese sind die typischen Merkmale des zu beurteilenden Sachverhalts, die auf eine enge Verbindung zu einer Rechtsordnung hindeuten. ${ }^{111}$ Dies können zum Beispiel der satzungsmäßige Sitz der Gesellschaft oder der tatsächliche Verwaltungssitz sein. ${ }^{112}$

\subsection{Anknüpfung}

Weder im deutschen Recht, noch auf gemeinschaftsrechtlicher Ebene ${ }^{113}$, existieren geschriebene Regelungen zur (gesellschaftsrechtlichen) Behandlung von grenzüberschreitend tätigen Gesellschaften. Der deutsche Gesetzgeber hat solche Regelungen explizit aus den nationalen IPR-Regeln ausgeklammert. ${ }^{114}$ Dies geschah mit der Absicht, Bemühungen der EG auf diesem Gebiet nicht vorzugreifen. ${ }^{115}$ Da diese Bemühungen bisher mehrfach gescheitert sind, ${ }^{116}$ blieb die Entscheidung über die Anknüpfung des Gesellschaftsstatuts der Lehre und Rechtsprechung überlassen. Dabei haben sich zwei grundlegende internationale gesellschaftsrechtliche Theorien

\footnotetext{
${ }^{109} \mathrm{Zu}$ den maßgeblichen Grundsätzen für einen deutschen Richter s. Fritz, D. F. in: Fritz, D. F./Herrmann O. (Hrsg.) (2008), Rn. 42.

${ }^{110}$ Teilweise in der Literatur auch als Anknüpfungspunkte bezeichnet. Vgl. hierzu Zessel, M. (2008), S. 27.

${ }^{111}$ Heldrich, A. in: Palandt, O. (2007),Bürgerliches Gesetzbuch, 66. Aufl, München, Einl. V. EGBGB, Rn. 21.

${ }^{112}$ Bezüglich der Ermittlung von Anknüpfungsgegenstand und Anknüpfungsmoment für das Schuldstatut, Deliktsstatut und Insolvenzstatut siehe Übersicht bei Fritz, D. F. in: Fritz, D. F./Herrmann O. (Hrsg.) (2008), Rn. 46.

113 Jedoch existieren einige Regelungen auf völkerrechtlicher Ebene. So z. B. der Freundschafts-, Handels- und Schifffahrtsvertrag zwischen der Bundesrepublik Deutschland und den Vereinigten Staaten von Amerika von 1954, BGB1. II 1956, 487 ff. Gemäß Art. XXV Abs. 5 ist der rechtliche Status von Gesellschaften die auf dem Gebiet und nach dem Recht des einen Vertragsstaates gegründet wurden in dem anderen Vertragsstaat anzuerkennen.

${ }^{114}$ Vgl. Art. 37 Nr. 2 EGBGB.

${ }^{115}$ Vgl. BT-Drucks. 10/504 S. 29 und S. 44.

116 Vgl. EG-Übereinkommen über die gegenseitige Anerkennung von Gesellschaften und juristischen Personen v. 29.2.1968, BGB1. II 1972, S. 370 welches von den Niederlanden nicht ratifiziert wurde und daher in allen Mitgliedsstaaten unwirksam ist.
} 
herausgebildet - die Sitztheorie und die Gründungstheorie. ${ }^{117}$ Diese sollen nun dargestellt werden, bevor auf den Einfluss der Rechtsprechung des EuGH, in Bezug auf im EU-Ausland gegründete Gesellschaften, die jedoch ausschließlich oder überwiegend in Deutschland geschäftlich aktiv sind, eingegangen wird.

\subsubsection{Sitztheorie}

Die Sitztheorie war seit Beginn des 20. Jahrhunderts die in Deutschland herrschende Theorie zur Ermittlung des Gesellschaftsstatuts einer Gesellschaft. ${ }^{118}$ Nach dieser bestimmt sich das Personalstatut einer juristischen Person bzw. einer Gesellschaft ohne Rechtspersönlichkeit nach dem Recht des Staates, auf dessen Hoheitsgebiet der tatsächliche Verwaltungssitz belegen ist. ${ }^{119}$ Der BGH definiert diesen als den Ort, an dem die ,grundlegenden Entscheidungen der Unternehmensleitung effektiv in laufende Geschäftsführungsakte umgesetzt werden.“" ${ }^{\text {"120 }}$ Der Ort der internen Willensbildung bzw. einer weisungsgebundenen Betriebsstätte bleibt dabei unerheblich. Einzig der nach außen erkennbare Tätigkeitsort der Geschäftsführung und der Vertretungsorgane, also der Ort an dem ein Beschluss nach außen erkennbar wird ist relevant. ${ }^{121}$

Die Sitztheorie ist eine präventive Schutztheorie ${ }^{122}$ und überlässt die Kontrolle von Gesellschaften daher dem Recht des Staates, der wirtschaftlich und politisch am stärksten betroffen ist. ${ }^{123}$ Dadurch soll ein größtmöglicher Schutz der öffentlichen Interessen, Anteilseigner, Gesellschaftsgläubiger und Arbeitnehmer gewährt werden. Ein weiterer Zweck ist die Verhinderung von Wettbewerbsverzerrung durch Schaffung von gleichen gesellschaftsrechtlichen Rahmenbedingungen und die einheitliche

\footnotetext{
${ }^{117}$ Die dazwischen vermittelnden Theorien sollen hier außer Acht bleiben. Eine Einführung zu diesen findet sich m. w. N. bei Zessel, M. (2008), S. $37 \mathrm{ff}$.

${ }^{118}$ So z. B. RG vom 5.6.1882, RGZ 7, S. 68 ff. (69 f.); BGH vom 30.01.1970, BGHZ 53, S. 181 ff. (183); zur Rechtsprechung des BGH und der Instanzengerichte vgl. auch die zahlreichen Nachweise bei Kindler, P. in: MünchKomm (2006), IntGesR, Rn. 5, Fn. 15.

${ }^{119}$ BGH vom 17.10.1968, BGHZ 51, S. 27 ff. (28); Kindler, P. in: MünchKomm (2006), IntGesR, Rn. 400.

${ }^{120}$ BGH vom 21.3.1986, BGHZ 97, S. 269 ff. (272).

121 Vgl. hierzu Großfeld in Staudinger, J. von (1998), Kommentar zum Bürgerlichen Gesetzbuch mit Einführungsgesetz und Nebengesetzen. EGBGB/IPR, Internationales Gesellschaftsrecht, Berlin, Rn. 220 .

122 BayObLG vom 26.8.1998, IPRax, S. 364 ff. (365).

${ }^{123}$ Kindler, P. in: MünchKomm (2006), IntGesR, Rn. 401.
} 
Anwendung nationalen Rechts für alle Gesellschaften innerhalb eines Staates. Dies alles beruht auf der Annahme, dass Gründungs- und Organisationsvorschriften anderer Staaten denen des eigenen Rechts nicht gleichwertig sind. ${ }^{124}$ Im Ergebnis soll eine Flucht in das Gesellschaftsrecht mit den geringsten Anforderungen verhindert werden. ${ }^{125}$ Die Sitztheorie war nicht nur in Deutschland vorherrschend. Auch andere europäische Mitgliedstaaten, wie z. B. Frankreich, Belgien und Italien folgten ihr in unterschiedlichen Ausprägungen. ${ }^{126}$

Für den Fall, dass eine englische Limited ihren tatsächlichen Verwaltungssitz in Deutschland einnehmen wollte, hatte dies fatale Konsequenzen, da dann nach der Sitztheorie deutsches Gesellschaftsrecht Anwendung fand. Denn so kam das Numerus Clausus Prinzip des deutschen Gesellschaftsrechts zur Anwendung. Nach diesem muss sich eine Gesellschaft in die vom nationalen Recht zur Verfügung gestellten Gesellschaftsformen einordnen lassen, um die Rechtsfähigkeit zu erlangen. ${ }^{127}$ Weiterhin wurde der englischen Limited von den Registergerichten die Eintragung ins Handelsregister verwehrt, die für Kapitalgesellschaften verpflichtend ist ${ }^{128}$, da sie nicht nach deutschem Recht gegründet wurde und sich ihr Satzungssitz nicht im Inland befand. ${ }^{129} \mathrm{Im}$ Ergebnis wurde einer Ltd. mit inländischem Verwaltungssitz die Rechtsfähigkeit und damit auch die Parteifähigkeit abgesprochen ${ }^{130}$ und diese als nicht existent behandelt. ${ }^{131}$ Vielmehr wurde die Neugründung und damit der Neuerwerb der Rechtsfähigkeit verlangt.

\footnotetext{
${ }^{124}$ Kindler, P. in: MünchKomm (2006), IntGesR, Rn. 403.

125 Auch bekannt als „race to the bottom“ oder „Flucht nach Delaware“ Vgl. hierzu Kindler, P. in: MünchKomm (2006), IntGesR, Rn. 433.

${ }^{126}$ Vgl. hierzu m. w. N. Eidenmüller, H. in: Eidenmüller, H. (Hrsg.) (2004), § 1 Rn. 5.

${ }^{127}$ BGH vom 11.7.1957, BGHZ 25, S. 134 ff. (144).

${ }^{128}$ Vgl. $\S 41$ Abs. 1, 1 Abs. 1 Satz 1 AktG, $\S 11$ Abs. 1, 13 Abs. 1 GmbHG.

${ }^{129}$ BGH vom 21.3.1986, BGHZ 97, S. 269 ff. (272).

${ }^{130}$ Vgl. m. w. N. BGH vom 21.03.1986, BGHZ 97, S. 269 ff. (271); Großfeld, B. in: Staudinger, J. von (1998); IntGesR, Rn. 427 ff.

${ }^{131}$ Vgl. OLG München vom 6.5.1986, NJW 1986, S. 2197 ff. (2198).
} 


\subsubsection{Gründungstheorie}

Die Gründungstheorie stellt im internationalen Gesellschaftsrecht den klassischen Gegensatz zur Sitztheorie dar. ${ }^{132}$ Das Gesellschaftsstatut wird hier an die Rechtsordnung des Staates angeknüpft, nach der die Gesellschaft gegründet wurde. Die Gründungstheorie stellt also, im Gegensatz zur Sitztheorie, nicht auf den tatsächlichen Verwaltungssitz sondern auf den satzungsmäßigen Sitz ab. ${ }^{133}$ Dadurch ermöglicht sie den Gründern im Zeitpunkt der Inkorporation der Gesellschaft die freie Wahl des Gesellschaftsrechts. Wenn die Gesellschaft einmal nach dem Recht dieses Staates wirksam gegründet wurde und sie dort ihre Rechtsfähigkeit erlangt hat, soll diese in jedem anderen Staat anerkannt werden. Der Hintergedanke dabei ist, Gesellschaften nach heimischem Recht gründen zu können und sie gleichzeitig am Ort der tatsächlichen Geschäftstätigkeit dem Schutz des Heimatrechts zu unterstellen.

Nach der Gründungstheorie können sich die Gründer einer Gesellschaft bewusst für eine Rechtsordnung entscheiden, in der der Schutz der öffentlichen Interessen, Anteilseigner, Gesellschaftsgläubiger und Arbeitnehmer wesentlich geringer ausgeprägt ist als am Ort der wirtschaftlichen Betätigung (des tatsächlichen Verwaltungssitzes). ${ }^{134}$ Das Hauptschutzinstrument zum Schutz des Rechtsverkehrs ist die Veröffentlichung von Informationen durch die Gesellschaften (Informationsmodel). Daher haben Staaten, die der Gründungstheorie folgen, oftmals eine wesentlich strengere Aufsicht über die Gesellschaften, die ihrem Gesellschaftsrecht unterstehen, auch wenn diese ihren tatsächlichen Verwaltungssitz im Ausland haben als Staaten, die der Sitztheorie folgen. ${ }^{135}$

\footnotetext{
${ }^{132}$ Vgl. m. w. N. Job, A. (2007), Besteuerung und Rechnungslegung ausländischer Kapitalgesellschaften mit inländischem Verwaltungssitz. Dargestellt am Beispiel einer englischen private limited company, Frankfurt am Main, S. 30.

${ }^{133}$ Vgl. Kindler, P. in: MünchKomm (2006), IntGesR, Rn. 339.

${ }^{134}$ Dies ist einer ihrer Hauptkritikpunkte im deutschen Schrifttum und der Rechtsprechung. Vgl. hierzu m. w. N. Großfeld, B. in: Staudinger, J. von (1998); IntGesR, Rn. 52; Kindler, P. in: MünchKomm (2006), IntGesR, Rn. 348.

${ }^{135}$ Rehm, G. in: Eidenmüller, H. (Hrsg.) (2004), § 10 Rn. 72.
} 
Der Gründungstheorie folgen neben England ${ }^{136}$ und den USA noch zahlreiche andere Staaten. ${ }^{137}$

Für eine englische Limited, die ihren tatsächlichen Verwaltungssitz bzw. Tätigkeitsschwerpunkt in Deutschland hat, ergeben sich nach der Gründungstheorie keine gesellschaftsrechtlichen Probleme. Voraussetzung ist nur, dass sie ihren Satzungssitz (registered office) in England oder Wales beibehält bzw. bei ihrer Gründung dort einnimmt.

\subsection{Europarechtlicher Rahmen}

Die im EG-Vertrag statuierte Niederlassungsfreiheit in Verbindung mit der dazu ergangenen Rechtsprechung des EuGH ist der Grund für die vorliegende Untersuchung. Ohne die dadurch eröffneten Freiheiten für Gesellschaften innerhalb Europas wäre die vorliegende Arbeit wahrscheinlich nicht entstanden. Deswegen werden sie in diesem Abschnitt vorgestellt. ${ }^{138}$

\subsubsection{Europäische Niederlassungsfreiheit}

Die Niederlassungsfreiheit ist eine besondere Ausprägung der Personenverkehrsfreiheit, welche zu den Grundfreiheiten innerhalb der EU zählt. ${ }^{139}$ Ihren Ausfluss findet diese in Art. 43 EGV und wird in die primäre und sekundäre Niederlassungsfreiheit unterteilt. ${ }^{140}$ Die primäre Niederlassungsfreiheit verbietet Beschränkungen der freien Niederlassungen von Staatsangehörigen eines Mitgliedstaates im Hoheitsgebiet eines anderen Mitgliedstaates. ${ }^{141}$ Die sekundäre Niederlassungsfreiheit erweitert dieses Verbot von Beschränkung auf die Gründung von Agenturen, Zweigniederlassungen oder

\footnotetext{
136 Hier hat diese auch ihren Ursprung, da England im 18. Jahrhundert als Kolonialmacht seine Wirtschaftsaktivitäten im Ausland durch englisches Recht effektiv zu schützen versuchte.

${ }^{137}$ Vgl. hierzu m. w. N. Job, A. (2007), S. 31. Aber auch Deutschland muss die Gründungstheorie auf Grund von bilateralen Staatsverträgen in Bezug auf einige Länder anwenden, da diese Verträge, als Völkerrecht dem deutschen IPR vorgehen (jedoch hinter dem Europarecht zurückstehen). Vgl. hierzu Art 3 Abs. 2 EGBGB; m. w. N. Job, A. (2007), S. 32.

${ }^{138}$ Dies soll in der gebotenen Kürze erfolgen, für eine eingehendere Betrachtung Ausführlich zur Niederlassungsfreiheit vgl. Kienzl, F. (2008) S. 3 ff. Ausführlich zu den besprochenen Urteilen vgl. Kienzl, F. (2008) S. $74 \mathrm{ff}$.

${ }^{139}$ Vgl. Fritz, F. D. in: Fritz, D. F./Herrmann O. (Hrsg.) (2008), Rn. 18.

${ }^{140}$ Vgl. Forsthoff, U. in: Hirte H./Bücker T. (Hrsg.) (2006), § 2 Rn. 11.

${ }^{141}$ Art. 43 Abs. 1 Satz 1 EGV.
} 
Tochtergesellschaften durch Angehörige eines Mitgliedstaates in einem anderen Mitgliedstaat. ${ }^{142}$ Mit Niederlassung bezeichnet man die tatsächliche Ausübung einer wirtschaftlichen Tätigkeit mittels einer festen Einrichtung in einem anderen Mitgliedstaat auf unbestimmte Zeit. ${ }^{143}$ Art. 48 EGV erweitert den Schutzbereich der Niederlassungsfreiheit auf Gesellschaften, die nach den Rechtsvorschriften eines Mitgliedstaates gegründet wurden. Voraussetzung dafür ist, dass diese Gesellschaften ihren satzungsmäßigen Sitz, die Hauptverwaltung oder die Hauptniederlassung innerhalb der Gemeinschaft haben und einem Erwerbszweck nachgehen. In Art. 48 Abs. 2 EGV ist der Begriff der Gesellschaften sehr weit gefasst, jedoch werden ausdrücklich auch die juristischen Personen des privaten Rechts erfasst. Dadurch kann eine englische Limited ohne weiteres als Gesellschaft i. S. d. Europarechts eingestuft werden, wodurch sie grundsätzlich dem Schutz der Niederlassungsfreiheit untersteht, wenn sie ihren Verwaltungssitz nach Deutschland verlegt hat. ${ }^{144}$

Die Niederlassungsfreiheit ist unmittelbar wirksam. ${ }^{145}$ Ein durch sie Begünstigter, im vorliegenden Fall die Limited, kann sich dementsprechend direkt auf sie berufen und hieraus seine Rechte herleiten. Als Gemeinschaftsrecht geht sie entgegenstehenden nationalen Rechts vor. Der EuGH folgert aus den Grundfreiheiten ein Beschränkungsverbot, so dass unverhältnismäßige Beschränkungen der Niederlassungsfreiheit auch dann einen Verstoß gegen das Europarecht darstellen, wenn die maßgeblichen Regelungen auch Inländer betreffen. ${ }^{146} \mathrm{Er}$ geht damit über den eigentlichen Wortlaut des Art. 43 EGV hinaus, denn dieser fordert lediglich eine Inländergleichbehandlung. Die Rechtslage ist folglich strenger als der Gesetzestext. Gemäß EuGH sind Beschränkungen alle nationalen Maßnahmen, die die Ausübung der Niederlassungsfreiheit unterbinden, behindern oder weniger attraktiv machen. ${ }^{147}$ An dieser Formel müssen sich grundsätzlich alle deutschen Normen messen lassen, die auf eine zugezogene Limited angewandt werden sollen.

\footnotetext{
${ }^{142}$ Art. 43 Abs. 1 Satz 2 EGV.

${ }^{143}$ EuGH vom 25.7.1991, Slg. 1991, S. I-3905 ff. (3965, Rn. 20).

${ }^{144}$ Art. 43 i. V. m. 48 EGV.

${ }^{145}$ Vgl. hierzu m. w. N. Forsthoff, U. in: Hirte H./Bücker T. (Hrsg.) (2006), § 2 Rn. 12.

146 EuGH vom 31.3.1993, Slg. 1993, S. I - 1663 ff. (Tz. 32); EuGH vom 30.11.1995, Slg. 1995, S. I - 4165 ff. (Tz. 37).

${ }^{147}$ EuGH vom 15.1.2002, Slg. 2002, S. I - 305 ff. (Tz. 22). Zu den vom EuGH gestellten Anforderungen an mögliche nationale Beschränkungen, vgl. die sog. Vier-Schranken-Doktrin am Ende von Kapitel 3.4.
} 


\subsubsection{Rechtsprechung des EUGH}

Wie aus den vorangegangenen Ausführungen in diesem Kapitel ersichtlich ist, war die in Deutschland und anderen Ländern der EU, auch für Gesellschaften aus anderen Mitgliedstaaten, geltende Sitztheorie nicht mit der Niederlassungsfreiheit vereinbar. Genau an diesem Punkt setzten die nachfolgend besprochenen Urteile des EuGH an. ${ }^{148}$

In der Rechtssache „Centros“ ${ }^{\text {“199 }}$ erkannte der Gerichtshof das aus der Niederlassungsfreiheit folgende Recht an, mit einer nach den jeweils am günstigsten erscheinenden nationalen Gesellschaftsgesetzen gegründeten Gesellschaft in einem anderen Mitgliedstaat mittels einer Zweigniederlassung ${ }^{150}$ wirtschaftlich tätig $\mathrm{zu}$ werden, auch ohne im Gründungsstaat eine Geschäftstätigkeit zu entfalten. Die einzige Ausnahme soll ein Betrug darstellen. ${ }^{151}$ Der Zuzugsstaat Dänemark durfte die Eintragung einer Zweigniederlassung, obwohl es sich bei dieser um den tatsächlichen Verwaltungssitz der Gesellschaft handelte, in sein Handelsregister insofern nicht verwehren. Das Argument, dass dies zu einer faktischen Umgehung der dänischen Kapitalaufbringungsvorschriften führte, ließ der EUGH nicht gelten. ${ }^{152} \mathrm{Ob}$ dies Auswirkungen für die Rechtslage in Deutschland haben würde war jedoch unklar, da Dänemark nach deutschem Verständnis der Gründungstheorie folgte.

Die Entscheidung „Überseering“'153 des EuGH wies in die gleiche Richtung, ging jedoch noch einen Schritt weiter. Hier entschied der Gerichtshof, dass eine in den Niederlanden gegründete Kapitalgesellschaft des niederländischen Rechts ${ }^{154}$ in Deutschland rechtsund parteifähig ist, selbst wenn sie in Deutschland ihren tatsächlichen Verwaltungssitz

\footnotetext{
${ }^{148}$ Hier sollen nur die Zuzugsfälle behandelt werden, da nur jene für die vorliegende Arbeit relevant sind.

${ }^{149}$ EuGH vom 9.3.1999, GmbHR 1999, S. 474 ff.

${ }^{150}$ Gemäß europarechtlichem Verständnis kann eine Hauptniederlassung nur am Satzungssitz bestehen, jede andere Niederlassung ist automatisch eine Zweigniederlassung. Vgl. hierzu m. w. N. Kienzl, F. (2008), S, 137 f.

${ }^{151}$ EuGH vom 9.3.1999, GmbHR 1999, S. 474 ff. (Tz. 17).

${ }^{152}$ Vgl. m. w. N. Hirte, H. in: Hirte H./Bücker T. (Hrsg.) (2006), § 1 Rn. 4.

${ }^{153}$ EuGH vom 5.11.2002, GmbHR 2002, S. 1137 ff.

${ }^{154}$ Genauer gesagt um eine BV, diese ist vergleichbar mit der deutschen GmbH. Vgl. ausführlich hierzu Kluvier, H.-J. de/Rammeloo, S. in: Hirte H./Bücker T. (Hrsg.) (2006), § 6 Rn. 1 ff.
} 
einnimmt. Die Aberkennung der Rechts- und Parteifähigkeit sah der EuGH als eine nicht zu rechtfertigende „Negierung“ der Niederlassungsfreiheit an. ${ }^{155}$

Im Urteil „Inspire Art“156 judizierte der Gerichtshof, dass eine in einem Mitgliedstaat wirksam gegründete Gesellschaft nicht verpflichtet werden kann, die Gründungserfordernisse des Niederlassungsstaates insbesondere in Hinblick auf die Erbringung eines Mindestkapitals zu erfüllen. ${ }^{157}$ Außerdem dürfen die Geschäftsführer aufgrund eines diesbezüglichen Verstoßes nicht persönlich haftungsrechtlich zur Verantwortung gezogen werden. Weiterhin waren im vorliegenden Fall die niederländischen Vorschriften, die über die abschließend geregelte Zweigniederlassungsrichtlinie ${ }^{158}$ hinaus gehen, europarechtswidrig.

Außerdem bestimmte der EuGH, dass sich die Rechtfertigungsgründe der Niederlande nicht auf Art. 46 EGV bezogen, so dass eine Rechtfertigung der Beschränkung der Niederlassungsfreiheit aus Gründen der öffentlichen Ordnung, Sicherheit oder Gesundheit ausscheide. ${ }^{159}$ Weiterhin verwies er auf die sog. Vier-Schranken-Doktrin ${ }^{160}$, wonach Beschränkungen der Niederlassungsfreiheit nur erlaubt sind, wenn sie in nicht diskriminierender Weise angewandt werden, aus zwingenden Gründen des Allgemeinwohls gerechtfertigt sind, zur Erreichung des verfolgten Ziels geeignet sind und nicht über das hinaus gehen, was zur Erreichung dieses Ziels erforderlich ist. ${ }^{161}$ An diesen Schranken müssen sich alle nationalen Maßnahmen messen lassen, die die Niederlassungsfreiheit beschränken können. ${ }^{162}$

\footnotetext{
${ }^{155}$ EuGH vom 5.11.2002, GmbHR 2002, S. 1137 ff. (Tz. 93).

${ }^{156}$ EuGH vom 30.9.2003, GmbHR 2003, S. 1260 ff.

${ }^{157}$ EuGH vom 30.9.2003, GmbHR 2003, S. 1260 ff. (Tz. 101).

${ }^{158}$ Elfte Richtlinie des Rates vom 21.12.1989 (89/666/EWG) über die Offenlegung von Zweigniederlassungen, die in einem Mitgliedstaat von Gesellschaften bestimmter Rechtsformen errichtet wurden, die dem Recht eines anderen Staates unterliegen, ABl. EG Nr. L. 395 v. 30.12.1989, S. 36 ff. Zum genauen Inhalt der Richtlinie vgl. m. w. N. Kienzl, F. (2008) S. 3 ff.

${ }^{159}$ EuGH vom 30.9.2003, GmbHR 2003, S. 1260 ff. (Tz. 131).

${ }^{160}$ Fritz D. F. in: Fritz, D. F./Herrmann O. (Hrsg.) (2008), Rn. 19.

${ }^{161}$ EuGH vom 30.9.2003, GmbHR 2003, S. 1260 ff. (Tz. 133).

162 Gemäß EuGH sind Beschränkungen alle nationalen Maßnahmen, die die Ausübung der Niederlassungsfreiheit unterbinden, behindern oder weniger attraktiv machen. EuGH vom 15.1.2002, Slg. 2002, S. I-305 ff. (Tz. 22).
} 


\subsection{Folgen für das deutsche Internationale Gesellschaftsrecht}

Nach diesen Urteilen des EuGH zur Niederlassungsfreiheit war die in Deutschland und anderen Staaten der EG geltende Sitztheorie im Bezug auf zuziehende Gesellschaften aus anderen Mitgliedstaaten und dem EWR nicht mehr aufrechtzuerhalten.

Das deutsche Recht geht für diese Gesellschaften nunmehr von der alleinigen Geltung der Gründungstheorie aus, wenn diese aus einem EG-Mitgliedstaat zuziehen, der der Gründungstheorie folgt. Diese können nunmehr ihr Gesellschaftsstatut uneingeschränkt nach Deutschland mitbringen. ${ }^{163}$

\subsection{Richtlinien und Verordnungen (Sekundärrecht)}

Es gibt mittlerweile zahlreiche Vorschriften des sekundären Europarechts, die für das Gesellschaftsrecht relevant sind. ${ }^{164}$ Diese erfolgen i. d. R. in Form von Richtlinien und Verordnungen.

Die wichtigsten sind:

- Europäische Insolvenzordnung (EuInsVO)

- Verordnung des Rates über die gerichtliche Zuständigkeit und die Anerkennung und Vollstreckung von Entscheidungen in Zivil- und Handelssachen (EuGVVO)

- Vierte Richtlinie 78/660/EWG des Rates vom 25. Juli 1978 aufgrund von Artikel 54 Absatz 3 Buchstabe g) des Vertrages über den Jahresabschluss von Gesellschaften bestimmter Rechtsformen

- Erste gesellschaftsrechtliche Richtlinie (Publizitätsrichtlinie) 68/151/EWG, Abl. L 65 vom 14. März 1968

- Elfte Richtlinie 89/666/EWG des Rates vom 21. Dezember 1989 über die Offenlegung von Zweigniederlassungen, die in einem Mitgliedstaat von

\footnotetext{
${ }^{163}$ Zuletzt m. w. N. BGH vom 27.10.2008, BB 2009, S. 14 ff. (Rn. 19 bb). Für (Kapital-) Gesellschaften aus anderen Staaten, mit denen auch keine entsprechenden Freundschaftsverträge existieren, gilt weiterhin die modifizierte Sitztheorie. Diese besagt, dass jene Gesellschaften als partei- und prozessfähigen Personengesellschaften behandelt werden, sobald sie in Deutschland am Geschäftsverkehr teilnehmen, BGH vom 27.10.2008, BB 2009, S. 14 ff. (Rn. 23c).

${ }^{164}$ Ausführlich hierzu m. w. N. Kienzl, F. (2008) S. 21 ff.
} 
Gesellschaften bestimmter Rechtsformen errichtet wurden, die dem Recht eines anderen Staates unterliegen Amtsblatt Nr. L 395 vom 30/12/1989 S. 0036 0039.

Auf den relevanten Inhalt dieser Vorschriften wird an den entsprechenden Stellen der Arbeit eingegangen. 


\section{Die Rechtsfolgen der Löschung für das in Deutschland belegene Vermögen}

In diesem Kapitel werden die Rechtsfolgen der Löschung einer Limited aus dem register of companies mit Verwaltungssitz in Deutschland für das hier belegene Vermögen untersucht. Zunächst werden die Gründe dargestellt, aufgrund derer es zur Löschung im englischen Gesellschaftsregister kommt und welche Folgen das für das in England belegene Vermögen hat. Anschließend werden die verschiedenen Möglichkeiten der juristischen Einordnung und Behandlung des in Deutschland belegenen Vermögens untersucht. Dabei wird ausführlich auf die einschlägige deutsche Rechtsprechung eingegangen und die verschieden Lösungsansätze dargestellt und diskutiert.

\subsection{Gründe für die Löschung einer Limited}

Limiteds, die ganz überwiegend oder ausschließlich in Deutschland wirtschaftlich aktiv sind, ${ }^{165}$ fehlt oft der Bezug zum englischen Gesellschaftsrecht und den darin für sie enthaltenen Rechnungslegungs- und Publizitätspflichten. ${ }^{166}$ Aber nicht nur mangelnde Kenntnis des englischen Gesellschaftsrechts, sondern auch Kommunikationsprobleme und Unachtsamkeit haben in der Vergangenheit dazu geführt, dass der Registrar of Companies eine Gesellschaft gelöscht hat, wenn diese ihren Pflichten nicht nachkam. ${ }^{167}$

Zunächst mögen die Löschung und die damit verbundene Auflösung der Gesellschaft für den deutschen Rechtsanwender als drakonische Maßnahme für eine solche Pflichtverletzung erscheinen. Jedoch erkennt man bei genauerer Betrachtung des Gesamtgefüges der englischen Gesellschaftsrechtsnormen den dahinter stehenden Gedanken: Diese Vorschriften bilden im englischen Rechtsraum eines der wichtigsten Schutzinstrumente für Gläubiger und potenzielle Geschäftspartner, da sich diese so

\footnotetext{
${ }^{165}$ Also hier ihren tatsächlichen Verwaltungssitz einnehmen. Im Folgenden auch „deutsche Limited“.

${ }^{166}$ Die Publizitätspflichten unterstehen unbestritten dem Gesellschaftsstatut. Nach h. M. sind auch die Rechnungslegungspflichten gesellschaftsrechtlicher und nicht ordnungsrechtlicher Natur. Aber selbst im zweiten Fall würde man über $\S 352$ a HGB i. V. m. Art. 3 der Publizitätsrichtlinie (Erste gesellschaftsrechtliche Richtlinie, Richtlinie 68/151/EWG, AB1. L 65 vom 14.3.1968, S. 8) zur Anwendung des englischen Rechts gelangen. Vgl. hierzu Just, C. (2008a), Rn. 258 ff.

${ }^{167}$ Bähr, R. in: Fritz, D. F./Herrmann O. (Hrsg.) (2008), Rn. 321; Just, C. (2008a), Rn. 262.
} 
umfassend über die finanziellen Verhältnisse und die Kreditwürdigkeit der Gesellschaft informieren können (Informationsmodell). ${ }^{168}$ Sie bilden insofern vor allem auch einen Ausgleich zum fehlenden Mindestkapital und das Korrelat zur Haftungsprivilegierung sowie zur Finanzierungsfreiheit der Ltd. ${ }^{169}$

Das umfangreiche System der Publizitätspflichten für eine Limited ist im CA 2006 geregelt. ${ }^{170}$ Dabei lassen sich die Vorschriften im Wesentlichen in zwei Gruppen einteilen. Zum einen muss das Companies House innerhalb einer bestimmten Frist über gewisse Ereignisse informiert werden. ${ }^{171}$ Zum anderen existieren regelmäßig wiederkehrende Veröffentlichungspflichten, die typischerweise jährlich erfüllt werden müssen. ${ }^{172}$ Für die einzureichenden Dokumente stehen in der Regel Formulare auf der Homepage des Companies House zur Verfügung und können dort eingesehen und abgerufen werden. ${ }^{173}$

So muss das Companies House über jede Anschriftenänderung des registered office (section 86 CA 2006) informiert werden. ${ }^{174}$ Die Mitteilung muss im Vorhinein erfolgen und hat deklaratorische Wirkung, nur in Ausnahmefällen besteht eine 14-tägige Frist. Weiterhin muss dem Registrar jede Änderung im Bereich der company directors ${ }^{175}$ oder company secretaries ${ }^{176}$ mitgeteilt werden. ${ }^{177}$ Dazu zählen die Bestellung und die

168 Just, C. (2008a), Rn. 280. Vgl. ausführlich Davies, P. L. (2008) S. 711 f. zum englischen Grundsatz ,forewarned ist forearmed“; es ist Sache eines jeden Gläubigers selbst, sich schon im Vorfeld über seinen möglichen Vertragspartner zu informieren, um sich erforderlichenfalls vertraglich abzusichern.

${ }^{169}$ Vgl. Zessel, M. (2008), S. 303.

${ }^{170}$ Viele der für diesen Teil der Arbeit relevanten Vorschriften treten erst ab 1. Oktober 2009 in Kraft, vgl. hierzu Anhang 1. Jedoch wurden diese i. d. R. ohne Änderungen aus dem CA 1985 übernommen. Sofern die alten Vorschriften noch gültig sind und/oder sich von den neuen Regelungen unterscheiden, wird darauf hingewiesen.

${ }^{171}$ Vgl. Zimmer, D./Naendrup, C. (2007), For Whom the Bell Tolls - Folgen einer Nichtbeachtung englischer Publizitätsgebote durch in Deutschland aktive Limited Companies, in: ZGR, S. 789 ff.

${ }^{172}$ Eine sehr umfassende Darstellung aller Pflichten findet sich bei Laughton, C. in: Fritz, D. F./Herrmann O. (Hrsg.) (2008), Rn. 194 ff., in den Broschüren (Guidance Booklets, GBA 1 bis 11) des Companies House, abrufbar unter: http://www.companieshouse.gov.uk/about/guidance.shtml, 1.5.2009 die regelmäßig aktualisiert werden und bei Davies, P. L. (2008), S. 711 ff.

173 Über den „WebFiling service“ des Companies House auf http://www.companieshouse.gov.uk können die meisten Formulare auch direkt online ausgefüllt werden.

${ }^{174}$ Bis zum 1.10.2009 gilt noch section 287 CA 1985.

${ }^{175}$ Section 167 i. V. m. section 163 CA 2006.

${ }^{176}$ Section 276 i. V. m. section 275 CA 2006.

${ }^{177}$ Bis zum 1.10.2009 gilt noch section 288 i. V. m. sections 289, 290 CA 1985. Hier musste zusätzlich auch eine Veränderung der Privatadresse, des directors an das Companies House gemeldet werden. 
Niederlegung eines Amtes aber auch Änderungen der persönlichen Daten, wie Anschrift und Name dieser Organe. Die Frist hierfür beträgt 14 Tage.

Die zuvor genannten Vorschriften dienen eher der ordnungsgemäßen Verwaltung der Gesellschaft. Hinzu kommen die Publizitätspflichten, die die wirtschaftliche Situation der Gesellschaft betreffen und eine Mitteilung an den Registrar innerhalb einer bestimmten Frist erfordern. Diese umfassen die Herausgabe neuer Anteile (shares) ${ }^{178}$, Kapitalherabsetzungen, -erhöhungen und -umwandlungen ${ }^{179}$, Gesellschafterbeschlüsse von besonderer wirtschaftlicher Relevanz ${ }^{180}$ und jede Belastung oder Sicherungsübereignung von Gesellschaftseigentum. ${ }^{181}$ Diese Mitteilungen sollen es dem Companies House und dem Informationssuchenden ermöglichen, sich ein aktuelles Bild von der Gesellschaft zu machen. ${ }^{182}$ Weitere wichtige Angaben beinhalten der jährlich einzureichende gesamte Jahresabschluss (annual accounts) ${ }^{183}$ und der Bericht (annual return), ${ }^{184}$ der vor allem die zuvor genannten Informationen gebündelt enthält. ${ }^{185}$ Die wichtigste Publizitätspflicht ist die Übersendung des Jahresabschlusses an das Gesellschaftsregister. Vor allem durch die darin enthaltenen Informationen können potentielle Gläubiger und Geschäftspartner die wirtschaftliche Situation der Gesellschaft einschätzen. Jedermann kann gegen Entrichtung einer geringen Gebühr, Einsicht in das Register und die eingereichten Dokumente beim Companies House nehmen. ${ }^{186}$

\footnotetext{
${ }^{178}$ Section 555 CA 2006. Bis zum 1.10.2009 gilt noch section 88 CA 1985.

${ }^{179}$ Danach auf versch. Sections aufgeteilt: Bis zum 1.10.2009 gelten noch section $122 \mathrm{f}$. CA 1985, die eine einmonatige Frist bestimmt. Danach Sections 644, 649 CA 2006, In Fällen von section 644 CA 2006 beträgt die First 15 Tage. In Fällen von section 649 CA 2006, hat die Eintragung deklaratorische Wirkung. Section 708 CA 2006, bestimmt eine 28-tägige Frist. Vgl. hierzu fortführend Just, C. (2008a), Rn. 208 ff.; Davies, P. L. (2008) S. 805 ff.

${ }^{180}$ Section 30 CA 2006. Bis zum 1.10.2009 gilt noch section 380 CA1985.

${ }^{181}$ Section 870 CA 2006. Bis zum 1.10.2009 gilt noch section 398 CA 1985.

${ }^{182}$ Vgl. Zimmer, D./Naendrup, C. (2007), S. 789 ff. (796).

${ }^{183}$ Section 395 ff. CA 2006.

${ }^{184}$ Sections 855, 865 CA 2006. Bis zum 1.10.2009 gilt noch section 364 CA 1985. Der Inhalt bleibt gleich und umfasst damit insbesondere die Anschrift der Gesellschaft, die Art der grundsätzlich verfolgten Aktivitäten, Angaben zu den company directors und der secretaries, Angaben zum Kapital der Gesellschaft sowie eine vollständige Liste der Gesellschafter.

${ }^{185}$ Section 441 CA 2006.

186 Sections 1085, 1086 CA 2006. I. d. R. erfolgt die Einholung der Auskunft elektronisch über den „WebCHeck service“ auf http://www.companieshouse.gov.uk.
} 
Der Jahresabschluss setzt sich grundsätzlich aus einer Bilanz (balance sheet), einer Gewinn- und Verlustrechnung (profit and loss account) mit Anhang (notes), einem Geschäftsbericht der Direktoren (directors' report) und dem Prüfungsbericht der Wirtschaftsprüfer (auditors' report) zusammen. Für kleine und mittelgroße private companies bestehen bestimmte Erleichterungen. ${ }^{187}$

Die Frist zur Übermittlung des vollständigen Jahresabschlusses endet neun Monate nach Abschluss des Geschäftsjahres (financial year). ${ }^{188}$ Der Bericht muss jährlich zum Stichtag der Eintragung der Gesellschaft oder falls davon abweichend, 12 Monate nach Einreichung des letzten annual return eingereicht werden. ${ }^{189}$ Die Frist hierfür beträgt 28 Tage.

Die Pflicht der Einreichung der Unterlagen obliegt vor allem den Direktoren. Jedoch können auch die Gesellschaft selbst oder die Sekretäre haftbar gemacht werden. ${ }^{190}$ Die Strafen reichen von (hohen) Geldstrafen für die Organe und die Gesellschaft für jeden Tag der Zuwiderhandlung bis hin zur Disqualifikation, gem. section 5, 6 CDDA 1986, eines Direktors. ${ }^{191}$

\subsection{Ablauf der Löschung}

Wenn eine Limited ihren Publizitätsvorschriften nicht ordnungsgemäß nachkommt, insbesondere der Pflicht zum Einreichen des Jahresabschlusses, geht der Registrar davon aus, dass diese erloschen (defunct) ist. ${ }^{192}$ Daraufhin übersendet er einen Brief per Post an die Gesellschaft - in der Regel an das registered office - in dem er nachfragt, ob

\footnotetext{
${ }^{187}$ Vgl. hierzu m. w. N. Just, C. (2008a), Rn. 268 ff.; Zimmer, D./Naendrup, C. (2007), S. 789 ff. (797). So müssen kleine Gesellschaften keinen Prüfungsbericht einreichen und kleine und mittelgroße Gesellschaften können eine verkürzte Bilanz einreichen.

${ }^{188}$ Section 442 (2) (a) CA 2006.

${ }^{189}$ Section 854 CA 2006. Bis zum 1.10.2009 gilt noch section 363 CA 1985.

${ }^{190}$ Bei Nichteinreichung des annual return vgl. sections 858, 859 CA 2006, bei den annual accounts vgl. sections 451 - 453 CA 2006. Bis zum 1.10.09 gelten noch die sections 363 bzw. 242 des CA 1985. Vgl. eingehend m. w. N. zu den Bußgeldern und den strafrechtlichen Konsequenzen für directors Davies, P. L. (2008) S. $747 \mathrm{ff}$.

${ }^{191}$ Vgl. hierzu ausführlich m. w. N. Zimmer, D./Naendrup, C. (2007), S. 789 ff. (797 f.).

${ }^{192}$ Vgl. m. w. N. Schmidt, J. (2007), Kommentar zu OLG Jena 2007-08-22 6 W, in ZIP, S. 1712 ff. (1712).
} 
diese noch aktiv ist. ${ }^{193}$ Wenn innerhalb eines Monats keine Antwort erfolgt, übersendet er innerhalb von 14 Tagen einen Brief per Einschreiben, in dem er sich auf den ersten Brief bezieht. Dieser beinhaltet die Mitteilung, dass er auf den vorhergegangenen Brief keine Antwort erhalten hat und kündigt an, dass, wenn keine Antwort auf den zweiten Brief erfolgt, in der London Gazette eine Mitteilung veröffentlicht wird, in der die Löschung der Limited aus dem Gesellschaftsregister angedroht ist. ${ }^{194}$ Wenn innerhalb eines Monats keine Reaktion auf das Einschreiben erfolgt, wird die Mitteilung in der Gazette und auf der Internetseite des Companies House (Eintrag: proposal to stike off) veröffentlicht und die Gesellschaft wird, per Post, über die Veröffentlichung informiert. Gleichzeitig wird in dem Brief angekündigt, dass nach einer Frist von drei Monaten die Limited aus dem Register gelöscht (striking off) und aufgelöst (dissolved) wird. ${ }^{195}$ Wenn jetzt noch immer keine Reaktion erfolgt, die belegt, dass die Gesellschaft noch operativ tätig ist, wird die Löschung vorgenommen. ${ }^{196}$ Dies wird dann in der Gazette veröffentlicht, und damit ist die Gesellschaft aufgelöst. ${ }^{197}$ Die Löschung hat also eine konstitutive Wirkung und beendet die Existenz der Limited.

Aus deutscher Sicht mag dieses Verfahren als zu schnell und zu einfach erscheinen, deswegen sei noch einmal daran erinnert, dass die Veröffentlichung von Informationen durch haftungsbeschränkte Gesellschaften das fundamentale Prinzip des Schutzes der Gläubiger, der Öffentlichkeit aber auch der Gesellschafter selbst in England ist. ${ }^{198}$

\subsection{Die Rechtsfolgen in Großbritannien}

Mit der Auflösung der Gesellschaft ist diese beendet und verliert ihre Rechtsfähigkeit. ${ }^{199}$ Falls es Haftungsansprüche gegen Direktoren, Sekretäre oder Gesellschafter gibt, bleiben diese bestehen und können durchgesetzt werden, als ob die Gesellschaft nicht

\footnotetext{
${ }^{193}$ Section 1000 (1) CA 2006 i. V. m. section 1002 CA 2006. Bis zum 1.10.2009 gilt noch section 652 (1) CA 1985.

${ }^{194}$ Section 1000 (2) CA 2006. Bis zum 1.10.2009 gilt noch section 652 (2) CA 1985.

${ }^{195}$ Section 1000 (3) CA 2006. Bis zum 1.10.2009 gilt noch section 652 (3) CA 1985.

${ }^{196}$ Section 1000 (4) CA 2006. Bis zum 1.10.2009 gilt noch section 652 (5) CA 1985.

${ }^{197}$ Section 1000 (5), (6) CA 2006. Bis zum 1.10.2009 gilt noch section 652 (5) CA 1985.

${ }^{198}$ Vgl. hierzu Davies, P. L. (2008) S. $711 \mathrm{f}$.

199 Krömker, M./Otte, S. (2008),Die gelöschte Limited mit Restvermögen in Deutschland: Stehen Gläubiger und Gesellschafter im Regen?, in: BB, S. 964 ff. (964).
} 
aufgelöst wurde. ${ }^{200}$ Das Gleiche gilt für den Fall der Abwicklung der Gesellschaft durch ein Gericht (winding up by a court).

Das in England belegene Vermögen, jedoch nicht die Verbindlichkeiten, fällt gem. section 1012 CA 2006 als sog. bona vacantia ${ }^{201}$ an die englische Krone. ${ }^{202}$ Dies beinhaltet sämtliche Vermögensgegenstände, die der Limited unmittelbar vor der Löschung zustanden. So werden zum Beispiel Konten eingefroren und ein eventuelles Guthaben eingezogen sowie in der Regel alle Vermögensgegenstände verkauft. ${ }^{203}$ Section 1013 CA $2006^{204}$ räumt der Krone allerdings eine Verzichtsmöglichkeit (disclaimer) ein, dann werden die Vermögensgegenstände so behandelt, als ob die Krone das Eigentum an ihnen nie erworben hätte. ${ }^{205}$

Wenn sich das registered office in England oder Wales befand, ist für die Verwaltung solcher Vermögensgegenstände die Bona Vacantia Division des Treasury Solicitor zuständig. ${ }^{206}$ Der Treasury Solicitor ist Leiter des Treasury Solicitor's Department (TSol). Diese zentrale Behörde wurde mit dem Treasury Solicitor Act 1876 geschaffen. Sie berät und unterstützt die englische Krone sowie über 180 englische Behörden und Ministerien in Rechtsfragen und vertritt diese in Rechtsstreitigkeiten, gem. Crown Proceedings Act 1974, darunter auch das BERR, dem das Companies House untersteht. $^{207}$

\footnotetext{
${ }^{200}$ Vgl. Section 1000 (7) CA 2006. Bis zum 1.10.2009 gilt noch section 652 (6) CA 1985.

${ }^{201}$ Das historische Heimfallrecht für herrenlose Güter zu Gunsten der englischen Krone. Vgl dazu Kapitel 4.3.; Heckel, M. (2006), Das Fiskuserbrecht im Internationalen Privatrecht. Eine rechtsvergleichende Untersuchung im Hinblick auf ein künftiges europäisches Erbkollisionsrecht, Tübingen, S. 24 ff. und ausführlich Ing, N. D. (1971), Bona Vacantia, London.

202 Begünstigter kann auch der Herzog von Cornwall oder das Herzogtum Lancaster sein, je nachdem wo die Gesellschaft ihren Sitz hatte. Bis zum 1.10.2009 gilt noch section 654 CA 1985.

${ }^{203}$ Vgl. Broschüre GBW2, Strike Off, Dissolution and Restoration des Companies House, abrufbar unter: http://www.companieshouse.gov.uk/about/guidance.shtml, 1.5.2009 die regelmäßig aktualisiert wird; die Broschüre $B V C l$ des TSol, abrufbar unter: http://www.bonavacantia.gov.uk/output/dissolvedcompany-guidelines.aspx, 1.5.2009.

${ }^{204}$ Bis zum 1.10.2009 gilt noch 656 CA 1985.

${ }^{205}$ Section 1014 CA 2006. Bis zum 1.10.2009 gelten noch die sections 656, 657.

${ }^{206}$ Section 1012 (1) (b) CA 2006, bis zum 1.10.2009 gilt noch section 654 (1) CA 1985.

${ }^{207}$ Vgl. hierzu http://www.tsol.gov.uk/about_us_main.htm, 1.5.2009.
} 


\subsection{Die Rechtsfolgen in Deutschland}

Aufgrund der Rechtsprechung des Europäischen Gerichtshofs in den Entscheidungen „Centros“, „Überseering“ und „Inspire Art“ ist es in der deutschen Rechtsprechung und Literatur unbestritten, dass sich das Gesellschaftsstatut einer englischen Limited nach dem Recht ihres Gründungsstaates, also England, bestimmt. ${ }^{208}$

Das Gesellschaftsstatut entscheidet darüber, ,unter welchen Voraussetzungen die juristische Person entsteht, lebt und vergeht". ${ }^{209}$ Dementsprechend entfaltet die Löschung aus dem register of companies ihre existenzvernichtende Wirkung auch bei einer Limited, die ausschließlich in Deutschland tätig ist. ${ }^{210}$ Die Beendigung der Gesellschaft nach englischem Recht muss also in ihrem vollen Umfang vom deutschen Recht akzeptiert werden.

Es ist auch unerheblich, ob die Zweigniederlassung der Limited in das deutsche Handelsregister eingetragen wurde, denn obwohl die Zweigniederlassung gegenüber der Hauptniederlassung organisatorisch selbständig ist, handelt es sich bei ihr jedoch um keine eigenständige juristische Person. Sie teilt mithin das Schicksal der Hauptniederlassung.

Wenn die Limited aus dem register of companies gelöscht wird, muss dies dem deutschen Handelsregister angezeigt werden, selbst wenn dort keine Zweigniederlassung gem. $\S 13 \mathrm{~d}$ HGB eingetragen war. ${ }^{211}$ Wenn eine Zweigniederlassung eingetragen war und die Löschung der Limited dem Handelsregister nicht angezeigt wird, besteht die Gefahr, dass das Registergericht das Bestehen einer nicht mehr existierenden Rechtsperson bekundet. ${ }^{212}$

\footnotetext{
${ }^{208}$ Vgl hierzu BGH vom 14.3.2005, in: ZIP 2006, S. 805 ff. (805); OLG Jena vom 22.8.2007, in: ZIP 2007, S. 1709 ff. (1710); OLG Nürnberg vom 10.8.2007, in: GmbHR 2008, S. 41 ff. (1709); AG Charlottenburg vom 7.11.2008, in: GmbHR 2009, S. 321 ff. (322). Zur Literatur: einige anstatt vieler m. w. N. Borges, G. (2005), Der rechtliche Status einer im Registerstaat erloschenen Gesellschaft, in: IPRax, S. 134 ff. (S. 137 f.); Kindler, P. in: MünchKomm (2006), IntGesR, Rn. 499; Bähr, R. M. in: Fritz, D. F./Herrmann O. (Hrsg.) (2008), Rn. 335.

${ }^{209}$ BGH vom 11.7.1957, in: NJW 1957, S. 1433 ff. (1434).

${ }^{210}$ Vgl. hierzu m. w. N. Zimmer, D./Naendrup, C. (2007), S. 789 ff. (802).

${ }^{211} \S 13$ g Abs. 7 HGB, Vgl. Zimmer, D./Naendrup, C. (2007), S. 789 (802).

${ }^{212}$ Bähr, R. M. in: Fritz, D. F./Herrmann O. (Hrsg.) (2008), Rn. 335.
} 
Falls die Limited in Deutschland ein Gewerbe angemeldet hatte, muss auch dieses wieder abgemeldet werden. ${ }^{213}$ Dies erfolgt nach den gleichen Vorschriften wie für deutsche Gesellschaften.

Bedeutend komplizierter gestaltet sich die Rechtslage, wenn die Limited nach ihrer Löschung und der damit verbundenen Auflösung in England noch über Restvermögen in Deutschland verfügt. Das zeigt schon die hierfür aktuelle einschlägige Rechtsprechung dreier deutscher Gerichte, die alle Fälle mit ähnlichem Sachverhalt zu entscheiden hatten und alle drei zu verschiedenen Urteilen kamen. Anhand der Urteile dieser drei Gerichte, AG Charlottenburg ${ }^{214}$, OLG Jena ${ }^{215}$ und OLG Nürnberg ${ }^{216}$, werden die bestehenden Probleme analysiert und die sachgerechteste Lösung ermittelt. Zunächst muss geklärt werden, ob das in Deutschland belegene Vermögen gem. section 1012 CA 2006 ebenfalls, also wie in England auch, als bona vacantia an die englische Krone fällt oder in Deutschland eine Restgesellschaft ${ }^{217}$ bzw. Rest-Limited entsteht.

Bisher ging die deutsche Rechtsprechung ${ }^{218}$ und ein großer Teil der Literatur ${ }^{219}$, meist jedoch ohne ein ausgeprägtes Problembewusstsein, davon aus, dass das hoheitliche Anfallsrecht der englischen Krone aufgrund des Territorialitätsprinzips (lex rei sitae) sich nicht auf etwaiges Auslandsvermögen erstreckt. Die lex rei sitae ${ }^{220}$ (kurz: 1. r. s.), auch Situs-Regel ${ }^{221}$ genannt, ist das grundlegende Prinzip des internationalen Sachenrechts. Gemäß dieser Regel unterfallen die Rechte an einer Sache, ob beweglich oder unbeweglich, dem Recht des Ortes, an dem sich die Sache befindet (Recht der Belegenheit der Sache). Dies führt zu einem weitestgehenden Entscheidungseinklang

\footnotetext{
${ }^{213}$ Vgl. Segner, K./Matuszok, T. (2009), Limited oder Mini-GmbH?, München, S. 94; § 14 Abs. 1 Satz 2 Nr. 3.

${ }^{214}$ AG Charlottenburg vom 7.11.2008, in: GmbHR 2009, S. $321 \mathrm{ff}$.

${ }^{215}$ OLG Jena vom 22.8.2007, in: ZIP 2007, S. 1709 ff.

${ }^{216}$ OLG Nürnberg vom 10.8.2007, in: GmbHR 2008, S. 41 ff.

${ }^{217}$ Zur Restgesellschaft vgl. Kapitel 4.4.2.2.

218 So auch zuletzt OLG Nürnberg vom 10.8.2007, in: GmbHR 2008, S. 41 ff. (42); OLG Jena vom 22.8.2007, in: ZIP 2007, S. 1709 ff. (1710).

${ }^{219}$ Vgl. m. w. N. Bähr, R. M. in: Fritz, D. F./Herrmann O. (Hrsg.) (2008), Rn. 337; Schmidt, J. (2008), Verfahren und Gefahren bei der Liquidation einer „Rest-Limited“, in: ZIP, S. 2400 ff (2400); Krömker, M./Otte, S. (2008), S. 964; Süß, R. in: Wachter, T. (Hrsg.) (2007), Handbuch das Fachanwalts für Handels- und Gesellschaftsrecht, Münster, Rn. 240.

${ }^{220}$ Lateinisch für: Recht der belegenen Sache:

${ }^{221}$ Situs ist lat. für Lage.
} 
auf diesem Rechtsgebiet. Dogmatisch wird die 1. r. s. mit dem zu schützenden Verkehrsinteresse damit begründet, dass Sachen, die innerhalb eines bestimmten Rechtsraums (Territorialprinzip) belegen sind, auch nur mit solchen Rechten belastet sein sollen, die der herrschenden Rechtsordnung nicht völlig unbekannt sind. Die lex rei sitae ist weltweit fast ausnahmslos anerkannt, auch in Deutschland und England. ${ }^{222}$ In Deutschland findet sie ihren Ausfluss in Art. 43 EGBGB und definiert, dass die Rechte an einer Sache dem Recht des Staates unterliegen, in dem sich die Sache befindet (lex rei sitae).

Entsprechend diesen Grundsätzen urteilten auch das OLG Jena ${ }^{223}$ und das OLG Nürnberg ${ }^{224}$, dass das in Deutschland belegene Vermögen einer Limited dem deutschen Recht unterstehe und die Legalokkupation der englischen Krone gemäß section 1012 CA 2006 in seiner Wirkung auf das englische Hoheitsgebiet beschränkt sei. Zu einer anderen Auffassung gelangt jedoch das AG Charlottenburg ${ }^{225}$.

\subsubsection{Ablehnung einer Restgesellschaft}

In seiner Entscheidung vom 7. November 2008 hatte es, wie die anderen beiden Gerichte auch, darüber $\mathrm{zu}$ entscheiden wie mit dem in Deutschland belegenen Restvermögen einer in England erloschenen Limited verfahren werden soll. Diese war am 8. April 2005 in das register of companies des Companies House in Cardiff eingetragen worden und war somit (nach englischem Recht) ordnungsgemäß inkorporiert. Der Darstellung des Sachverhalts durch das Gericht folgend ${ }^{226}$, wurde diese am 21. Januar 2008 gemäß section 1000 CA 2006 aus dem Register gelöscht, da sie es versäumt hatte, ihren Publizitätspflichten gegenüber dem Gesellschaftsregister

\footnotetext{
${ }^{222}$ Für England, vgl. hierzu RE Barnett's Trust [1902] 1 Ch 847, Heckel, M. (2006), S. 84 ff.

${ }^{223}$ OLG Jena vom 22.8.2007, in: ZIP 2007, S. 1709 ff. (1710).

${ }^{224}$ OLG Nürnberg vom 10.8.2007, in: GmbHR 2008, S. 41 ff. (42).

${ }^{225}$ Vgl. AG Charlottenburg vom 7.11.2008, in: GmbHR 2009, S. 321 ff. (321).

${ }^{226}$ In der folgenden Darstellung des Sachverhalts werden die Begriffe und Formulierungen benutzt, die das AG Charlottenburg in seinem Urteil verwendet.
} 
nachzukommen. ${ }^{227}$ Dies habe zur Folge, dass das Gesellschaftsvermögen nach britischem Gesellschaftsrecht an die britische Krone fällt. ${ }^{228}$

Die gelöschte Limited unterhielt in Deutschland keine Zweigniederlassung, sondern lediglich ein „Korrespondenzbüro“229. Sie verfügte nach ihrer Löschung über verschiedene in Deutschland befindliche Vermögenspositionen im Wesentlichen einen Gesellschaftsanteil einer in Berlin ansässigen Gesellschaft bürgerlichen Rechts, die wiederum über inländisches Grundvermögen verfügte sowie über mehre Ansprüche auf Übertragung von in Deutschland belegenen Grundstücken und Schadensersatzansprüche. ${ }^{230}$

Am 16. Juni 2008 stellte die „Gesellschaft“ beim AG Charlottenburg einen Antrag auf Bestellung eines Nachtragsliquidators mit dem Ziel, das in Deutschland belegene Vermögen $\mathrm{zu}$ verwalten und die im register of companies gelöschte Gesellschaft, welche nach Auffassung der Antragstellerin unter der Berücksichtigung der Grundsätze

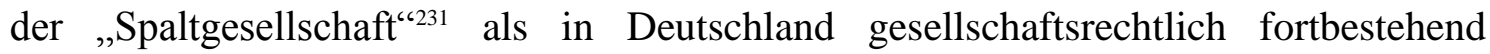
anzusehen sei, abzuwickeln. ${ }^{232}$ Dementsprechend war das AG Charlottenburg berufen, über die Anordnung einer Nachtragsliquidation gem. § 273 Abs. 4 AktG zu entscheiden.

Das Gericht neigt zu der Auffassung, der in section 1012 CA 2006 angeordnete Anfall des Vermögens der Limited Company zugunsten der britischen Krone wirke sich auch bezüglich des in Deutschland belegenen Vermögens dieser Gesellschaft, insbesondere auch bezüglich ihres Grundstücks aus. ${ }^{233}$ Es ist der Auffassung, dass die allgemeinen völkerrechtlichen Grundsätze, dass enteignende Maßnahmen eines anderen Staates sich nur auf das eigene Territorium, nicht jedoch auf die auf dem Territorium eines anderen Staates belegenen Vermögensgegenstände erstrecken (lex rei sitae), im Verhältnis von

\footnotetext{
${ }^{227}$ Anzumerken ist, dass section 1000 CA 2006 erst am 1.10.2009 in Kraft tritt und die Löschung somit wohl gemäß section 652 CA 1985 erfolgte.

${ }^{228}$ Auch hier stellt das AG auf section 1012 CA 2006 ab, obwohl dieser erst ab 1.10.2009 in Kraft tritt. Einschlägig ist vielmehr section 654 CA 1985.

${ }^{229}$ Vgl. AG Charlottenburg vom 7.11.2008, in: GmbHR 2009, S. 321 ff. (321).

${ }^{230}$ AG Charlottenburg vom 7.11.2008, in: GmbHR 2009, S. 321 ff. (S. 321). Es ist hier nicht ganz eindeutig, ob es sich hier um Eigentumsverschaffungsansprüche (Auflassungsvormerkungen) handelt.

${ }^{231}$ Zur Spaltgesellschaft s. Kapitel 4.4.2.1., obwohl es sich hier um eine Restgesellschaft handelt.

${ }^{232}$ AG Charlottenburg vom 7.11.2008, in: GmbHR 2009, S. 321 ff. (321).

${ }^{233}$ Vgl. AG Charlottenburg vom 7.11.2008, in: GmbHR 2009, S. 321 ff. (322).
} 
Mitgliedstaaten der Gemeinschaft untereinander dann keine Geltung haben, wenn sich wie im vorliegenden Fall - eine Gesellschaft in Ausübung der Niederlassungsfreiheit gemäß Art. 43, 48 EG bewusst dem Gesellschaftsrecht des einen Mitgliedstaates unterwirft und in dem anderen Mitgliedstaat wirtschaftlich tätig ist. Zwar erkennt das Gericht an, dass dem section 1012 CA 2006 eine enteignende Wirkung im Sinne des internationalen Privatrechts zukommt und deswegen gem. Art. 43 I EGBGB im Inland keine unmittelbare Wirkung entfalte, jedoch sei es im internationalen Privatrecht anerkannt, dass es davon Ausnahmen geben kann. Die Möglichkeit solch einer Ausnahme sei gegeben, wenn der Staat der „belegenen Sache“ durch Gesetz oder Staatsvertrag sein Einverständnis mit dem Eintritt der enteignenden Wirkung im Inland erklärt hat. Das Gericht verweist hier auf: „Sonnenberger in Münch.Komm.BGB, 4. Aufl., IntGesR Rz. 982“. ${ }^{234}$ Dies sei nach Rechtsprechung des BGH (unter Verweis auf: „BGH v. 13. 121956 - II ZR 86/54, MDR 1957, 276) sogar allein durch einen billigenden Realakt, also tatsächliches Handeln, möglich.

Bei Verletzung der Pflichten des frei gewählten Gesellschaftsrechts des ersten Mitgliedstaates soll sich diese Gesellschaft nicht unter Berufung auf die Grundätze der „Spaltgesellschaft“ in das für diesen Fall günstigere Gesellschaftsrecht des zweiten Mitgliedstaates „flüchten“ können, auf dessen Territorium sich diejenigen Vermögensgenstände befinden, die von der selbst verschuldeten negativen Rechtsfolge „,in Sicherheit gebracht“ werden sollen. Vielmehr ist das Gericht der Auffassung, dass sämtliches Gesellschaftsvermögen gem. section 1012 CA 2006 an die britische Krone („Crown“) fallen soll, da dies nur gegenüber der Gesellschaft in ihrer Gesamtheit angeordnet werden kann und sich die Rechtswirkung auch auf das in anderen Mitgliedstaaten der Europäischen Gemeinschaft belegene Gesellschaftsvermögen erstreckt. Weiterhin dürfe eine Gesellschaft sich vor dem Hintergrund der Rechtsprechung des EuGH zur Niederlassungsfreiheit nicht von ihrer Gründung bis zur Löschung uneingeschränkt dem englischen Gesellschaftsrecht als Gesellschaftsstatut unterstellen und bei Eintritt negativer Rechtsfolgen wieder in das insofern ,günstigere“ bundesdeutsche Gesellschaftsrecht fliehen können. Dies bezeichnet das Gericht als „Herauspicken von Rosinen“, und dafür dürfe im Einklang mit der Rechtsprechung des Europäischen Gerichtshofs kein Raum sein.

${ }^{234}$ AG Charlottenburg vom 7.11.2008, in: GmbHR 2009, S. 321 ff. (322). 
Insofern neigt das Gericht zu der Auffassung, dass Deutschland durch Abschluss und Ratifikation des EG-Vertrags, insbesondere durch die Art 10, 43, 48 EG, jedenfalls dann dem Eintritt enteignender Wirkung auf ihrem Territorium zugestimmt haben dürfte, wenn sich eine Gesellschaft mit im Inland gelegenem Vermögen freiwillig und ausdrücklich dem Gesellschaftsrecht eines anderen Mitgliedstaates der Gemeinschaft unterstellt und die enteignende Wirkung in diesem Rahmen von diesem anderen Mitgliedstaat ausgeht.

Der Argumentation des AG Charlottenburg ist zunächst grundsätzlich zu folgen. Richtig ist, dass eine englische Limited mit Verwaltungssitz in Deutschland sich freiwillig und ausdrücklich dem englischen Gesellschaftsrecht unterstellt hat. In der Regel haben sich ihre Gesellschafter auch gerade für diese Rechtsform entschieden, da sie das englische Gesellschaftsrecht als regelungsärmer und für sie vorteilhafter empfinden. Insofern muss auch für solche Gesellschaften das englische Gesellschaftsrecht in seiner ganzen Breite und mit all seinen Konsequenzen zur Anwendung kommen, also auch section 1012 CA 2006.

Section 1012 CA 2006 beinhaltet, wie bereits dargestellt, dass das Vermögen einer gelöschten Limited als bona vacantia unmittelbar an die englische Krone bzw. an das Herzogtum Lancaster oder den Duke von Cornwall fällt. ${ }^{235}$ Wer Begünstigter ist, hängt davon ab, wo sich das letzte registered office befand und wo die Vermögenswerte gelegen sind. Wenn sich der letzte Sitz der Gesellschaft und die Vermögenswerte im gleichen Territorium befinden, ist die Zuordnung eindeutig. ${ }^{236}$ Wenn diese jedoch auseinanderfallen, ist Begünstigter derjenige, in dessen Gebiet sich die Vermögensgegenstände befinden. In der Broschüre des TSol sind explizite Regelungen für England und Wales, Schottland, Nordirland, die Republik Irland sowie die Herzogtümer Cornwall und Lancaster enthalten; jedoch keine Angaben, wie mit Vermögen zu verfahren ist, welches sich in anderen Staaten befindet. Vielmehr enthält die Broschüre unter Punkt 12 die Aussage, dass die Kompetenz des TSol geografisch auf England und Wales beschränkt ist. Dies ist ein Indiz dafür, dass im Ausland

\footnotetext{
${ }^{235}$ Section 1012 (1) (b) CA 2006. Bis zum 1.10.2009 erfolgt dies noch gem. 654 CA 1985.

${ }^{236}$ Vgl. Punkt 11 Jurisdiction in der Broschüre des TSol BVC1 Assets of Dissolved Companies that have vested in the Crown as Bona Vacantia auf http://www.bonavacantia.gov.uk/output/dissolved-companyguidelines.aspx, 14.5.2009.
} 
belegenes Vermögen nicht von section 1012 CA 2006 erfasst werden soll. Der Eindruck verstärkt sich, wenn man bedenkt, dass es sich beim Companies Act 2006 um ein junges Gesetz handelt und zum Zeitpunkt seiner Entstehung das Problem des im Ausland belegenen Vermögens von gelöschten private companies limited by shares bereits bekannt war. Aber weder im Company Law Reform Bill - White Paper $2005^{237}$ noch in der auf dessen Veröffentlichung folgenden Diskussion durch die Öffentlichkeit, Experten und Interessengruppen zu den vorgeschlagenen Regelungen hat jemand dieses Problem angesprochen, bzw. als solches erkannt. ${ }^{238}$ So wurden die bona vacantia Vorschriften ohne inhaltliche Änderungen aus dem CA 1985 übernommen. ${ }^{239}$

Ein weiterer Hinweis darauf, dass im Ausland belegenes Vermögen nicht an die englische Krone fällt, obwohl sich das letzte registered office einer Gesellschaft in England oder Wales befand, ergab eine diesbezügliche Anfrage an die Bona Vacantia Division des TSol via e-mail. ${ }^{240}$ Auf die Frage welches die gesetzliche Grundlage für den Eigentumsübergang auf die englische Krone ist, wurde geantwortet, dass dieser auf die historischen Machtbefugnisse der Krone zurück geht, sich Vermögen anzueignen, welches Gesellschaften zum Zeitpunkt ihrer Auflösung gehörte. Dementsprechend habe die Krone auch nicht die Macht, sich Vermögensgegenstände anzueignen, die sich in Übersee befinden. Dies sei Sache der Staaten, auf deren Territorium sich diese befinden. Nach diesem Rechtsverständnis hat das TSol bisher auch strikt gearbeitet, denn bisher ist kein Fall bekannt, in dem die Krone versucht hat, den Heimfall von Vermögen außerhalb von England und Wales geltend zu machen. ${ }^{241}$

237 Herunterladbar auf http://www.berr.gov.uk/whatwedo/businesslaw/co-act-2006/white-paper/page228 00.html, 14.5.2009.

${ }^{238}$ Herunterladbar auf http://www.berr.gov.uk/whatwedo/businesslaw/co-act-2006/white-paper/page228 00.html, 14.5.2009, Responses to White Paper (2005 - Modern Company Law) - URN 05/928.

${ }^{239}$ Vgl. section 1012 CA 2006 und section 654 CA 1985.

240 "The power given to the Treasury Solicitor to deal with assets of dissolved companies, on behalf of the Crown, stems from the ancient power of the Crown to take assets in England and Wales that were owned by a company at the date it was dissolved. The Crown does not have the authority to take assets located overseas, and such assets fall to the overseas country to deal with." E-mail vom 5.5.2009 von Chris Turner, TSol.

${ }^{241}$ Leible, S./Lehmann, M. (2007), Auswirkung der Löschung einer Private Limited Company auf ihr in Deutschland belegenes Vermögen, in: GmbHR, S. 1095 ff. (1096); Bähr, R. M. in: Fritz, D. F./Herrmann O. (Hrsg.) (2008), Rn. 322. 
Das AG Charlottenburg hat die Frage, ob die Folgen der Löschung aus dem britischen Gesellschafsregister sich allein nach britischem Gesellschaftsrecht, also section 1012 CA 2006 richten, dem Europäischen Gerichtshof zur Vorabentscheidung gem. Art. 234 EG im Rahmen der Auslegung des primären Gemeinschaftsrechts vorgelegt. ${ }^{242}$ Dem EuGH könnten die zuvor genannten Indizien als Ausganspunkt seiner Untersuchung dienen, die alle darauf hindeuten, dass kein Heimfallrecht zu Gunsten der englischen Krone für im Ausland belegenes Vermögen existiert.

In seiner Entscheidung wird der EuGH sich die Frage stellen müssen, ob section 1012 CA 2006 gesellschaftsrechtlicher oder hoheitsrechtlicher Natur ist. Denn nur im ersten Fall würde sie für das Restvermögen einer aus dem register of companies gelöschten Limited zur Anwendung kommen, da sich deren Gesellschaftsstatut nach dem englischen Gesellschaftsrecht bestimmt.

Zunächst erscheint eine Zuordnung zum Gesellschaftsrecht als naheliegend, da die Vorschriften im Companies Act verortet sind und sich ja gerade nach diesem, dass die Limited regelnde Gesellschaftsrecht, bestimmt. Andererseits jedoch ist es kennzeichnend für nationale Rechtssysteme, dass die Verortung von Vorschriften einer gewissen „Zufälligkeit“ unterliegt. Dies ist oftmals historisch und nicht dogmatisch begründet, da zur Zeit ihrer Entstehung die entsprechenden Gesetze nur für das Hoheitsgebiet des eigenen Staates galten. An einen möglichen Auslandsbezug und die daraus resultierenden Probleme wurde zu dieser Zeit nicht gedacht. Ein viel diskutiertes aktuelles Beispiel dafür aus dem deutschen Gesellschaftsrecht ist die bisherige Regelung der Insolvenzantragspflicht. ${ }^{243}$ Erst mit dem Inkrafttreten des MoMiG zum 1. November 2008 wurde diese für alle Gesellschaftsformen in $§ 15$ a InsO geregelt, gerade auch um Schutzlücken zu vermeiden und Auslandsgesellschaften mit Verwaltungssitz in Deutschland der Antragspflicht zu unterwerfen. Bis dahin war es in der Literatur heftig umstritten, ob diese Pflicht gesellschaftsrechtlicher oder insolvenzrechtlicher

\footnotetext{
${ }^{242}$ AG Charlottenburg vom 7.11.2008, in: GmbHR 2009, S. 321 ff. (323).

${ }^{243}$ Zur Entstehungsgeschichte und zur zufälligen Verortung vgl. kurz: Kienzl, F. (2008) S. 35, Fn. 169; ausführlich: Borges, G. (2004), Gläubigerschutz bei ausländischen Gesellschaften mit inländischem Sitz, in: ZIP, S. 733 ff.
} 
Natur ist und insofern für eine Limited mit Verwaltungssitz in Deutschland zur Anwendung kommt. ${ }^{244}$

Ähnlich verhält es sich beim Recht der englischen Krone auf bona vacantia. Hierfür gibt es kein einheitliches Gesetz. Vielmehr ist dieses Recht in verschiedenen Gesetzen geregelt und vor allem von der englischen Rechtsprechung entwickelt worden. So findet sich diese Vorschrift nicht nur in section 1012 (1) CA 2006:

„When a company is dissolved, all property and rights (...) are deemed to be bona vacantia"

sondern auch in section 46 I (vi) Administration of Estate Act 1925:

“(...)the residuary estate of the intestate shall belong to the Crown (...) as bona vacantia"

Eine rein gesellschaftsrechtliche Natur sollte somit ausgeschlossen sein. Zur genauen Qualifikation muss das Recht der englischen Krone auf bona vacantia im historischen Kontext betrachtet werden. ${ }^{245}$

Ursprünglich gab es in England zwei verschiedene staatliche Zugriffsrechte auf erbenlose Nachlässe. So hatte die Krone ein „Anfallsrecht“ (right to escheat) bezüglich des unbeweglichen Nachlasses. Dieses leitete sich aus dem Lehenswesen ab und erfüllte das Erfordernis, dass Land immer „im Besitz“ (seised) sein musste. Das Recht auf bona vacantia konnte die Krone auf beweglichen Nachlass geltend machen. Mit section 45 (1) (d) Administration of Estate Act 1925 wurde das alte Recht auf escheat abgeschafft und erbenlose Nachlässe fallen, egal ob beweglich oder unbeweglich, als bona vacantia gem. section 46 (1) (vi) Administration of Estate Act 1925, an die englische Krone. ${ }^{246}$ Auch wenn die Frage, ob das Recht auf bona vacantia der englischen Krone Teil des (privaten) Gesellschaftsrechts der englischen Limited oder Teil des englischen (öffentlichen) hoheitlichen Rechts ist, nicht abschließend geklärt werden kann, so scheint die Zuordnung zum zweiten als naheliegend. Die Wiederverwirklichung des Obereigentums der Krone, im Rahmen des Rechts auf bona vacantia, wurzelt in der

\footnotetext{
${ }^{244}$ Ausführlich zum Streit in der deutschen Literatur m. w. N. Kienzl, F. (2008) S. 186 ff.

${ }^{245}$ Vgl. m. w. N. Heckel, M. (2006), S. 24 ff.

${ }^{246}$ Vgl. hierzu Heckel, M. (2006), S. 25 ff.
} 
Souveränität der englischen Krone, da sie actus contrarius der Landgewährung durch die Krone und diese ist unzweifelhaft Ausfluss der Souveränität ist. ${ }^{247}$

Wenn der EuGH trotz der oben angeführten Argumente zu dem Schluss kommt, dass section 1012 CA 2006 Teil des Gesellschaftsrechts ist, dann muss er klären, wie dieses Recht, auf bona vacantia, ausgestaltet ist. Zu unterscheiden ist dabei zwischen einer erbrechtlichen und einer aneignungsrechtlichen Ausgestaltung. Während ein Erbrecht eines Staates universale Wirkung hat, also auch im Ausland gilt, ist das Aneignungsrecht immer auf das eigene Territorium des Staates begrenzt. ${ }^{248}$

Maßgebliche Bedeutung hat zur Qualifikation der Rechtnatur des Erwerbs der englischen Krone eine Entscheidung des Court of Appeal aus dem Jahr 1942. ${ }^{249}$ In der Entscheidung kam das Gericht zu dem Schluss, dass der staatliche Erwerb der englischen Krone nicht erbrechtlicher Natur ist. ${ }^{250}$ Wie bereits oben dargestellt, ist das Recht auf bona vacantia Ausfluss der Souveränität der Krone, so dass nur ein hoheitliches Aneignungsrecht der Krone in Frage kommt. Dieses erstreckt sich seinem Sinn nach im IPR immer nur auf das eigene Staatsgebiet. Interessanterweise gibt es auch kein Gerichtsurteil, in dem die englische Krone versucht hat, auf ein im Ausland gelegenes Vermögen zuzugreifen. ${ }^{251}$ Mehr noch, Jenkins, L. J. hat in der MaldonadoEntscheidung $^{252}$ in einem obiter dictum (lat. „nebenbei Gesagtes“) ausdrücklich Ansprüche der englischen Krone auf einen im Ausland belegenen erbenlosen Nachlass ausgeschlossen. Dafür hat er auch einhellige Zustimmung im englischen Schrifttum erhalten. ${ }^{253}$ Das Zugriffsrecht der Krone (aus section 1012 CA 2006 und section 46 (1) (vi) Administration of Estates Act 1925) ist deswegen methodisch territorial zu begrenzen.

\footnotetext{
${ }^{247}$ Heckel, M. (2006), S. 26 ff.

248 Heckel, M. (2006), S. 1; m. w. N. S. 10 f; Neuhaus, P. H. (1976), Die Grundbegriffe des internationalen Privatrechts, 2. Aufl., Tübingen, S. 130.

${ }^{249}$ In the Estate of Hanley [1942] P. 33 (C.A.).

${ }^{250}$ Ausführlich hierzu m. w. N. Heckel, M. (2006), S. 25 f.

${ }^{251}$ Heckel, M. (2006), S. 89

${ }^{252}$ In the Estate of Maldonado, decd. [1954] P. 223 (C. A.).

${ }^{253}$ Vgl. m. w. N. Ing, N. D. (1971), S. 11, 60.
} 
Es ist unerheblich, wie das ausländische Aneignungsrecht im Rahmen des IPR qualifiziert wird. ${ }^{254}$ Alle Ansichten führen im Ergebnis dazu, dass außerhalb des Staatsgebiets des Aneignungsstaates dieser keinen Zugriff hat. Auf in Deutschland belegenes Vermögen ist somit deutsches Sachrecht anzuwenden. Außerdem berücksichtigt dieses Ergebnis am treffendsten den Charakter dieses Zugriffsrechts. Dieses soll meist nicht außerhalb des Staatsgebiets des Aneignungsrechtsstaates angewandt werden. ${ }^{255}$ Die herrschende Meinung schließt darauf, in dem sie von einer (versteckten) Teilrückverweisung des Internationalen Privatrechts des ausländischen Staates auf das inländische Belegenheitsrecht ausgeht. ${ }^{256}$

Unabhängig davon, für welchen Weg sich der EuGH entscheidet, dass Ergebnis ist dasselbe: Das in Deutschland belegene Vermögen einer aus dem register of companies gelöschten und damit aufgelösten Limited fällt nicht gem. section 1012 CA 2006 an die englische Krone. ${ }^{257}$ Nach der dargestellten Rechtslage sollte keine andere Entscheidung des EuGH möglich sein.

Es handelt sich hier um ein Defizit, das aus der fehlenden Harmonisierung der Rechtsordnungen der Mitgliedstaaten der Europäischen Union resultiert. Deswegen wäre es zu wünschen, dass hierfür Regelungen auf europäischer Ebene erlassen werden.

\subsubsection{Annahme einer Restgesellschaft}

Das OLG Nürnberg ${ }^{258}$ und das OLG Jena ${ }^{259}$ gehen in ihren Urteilen beide davon aus, dass in Bezug auf das in Deutschland belegene Vermögen einer englischen private company limited by shares eine Restgesellschaft existiert. In beiden Fällen ging es um

\footnotetext{
${ }^{254}$ Vgl. eingehend hierzu m. w. N. Heckel, M. (2006), S. $113 \mathrm{ff}$.

${ }^{255}$ Vgl. m. w. N. Heckel, M. (2006), S. 117.

256 So auch Mansel der von einer versteckten, beschränkten Rückverweisung auf spricht. Vgl. hierzu Mansel in: Krüger, H./Mansel, H. P. (Hrsg.) (2002), Liber amicorum Gerhard Kegel, München, S. 117 ff. Dem zustimmende Kindler, P. in: MünchKomm (2006), IntGesR, Rn. 663; Mock, S./Schildt, D. in: Hirte H./Bücker T. (Hrsg.) (2006), § 17 Rn. 129 f.

${ }^{257}$ So auch Borges, G. (2005), S. 134 ff. (136), der ebenfalls darauf abstellt, dass der Companies Act in diesem Fall nur in England gelten will. Wenn das Recht eines anderen Staates als Erbrecht ausgestaltet ist, dann bestünde durchaus die Möglichkeit des Zugriffs auf in Deutschland belegenes Vermögen. Vgl. hierzu m. w. N. Heckel, M. (2006), S. 125.

${ }^{258}$ OLG Nürnberg vom 10.8.2007, in: GmbHR 2008, S. 41 ff.

${ }^{259}$ OLG Jena vom 22.8.2007, in: ZIP 2007, S. 1709 ff.
} 
eine Limited, die aus dem englischen Gesellschaftsregister des Companies House gelöscht wurde.

Im Fall des OLG Jena erfolgte die Löschung durch den Registrar von Amts wegen aufgrund des Versäumnisses der Ltd., ihre Jahresabschlüsse einzureichen. ${ }^{260}$ Die Gesellschaft (W.T. Stiftung für Fertilisation Ltd.) verfügte über einen Verwaltungssitz, jedoch über keine eingetragene Zweigniederlassung in Deutschland. Nach ihrer Löschung bestand ihr in Deutschland belegenes Vermögen im Wesentlichen aus zwei Grundstücken und einem Konto bei einer Hamburger Bank.

Aus dem Urteil des OLG Nürnberg ist nicht ersichtlich, warum die Limited im register of companies gelöscht wurde. Ebenfalls ist nicht ersichtlich, ob die Gesellschaft über eine eingetragene Zweigniederlassung verfügte. Es ist lediglich vom „Verwaltungssitz“ in Deutschland die Rede. ${ }^{261}$ Die gelöschte Limited verfügte noch über Werklohnansprüche in Deutschland. Diese resultieren aus einem in Deutschland geschlossenen Werkvertrag für einen Rohbau an einem in Deutschland errichteten Wohnhaus für einen in Deutschland ansässigen Vertragspartner. Auf diese Ansprüche ist gem. Art. 28 Abs. 1 EGBGB unstrittig deutsches Recht anzuwenden.

Beide Gerichte erkennen zunächst die Rechtslage in Folge der Entscheidungen „Centros“, „Überseering“ und „Inspire Art“ an, nämlich, dass sich das Gesellschaftsstatut der betreffenden Limiteds grundsätzlich nach dem englischen Recht bestimmt, auch wenn diese in Deutschland ihren Verwaltungssitz haben. ${ }^{262}$ Beide weisen auch darauf hin, dass die Limited in Folge der Löschung gem. section 652 CA 1985 nach englischem Recht nicht mehr existiert und das in England belegenes Vermögen gem. section 654 CA 1985 an die englische Krone fällt. Dieses sei für deren Heimatland ausdrücklich anzuerkennen.

Hiervon sei jedoch nach Auffassung beider Senate das in Deutschland belegene Vermögen nicht erfasst. Das OLG Jena stellt dabei auf Art. 43 Abs. 1 EGBGB (den Grundsatz des lex rei sitae) ab, also dass die dingliche Rechtslage von Sachen sich nach

\footnotetext{
${ }^{260}$ Vgl. OLG Jena vom 22.8.2007, in: ZIP 2007, S. 1709 ff. (1709)

${ }^{261}$ Vgl. OLG Nürnberg vom 10.8.2007, in: GmbHR 2008, S. 41 ff. (42).

262 OLG Nürnberg vom 10.8.2007, in: GmbHR 2008, S. 41 ff. (42); OLG Jena vom 22.8.2007, in: ZIP 2007, S. 1709 ff. (1710).
} 
dem Recht des Lageortes bestimmen. ${ }^{263}$ Das OLG Nürnberg verweist zwar nicht explizit auf Art. 43 Abs. 1 EGBGB, jedoch spricht es vom „Territorialitätsprinzip“, welches bestimme, dass die Legalokkupation nach section 654 CA 1985 durch die englische Krone nur das in England belegene Vermögen erfasst, nicht jedoch etwaiges Auslandsvermögen. ${ }^{264}$ Auch wenn die Anwendung des Grundsatzes des lex rei sitae fraglich ist, ist dem Ergebnis zuzustimmen, dass in Deutschland belegene Vermögen wird nicht vom englischen Heimfallrecht der Krone gem. section 654 CA 1985 erfasst. $^{265}$

Nicht nur beide Gerichte, sondern ebenfalls die herrschende Meinung in der Literatur, gehen vom Fortbestehen der Gesellschaft als Restgesellschaft aus, solange diese in Deutschland noch über Vermögen verfügt. ${ }^{266}$ Es entsteht eine Rest-Limited. Deswegen werden ihre Grundlagen und Entstehungsgeschichte im Folgenden dargestellt.

\subsubsection{Die Lehre der Rest- und Spaltgesellschaft}

Die Lehre von der Rest- und Spaltgesellschaft wurde von der Rechtsprechung und der ganz überwiegenden Meinung der Literatur in Folge des Zweiten Weltkriegs und während des Kalten Krieges entwickelt. ${ }^{267}$ Mit der Schaffung dieses Instruments wurde auf die Enteignung ehemaliger deutscher Industriebetriebe in der Deutschen Demokratischen Republik und Osteuropa reagiert.

\footnotetext{
${ }^{263}$ OLG Jena vom 22.8.2007, in: ZIP 2007, S. 1709 ff. (1710).

${ }^{264}$ OLG Nürnberg vom 10.8.2007, in: GmbHR 2008, S. 41 ff. (42).

${ }^{265}$ Vgl. hierzu die Ausführungen in Kapitel 4.4.1 und noch einmal ausführlich: Mock, S./Schildt, D. in: Hirte H./Bücker T. (Hrsg.) (2006), § 17 Rn. 126 ff.

${ }^{266}$ OLG Nürnberg vom 10.8.2007, in: GmbHR 2008, S. 41 ff. (42); OLG Jena vom 22.8.2007, in: ZIP 2007, S. 1709 ff. (1710). Zur Literatur vgl. m. w. N. Hirte, H. in: Hirte H./Bücker T. (Hrsg.) (2006), § 1 Rn. 77a; Mock, S./Schildt, D. in: Hirte H./Bücker T. (Hrsg.) (2006), § 17 Rn. 127 f.; Mansel in: Krüger, H./Mansel, H. P. (Hrsg.) (2002), S. 121 f.; Borges, G. (2005), S. 134 ff. (141); Schmidt, J. (2007), S. 1712 ff. (1713); Kindler, P. in: MünchKomm (2006), IntGesR, Rn. 663; Krömker, M./Otte, S. (2008), S. 964 ff. (964).Großfeld, B. in: Staudinger, J. von (1998); IntGesR, Rn. 841 ff; Süß, R. in: Wachter, T. (Hrsg.) (2007), Rn. 115.

267 Vgl. hierzu BGH vom 30.1.1956, BGHZ 20, 4; vom 11.7.1957, BGHZ 25, 134; vom 19.2.1959, BGHZ 29, 320; vom 5.5.1960, BGHZ 32, 256; vom 6.10.1960, BGHZ 33, 195; vom 20.9.1962, BGHZ 38, 36; vom 31.3.1971, BGHZ 56, 66; zuletzt: vom 30.9.1991, ZIP 1991, 1423. Zur Literatur m. w. N. Großfeld, B. in: Staudinger, J. von (1998); IntGesR, Rn. 832 ff.; Kindler, P. in: MünchKomm (2006), IntGesR, Rn. 961; Krömker, M./Otte, S. (2008), S. 964 ff. (964) 964; Schmidt, J. (2008), S. 2400 ff. (2400).
} 
Dieser Theorie entsprechend entsteht eine Restgesellschaft, wenn im Enteignungsstaat (Ausland) mit der Enteignung des Gesellschaftsvermögens auch die Vernichtung der Gesellschaft verbunden ist. $^{268}$ Dies ist der Fall, wenn die Gesellschaft im Enteignungsstaat ihren Sitz hatte. Da dann die Gesellschaft im Zuge der Enteignung im Statutstaat erlischt, verliert sie ihre Rechtsfähigkeit auch im Inland, in dem noch Gesellschafsvermögen vorhanden ist, da sich die Frage der Beendigung der Gesellschaft unstrittig nach ihrem Gesellschaftsstatut bestimmt und dieses an den Sitz geknüpft ist. Um das im Inland belegene Vermögen einer im Statutstaat vernichteten Gesellschaft nicht herrenlos werden zu lassen, besteht diese mit ihrem hier belegenen Vermögen als Restgesellschaft so fort, als wenn ihre Integrität nicht angetastet worden wäre. Hierfür wird die Vernichtung der Gesellschaft im Ausland dem Territorialprinzip unterworfen und ihre Beendigung demensprechend für das Inland nicht anerkannt. Eine weitere Folge des Territorialprinzips ist, dass Rechtsträger des außerhalb des enteignenden Staats belegenen Vermögens weder der enteignende Staat selbst, noch ein sonst von der Enteignung Begünstigter sein kann.

Eine Spaltgesellschaft hingegen entsteht im Inland, wenn der ausländische Staat im Rahmen der Enteignung nicht unmittelbar auf das Gesellschaftsvermögen zugreift oder gar die Gesellschaft in ihrer rechtlichen Existenz völlig vernichtet. ${ }^{269}$ Vielmehr entsteht diese durch Einziehung von Mitgliedschaftsrechten. Das Problem hierbei ist, dass die Gesellschaft grundsätzlich weiterhin besteht, selbst wenn sämtliche Mitgliedschaftsrechte enteignet wurden. Formell ist nunmehr lediglich der Enteignungsstaat alleiniger Gesellschafter. Hier kommt ebenfalls im Inland das Territorialprinzip zur Anwendung und erkennt die Enteignung der Mitgliedschaftsrechte bzw. deren Übergang auf den Enteignungsstaat nicht an.

\subsubsection{Anwendbarkeit der Restgesellschaft für die Rest-Limited}

Das AG Jena begründet die Anwendung der Theorie der Restgesellschaft für eine RestLimited mit der Analogie der Ausgangslage in beiden Situationen, denn ${ }^{270}$ in beiden

\footnotetext{
268 Behrens, P. in: Behrens, P. (Hrsg.) (1997), Die Gesellschaft mit beschränkter Haftung im internationalen und europäischen Recht, 2. Aufl., Berlin, S. 47 ff.

${ }^{269}$ Behrens, P. in: Behrens, P. (Hrsg.) (1997), S. 50 ff.

${ }^{270} \mathrm{Vgl}$. OLG Jena vom 22.8.2007, in: ZIP 2007, S. 1709 ff. (1710).
} 
Fällen wurde die Gesellschaft im Ausland durch staatliche Zwangseinwirkung aufgelöst und ist nicht mehr existent. Im Fall der englischen Limited mit Verwaltungssitz in Deutschland, sei dies in Folge der Rechtsprechung des EuGH zur Niederlassungsfreiheit uneingeschränkt anzuerkennen. Für die Abwicklung des in Deutschland belegenen Restvermögens im Interesse der Gesellschafter sowie insbesondere potenzieller Gesellschaftsgläubiger sei im Inland jedoch vom Vorliegen einer Restgesellschaft auszugehen. Nur so könne die im Inland gelegene Haftungsmasse sachgerecht erhalten bleiben. Die Behandlung als herrenloses Gut oder rechtsträgerlose Vermögensmasse verwirft der Senat mit der Begründung, dass dies den Interessen der bisherigen Vermögensinhaber entgegensteht. Dem kann uneingeschränkt zugestimmt werden, denn eine solche Qualifikation hätte ein Aneignungsrecht des deutschen Fiskus gem. § 928 Abs. 2 BGB zur Folge und würde den Interessen von Gesellschaftern, Gläubigern und Rechtsverkehr diametral zuwiderlaufen. ${ }^{271}$ Auch komme eine Übertragung auf die Gesellschafter der vernichteten Gesellschaft nach Bruchteilen oder zur gesamten Hand nicht in Frage, da die Gesellschaftsgläubiger der gelöschten Limited dadurch ggf. einer Vielzahl von Schuldnern gegenüberstehen würden. Auch sei es den inländischen Gläubigern nicht zuzumuten, ihre Ansprüche in einem aufwendigen und komplizierten Verfahren gegenüber dem Companies House durchzusetzen. ${ }^{272}$

Das OLG Nürnberg ist der gleichen Auffassung wie das OLG Jena und geht von der Existenz einer Restgesellschaft für das in Deutschland belegene Vermögen einer in England erloschenen und somit aufgelösten Limited aus. ${ }^{273}$

Auf die Auffassung des AG Charlottenburg wurde in Kapitel 4.4.1 ausführlich eingegangen. Anzumerken ist hierzu jedoch, dass es fälschlicherweise vom Vorliegen einer Spaltgesellschaft ausgeht, wenn section 1012 CA 2006 für das in Deutschland belegen Vermögen einer erloschenen englischen Limited nicht anwendbar ist. ${ }^{274}$

\footnotetext{
${ }^{271}$ M. w. N. Schmidt, J. (2008), S. 2400 ff. (2400).

${ }^{272} \mathrm{Vgl}$. OLG Jena vom 22.8.2007, in: ZIP 2007, S. 1709 ff. (1711).

${ }^{273}$ Vgl. OLG Nürnberg vom 10.8.2007, in: GmbHR 2008, S. 41 ff. (42 f.).

274 AG Charlottenburg vom 7.11.2008, in: GmbHR 2009, S. 321 ff. (323). Zur dogmatischen Fehlerhaftigkeit der Annahme einer Spaltgesellschaft an Stelle einer Restgesellschaft vgl. Kapitel 4.4.2.1.
} 
Wenn sich der EuGH der Beurteilung des AG Charlottenburg anschließen sollte, dann würde keine Restgesellschaft vorliegen. Das in Deutschland belegene Vermögen müsste dann auf die englische Krone übergehen (auch wenn dies dem englischen Rechtsverständnis wiedersprechen würde) und sich die daraus ergebenden Rechtsfolgen nach dem englischen Recht richten, die in Kapitel 4.3 dargestellt wurden. ${ }^{275}$ In der Literatur wird der Auffassung des OLG Nürnberg und des OLG Jena gefolgt, ebenso im Ergebnis in der vorliegenden Arbeit. ${ }^{276}$ Wie mit einer Rest-Limited praxis- und interessengerecht verfahren wird, ist Bestandteil der folgenden Ausführungen.

\subsubsection{Gesellschaftsstatut der Rest-Limited}

Eine schwierige Frage ist die nach dem Gesellschaftsstatut einer in England erloschenen Limited, wenn diese zum Zeitpunkt ihrer Löschung noch über Vermögen in Deutschland verfügte. Keines der drei Gerichte äußert sich ausdrücklich zu dieser Frage. In der bisherigen Rechtsprechung unterlag die Restgesellschaft aufgrund der Sitztheorie und der damit verbundenen Anknüpfung an den tatsächlichen Verwaltungssitz deutschem Recht. Dementsprechend wurde sie nach diesem beurteilt, umgegründet und abgewickelt. ${ }^{277}$

Infolge der Rechtsprechung des EuGH zur Niederlassungsfreiheit, untersteht eine englische Limited mit tatsächlichem Verwaltungssitz unstrittig dem englischen Gesellschaftsrecht, da für sie die Gründungstheorie zur Anwendung kommt. Wie bereits dargestellt, ist das (englische) Gesellschaftsstatut dabei weit gefasst zu verstehen und bestimmt nicht nur das Entstehen, sondern auch die Auflösung, Liquidation und Beendigung der Gesellschaft. ${ }^{278}$ Welchem Gesellschaftsstatut die in England als Limited gelöschte Gesellschaft in Deutschland nach Anerkennung der Gründungstheorie unterliegt, ist bisher in Rechtsprechung und Literatur ungeklärt. Hierzu werden verschiedene Auffassungen vertreten.

\footnotetext{
${ }^{275}$ Die daraus möglicherweise resultierenden Probleme werden im Rahmen dieser Arbeit nicht betrachtet, da es aufgrund der dargelegten Ausführungen hier als unwahrscheinlich angesehen wird, dass der EuGH sich für die Anwendbarkeit von section 1012 CA 2006 auf eine gelöschte Limited mit Verwaltungssitz entscheiden wird.

${ }^{276} \mathrm{Zu}$ den zahlreichen Nachweisen in der Literatur vgl. nur die entsprechenden Fn. bei Krömker, M./Otte, S. (2008), S. 964 ff. (964); Schmidt, J. (2008), S. 2400 ff (2401).

${ }^{277}$ Vgl. zuletzt: BGH vom 30.9.1991, ZIP 1991, 1423ff.; Krömker, M./Otte, S. (2008), S. 964 ff. (964 f.).

${ }^{278}$ Vgl. m. w. N. Krömker, M./Otte, S. (2008), S. 964 ff. (965).
} 
Die erste Ansicht ist trotz der EuGH-Rechtsprechung noch immer der Meinung, dass die gelöschte Limited in Deutschland deutschem Recht unterliege. ${ }^{279}$ Begründet wird dies damit, dass solch ein Statutenwechsel von der herrschenden Meinung im Falle der Enteignung für die in Deutschland fortbestehende Rest- oder Spaltgesellschaft angenommen wird. ${ }^{280}$ Auf Grund der Vergleichbarkeit der Ausgangslage bei Enteignungsfällen und Fällen der Löschung im Ausland, soll dies ebenfalls für gelöschte Limiteds gelten. Entsprechend den Grundsätzen der Sitztheorie soll daher eine Rest-Limited in vollem Umfang den Anforderungen des deutschen Gesellschaftsrechts unterworfen werden. ${ }^{281}$ Dies hat im Ergebnis zur Folge, dass die Limited von der Kapitalgesellschaft zur Personengesellschaft umqualifiziert wird und dann auch in Deutschland weiter werbend tätig sein kann. Entsprechend ihrer Ausgestaltung kann dies entweder eine GbR, OHG oder ein Einzelunternehmen sein. ${ }^{282}$

Eine zweite Ansicht ist, dass die gelöschte Limited in Folge der Rechtsprechung des EuGH zur Niederlassungsfreiheit auch nach ihrer Löschung dem englischen Gründungsrecht unterliegt. ${ }^{283}$ Begründet wird dies damit, dass das Gründungsrecht ebenfalls auf die Auflösung und die rechtliche Beendigung der Gesellschaft anwendbar ist. Weiterhin stehe die entstandene Rest-Limited im unmittelbaren Zusammenhang mit der Beendigung der Gesellschaft in England. Deswegen müsse dies auch für das Gesellschaftsstatut gelten. Die Umqualifizierung der fortbestehenden Restgesellschaft in Folge eines Statutenwechsels zu einer Personengesellschaft, mit der Folge einer persönlichen Haftung der Gesellschafter, sei mit der EuGH-Rechtsprechung nicht vereinbar und den Gesellschaftern nicht zumutbar. Dazu käme noch eine praktische Erwägung: wenn die Gesellschaft wiederauflebt, also im register of companies wieder eingetragen wird (restoration of dissolved companies) (284 $^{28 n t e r l i e g t ~ d i e ~ w i e d e r a u f l e b e n d e ~}$ Limited ohnehin wieder dem englischen Gesellschaftsrecht. Wenn diese in der

\footnotetext{
${ }^{279}$ Vgl. Borges, G. (2005), S. 134 ff. (140); Mansel in: Krüger, H./Mansel, H. P. (Hrsg.) (2002), S. 111.

${ }^{280}$ Vgl. Großfeld, B. in: Staudinger, J. von (1998); IntGesR, Rn. 911 ff.; Kindler, P. in: MünchKomm (2006), IntGesR, Rn. 1005.

${ }^{281}$ Borges, G. (2005), S. 134 ff. (140).

${ }^{282}$ Borges, G. (2005), S. 134 ff. (141).

${ }^{283}$ Krömker, M./Otte, S. (2008), S. 964 ff. (965), dieser Ansicht scheint auch das OLG Jena zu folgen, denn es spricht davon, dass: „Die Limited besteht (...) als sog. Restgesellschaft in Deutschland fort.“ OLG Jena vom 22.8.2007, in: ZIP 2007, S. 1709 ff. (1711).

${ }^{284}$ Vgl. hierzu Kapitel 4.6.
} 
Zwischenzeit zu einer Personengesellschaft des deutschen Rechts umqualifiziert wurde, käme es zu einem doppelten Statutenwechsel und dieser wäre nicht sachgerecht und zu kompliziert. Daneben sei eine Differenzierung des Gesellschaftsstatuts der Restgesellschaft danach, ob ein Antrag auf Wiedereintragung in das englische Gesellschaftsregister Erfolg verspricht ungeeignet, da dies $\mathrm{zu}$ extremer Rechtsunsicherheit führen würde. Denn dies würde bedeuten, dass bei einer werbenden Tätigkeit eine deutsche Personengesellschaft mit deutschem Gesellschaftsstatut vorliegt und bei Aufgabe des Geschäftsbetriebs das englische Gesellschaftsstatut weiter besteht.

Die dritte Ansicht will die Rest-Limited ebenfalls deutschem Gesellschaftsrecht unterstellen, doch stellt diese nicht auf das Konstrukt der Restgesellschaft ab. ${ }^{285}$ Vielmehr beruft sie sich auf Grundsätze des IPR. Gemäß dieser Argumentation sei zu beachten, dass die Figur der Restgesellschaft dem englischen Recht fremd sei, es handele sich dabei um eine Erfindung der deutschen Rechtsprechung. Diese dürfe dem englischen Recht die von ihr kreierte Rechtsform nicht aufdrängen, denn nach den allgemeinen Grundsätzen des IPR habe ein Richter nicht die Kompetenz, das ausländische Recht zu verändern. Er dürfe keine Rechtsfortbildung betreiben, sondern muss das ausländische Recht vielmehr so hinnehmen, wie es durch die ausländische Rechtsprechung ausgelegt wird. Ausnahmen seien nur zur Angleichung des materiellen Rechts zulässig. Dies sei hier jedoch nicht der Fall, denn dem englischen Recht werde eine dort gelöschte Gesellschaft als in Deutschland fortbestehend untergeschoben. Deswegen könne eine Rest-Limited nur deutschem Recht unterliegen. Kollisionsrechtlich soll dies mit einer möglichen versteckten Rückverweisung des englischen Rechts auf das deutsche Recht möglich werden, auch wenn auf eine solche sonst nur aus Zuständigkeitsregeln geschlossen werde. Ebenso führe die Anwendbarkeit des deutschen Rechts i. Ü. zu dem Vorteil, dass der Sitz der Restgesellschaft i. S. d. Art. $22 \mathrm{Nr}$. EuGVVO in Deutschland liegt. Dann wären für gesellschaftsrechtliche Streitigkeiten nicht mehr die Gerichte des (englischen) Gründungsstaates, sondern deutsche Gerichte zuständig, da für solche Verfahren immer an den Sitz der Gesellschaft angeknüpft wird. ${ }^{286}$ Darüber hinaus verwehrt sich diese Auffassung dagegen, ein Anhänger der europarechtlich verfemten Sitztheorie zu sein, denn die

\footnotetext{
${ }^{285}$ Vgl. m. w. N. Leible, S./Lehmann, M. (2007), S. 1095 ff. (1098 f.).

${ }^{286}$ Vgl. hierzu m. w. N. Leible, S./Lehmann, M. (2007), S. 1095 ff. (1096).
} 
Restgesellschaft unterstehe deutschem Recht nicht wegen ihres Sitzes in Deutschland, sondern weil sie ein Konstrukt der deutschen Rechtsordnung ist. Das deutsche Recht sei dasjenige, welches sie hervorgebracht habe und damit im weitesten Sinne ihr Gründungsrecht. Damit liege auch kein Verstoß gegen die geforderte europarechtliche Gründungstheorie vor.

Eine vierte Ansicht differenziert danach, ob die Gesellschaft in Deutschland lediglich abgewickelt werden soll, oder ob diese in Deutschland weiter eine Geschäftstätigkeit wahr nimmt. ${ }^{287}$ Grundsätzlich sei von der Annahme einer Restgesellschaft für in Deutschland belegenes Vermögen auch für den Fall auszugehen, dass die Beendigung Folge der Löschung im Register ist. Diese stimmt mit dem Grundprinzip des deutschen internationalen Gesellschaftsrechts überein, wonach eine Beendigung im Ausland zwar grundsätzlich anerkannt wird, die Gesellschaft aber als fortbestehend gilt, soweit noch Vermögen in Deutschland vorhanden ist. Da die Gesellschaft geordnet abgewickelt werden soll, wird die Gesellschaft demnach in Deutschland als Abwicklungsgesellschaft weiterbestehend angesehen, inklusive der Fortgeltung des „alten“ Gesellschaftsstatuts. ${ }^{288}$ Nun soll jedoch danach differenziert werden, ob die Löschung im Gesellschaftsregister erfolgt, weil die Limited ihren Publizitätspflichten in England nicht mehr nachkommt, weil sie tatsächlich - auch in Deutschland - keine Geschäftstätigkeit mehr wahr nimmt, oder ob sie diesen nicht nachkommt, obwohl sie in Deutschland weiterhin werbend tätig ist. Nur im ersten Fall könne es überhaupt um eine „geordnete“ Abwicklung gehen. Im zweiten Fall helfe die Annahme einer fortbestehenden Gesellschaft als „Abwicklungsgesellschaft“ nicht weiter. Es gehe dann nicht nur um die Zuordnung des bei der Auflösung der Gesellschaft „,vergessenen“ Auslandsvermögen, sondern vielmehr um in die Zukunft gerichtete Fragen nach der Rechtsnatur, den Vertretungsverhältnissen sowie der Haftung in Bezug auf die fortgesetzte Geschäftstätigkeit der - im englischen Register - gelöschten Gesellschaft. Wenn also die Gesellschaft als reine „Abwicklungsgesellschaft“ fortbesteht, dürfe sie ihr Gesellschaftsstatut behalten und die Abwicklung sei nach „ihrem“ Gesellschaftsstatut vorzunehmen. Soweit die Gesellschaft aber als werbende Gesellschaft fortgesetzt wird, wird eine Behandlung nach deutschem Gesellschaftsrecht

\footnotetext{
${ }^{287}$ Zimmer, D./Naendrup, C. (2007), S. 789 ff. (803 ff.).

${ }^{288}$ Vgl. m. w. N. Zimmer, D./Naendrup, C. (2007), S. 789 ff. (804 ff.).
} 
für sachgerecht erachtet, es käme also auf Grund des deutschen Rechtformenzwangs zu einer Umqualifizierung in eine Personengesellschaft. Die Qualifizierung zu einer VorGmbH scheide hingegen aus. ${ }^{289}$ Dies entspräche in den Grundzügen der Lehre der Restgesellschaft im Fall der Enteignung durch den „Heimat“-Staat der Gesellschaft.

Die vier dargestellten Ansichten scheinen zunächst, jede für sich betrachtet, stimmig und logisch. Jedoch kann im Ergebnis nur der zweiten, von Krömker/Otte, gefolgt werden. ${ }^{290}$ Die anderen scheiden schon deshalb aus, weil sie auch von der Möglichkeit des Fortbestehens der Restgesellschaft als werbende Gesellschaft in Deutschland ausgehen. Diese Annahme war für die ursprüngliche Lehre der Rest- und Spaltgesellschaft durchaus angebracht, denn hier wurde die Gesellschaft unverschuldet im Ausland enteignet. Anders verhält es sich jedoch, wenn eine Gesellschaft ihren Publizitätspflichten gemäß dem von ihr frei gewählten englischen Gesellschaftsrecht nicht nachkommt. Wie bereits zuvor dargelegt handelt es sich hierbei um ein wichtiges Instrument zum Schutz der Gläubiger und des Rechtverkehrs. Der Sanktionscharakter der Löschung und der damit verbundenen Auflösung würde für eine Limited mit Verwaltungssitz verloren gehen, wenn diese trotz Verletzung ihrer Pflichten gegenüber dem Companies House in Deutschland als Personengesellschaft weiter einer Geschäftstätigkeit nachgehen könnte. ${ }^{291}$

Gegen die Möglichkeit der Fortführung einer gelöschten Limited in Deutschland spricht auch, dass dann genau wieder die Organe, vor allem die ehemaligen directors, die neue Gesellschaft vertreten würden, die durch Verletzung ihrer Sorgfaltspflichten die Löschung herbeigeführt haben. ${ }^{292}$

Ebenso widerspricht die Annahme der Möglichkeit einer Fortführung der Geschäftstätigkeit als Personengesellschaft in Deutschland der Rechtsprechung des EuGH zur Niederlassungsfreiheit. Da sich in deren Folge das Gesellschaftsstatut einer

\footnotetext{
${ }^{289}$ Vgl. hierzu Zimmer, D./Naendrup, C. (2007), S. 789 ff. (809 f.)

${ }^{290}$ Krömker, M./Otte, S. (2008), S. 964 ff. Der gleichen Ansicht scheint auch das OLG Jena zu folgen, denn es spricht davon, dass: „Die Limited besteht (...) als sog. Restgesellschaft in Deutschland fort.“ OLG Jena vom 22.8.2007, in: ZIP 2007, S. 1709 ff. (1711).

${ }^{291}$ Schmidt, J. (2008), S. 2400 ff. (2401).

${ }^{292}$ Schmidt, J. (2007), S. 1712 ff. (1713); Im Ergebnis genauso OLG Jena vom 22.8.2007, in: ZIP 2007, S. 1709 ff. (1711 f.).
} 
englischen Limited mit Verwaltungssitz in Deutschland ausschließlich nach englischem Recht richtet, entscheidet auch nur dieses über die Beendigung der Limited und genau das muss uneingeschränkt anerkannt werden. Wenn das englische Recht die Limited für „tot““ erklärt, muss das für die ganze Limited gelten. ${ }^{293}$

Auch der an dieser Stelle von Leible/Lehmann vorgebrachte Einwand ${ }^{294}$, dass dem englischen Recht ein Konstrukt der deutschen Rechtsprechung, eine Restgesellschaft mit englischem Gesellschaftsstatut, untergeschoben werden soll, kann nicht überzeugen. Es stimmt zwar, dass diese Art der Gesellschaft dem englischen Recht nicht bekannt ist. Jedoch soll diese entsprechend der hier vertretenen Meinung nur für das in Deutschland belegene Vermögen geschaffen werden, um hier belegenes Vermögen einer gelöschten Limited zu liquidieren und nicht um deren Fortbestand zu fingieren.

Das oberste Ziel im Umgang mit einer Rest-Limited muss es sein, möglichst schnell und unter Beachtung der Rechtsprechung des EuGH und des englischen Gesellschaftsrechts, ein Ergebnis herbeizuführen, dass den Rechtsfolgen des section 1012 CA 2006 möglichst nahe kommt. Da nach der derzeitigen Rechtslage der direkte Anfall des in Deutschland belegenen Vermögens an die englische Krone nicht möglich ist, kommt hierfür nur eine Liquidation der Rest-Limited in Frage.

Im Ergebnis handelt es sich also um eine reine Liquidationsgesellschaft, die grundsätzlich ihrem Gründungsgesellschaftsstatut untersteht. ${ }^{295}$ Dies steht auch nicht im Widerspruch der Rechtsprechung des EuGH zur Niederlassungsfreiheit, denn eine nach ihrem Heimatrecht erloschene und damit nicht mehr existierende Gesellschaft fällt a priori nicht mehr in den Schutzbereich der Art. 43, 48 EG. ${ }^{296}$

\subsubsection{Rechts- und Parteifähigkeit der Rest-Limited}

Leichter gestaltet sich die Frage, ob die Rest-Limited noch Trägerin von Rechten und Pflichten sein und ob sie noch in Gerichtsprozessen auftreten kann. Sowohl das OLG

\footnotetext{
${ }^{293}$ Schmidt, J. (2008), S. 2400 ff. (2401).

${ }^{294}$ Leible, S./Lehmann, M. (2007), S. 1095 ff. (1098).

${ }^{295}$ Schmidt, J. (2008), S. 2400 ff. (2401). Im Ergebnis ebenso OLG Jena vom 22.8.2007, in: ZIP 2007, S. 1709 ff. (1711); Krömker, M./Otte, S. (2008), S. 964 ff. (965); Schmidt, J. (2007), S. 1712 ff. (1713).

${ }^{296}$ M. w. N. Schmidt, J. (2007), S. 1712 ff. (1713).
} 
Nürnberg, das OLG Jena als auch die herrschende Meinung in der Literatur gehen von der Rechts- und Parteifähigkeit der Rest-Limited aus. ${ }^{297}$ Da diese Inhaberin des verbliebenen Inlandsvermögens ist, kann ihr die Rechtsfähigkeit und damit verbunden auch die Parteifähigkeit nach $\S 50$ ZPO nicht abgesprochen werden. Dieses Ergebnis steht auch im Einklang mit dem von der Rechtsprechung anerkannten Grundsatz, dass eine erloschene juristische Person solange als parteifähig gilt, als ihr in einem Rechtsstreit nach dem Parteivortrag noch vermögensrechtliche Ansprüche zustehen. ${ }^{298}$ Ebenso gelten im Insolvenzrecht sowohl juristische Personen als auch Gesellschaften ohne Rechtspersönlichkeit selbst noch nach ihrer Löschung im jeweiligen Register als insolvenzfähig, so lange noch verteilbares Vermögen vorhanden ist. ${ }^{299}$ Somit kann die Restgesellschaft unstreitig als rechtlich selbständig angesehen werden.

Als solche ist sie auch ins deutsche Handelsregister einzutragen. ${ }^{300}$ Dies erfolgt in der Regel dann, wenn das zuständige Gericht vom Vermögen in Deutschland der gelöschten Limited erfährt. Dazu kommt es spätestens, wenn bei dem entsprechenden Gericht ein Vertreter für die Rest-Limited bestellt wird. Der Eintragung kommt jedoch nur eine deklaratorische Bedeutung zu, sie erfolgt als Restgesellschaft ex officio (lat. von Amts wegen). Die Rechtsfähigkeit der Restgesellschaft ergibt sich bereits daraus, dass diese als rechtlich selbständige Gesellschaft, die nach dem englischen Recht zu behandeln ist, ohnehin rechtsfähig ist. ${ }^{301}$

\subsubsection{Vertretung der Rest-Limited}

Umstritten ist hingegen die Frage durch wen die Restgesellschaft vertreten werden kann und soll. Dabei wird entweder auf die Bestellung eines Pflegers im Sinne des § 1913 BGB oder die eines Nachtragsliquidators entsprechend $\S 66$ Abs. 5 GmbHG, 273 Abs. 4 AktG abgestellt.

\footnotetext{
${ }^{297}$ Vgl. m. w. N. OLG Nürnberg vom 10.8.2007, in: GmbHR 2008, S. 41 ff. (43); im Ergebnis ebenso: OLG Jena vom 22.8.2007, in: ZIP 2007, S. 1709 ff. (1710). Zur Literatur: vgl. m. w. N. Krömker, M./Otte, S. (2008), S. 964 ff. (966).

298 Vgl. BGH vom 29.9.1967, BGHZ 48, S. 303 ff.; vom 8.10.1979, BGHZ 75, S. 178 ff.; vom 17.10.1994, in: ZIP 1994, S. 1887 ff.

${ }^{299}$ M. w. N. OLG Nürnberg vom 10.8.2007, in: GmbHR 2008, S. 41 ff. (42).

${ }^{300}$ Vgl. hierzu m. w. N. Großfeld, B. in: Staudinger, J. von (1998); IntGesR, Rn. 858 ff.; Krömker, M./Otte, S. (2008), S. 964 ff. (966).

${ }^{301} \mathrm{Vgl}$. dazu die Ausführungen im vorigen Kapitel.
} 
Nach der (alten) Lehre von der Restgesellschaft war in den Fällen der Enteignung der Gesellschaft für die Geschäftsführungs- und Vertretungsbefugnis der Restegesellschaft die Organstellung nach den Regeln des alten Gesellschaftsstatuts maßgeblich. ${ }^{302}$ Hierfür kam ebenfalls wieder das Territorialprinzip zur Anwendung. Aus diesem folgte, dass die Enteignung nicht zur Beendigung der Geschäftsführungs- und Vertretungsbefugnisse der bisherigen Organe für das Vermögen außerhalb des enteignenden Staats führen sollte. Die Vertretungsorgane der aufgelösten Gesellschaft vertraten grundsätzlich auch die Restgesellschaft. Dahinter stand der Gedanke, das Gesellschaftsstatut größtmöglich zu schonen. Da die Gesellschaft unverschuldet vernichtet wurde, ist diese Überlegung recht und billig.

Anders verhält es sich jedoch, wenn eine Gesellschaft durch Eigenverschulden aus dem englischen register of companies gelöscht wird, weil ihre directors es versäumt haben, ihren Publizitätspflichten nachzukommen. ${ }^{303}$ Hier kann nicht auf die Grundsätze der Restgesellschaft zurückgegriffen werden, denn diese beruhen ja gerade darauf, dass die Gesellschaft keine Schuld an ihrer Vernichtung trifft. Wenn die ehemaligen Vertretungsorgane jedoch die Löschung durch ihr Fehlverhalten selbst herbeigeführt haben, dann ist es nicht sachgerecht diese zur Vertretung der Restgesellschaft zu bestimmen. Vielmehr muss die rechtswirksame Beendigung der Vertretungsbefugnisse einer Limited nach dem (englischen) Gesellschaftsstatut beachtet werden. ${ }^{304}$ Die Löschung und Auflösung erfolgt auch nicht willkürlich oder leichtfertig, sondern ist die letzte Sanktion am Ende einer Reihe von Maßnahmen zur Durchsetzung der Publizitätspflicht. ${ }^{305}$

Die ehemaligen directors kommen demnach im Fall der Löschung aufgrund der Verletzung der englischen Publizitätspflichten zur Vertretung der Rest-Limited i. d. R. nicht in Betracht.

\footnotetext{
302 OLG Jena vom 22.8.2007, in: ZIP 2007, S. 1709 ff. (1711.); Großfeld, B. in: Staudinger, J. von (1998); IntGesR, Rn. 863.

${ }^{303}$ Vgl. hierzu OLG Jena vom 22.8.2007, in: ZIP 2007, S. 1709 ff. (1711); dem zustimmend: Bähr, R. M. in: Fritz, D. F./Herrmann O. (Hrsg.) (2008), Rn. 339. Krömker, M./Otte, S. (2008), S. 964 ff. (965); Schmidt, J. (2007), S. 1712 ff. (1713); Schmidt, J. (2008), S. 2400 ff (2401).

${ }^{304}$ Vgl. m. w. N. Schmidt, J. (2008), S. 2400 ff (2401); Süß, R. in: Wachter, T. (Hrsg.) (2007), Rn 240.

${ }^{305}$ Vgl. hierzu Kapitel 4.1.
} 


\subsubsection{Bestellung eines Pflegers}

Das OLG Nürnberg hat in dem von ihm entschiedenen Fall, als die Rest-Limited noch Forderungen in Deutschland hatte, die Bestellung eines Abwesenheitspfleger gem. $\S$ 1913 BGB zur Vertretung der Restgesellschaft bejaht. ${ }^{306}$ Begründet hat es dies damit, dass der rechtliche Status der Limited nach deren Löschung aus dem register of companies ungewiss sei und sich ein Fürsorgebedürfnis aus den Vermögensinteressen der Restgesellschaft ergebe. In Fällen, in denen eine ausländische juristische Person durch einen Hoheitsakt eines ausländischen Staates aufgelöst wird und sie in diesem Staat ihren Sitz hat, sei bei der Annahme des Fortbestehens dieser Gesellschaft in Bezug auf in Deutschland belegenes Vermögen § 1913 BGB einschlägig und diesem entsprechend ein Pfleger zu bestellen. Dieser Meinung sind auch große Teile der deutschen Literatur. ${ }^{307}$

\subsubsection{Bestellung eines Nachtragsliquidators}

Das OLG Jena hat hingegen die Bestellung eines Nachtragsliquidators gem. $\S \S 66$ Abs. 5 GmbHG, 273 Abs. 4 AktG bejaht. ${ }^{308}$ Gemäß der Auffassung des Senats sei dies die sachgerechteste Lösung, wenn die Löschung der ausländischen Gesellschaft in ihrem Heimatstaat aufgrund von Versäumnissen der bisherigen Vertretungsorgane erfolgt. So könne die Auswahl dem Gericht überlassen werden, wer mit der Abwicklung der Rechtslage betraut wird.

\subsubsection{Eigene Stellungnahme}

Die Ansicht der OLG Jena hat in seiner Folge viel Zustimmung in der jüngeren Literatur erfahren. ${ }^{309}$ Auch die vorliegende Arbeit geht für die zugrunde liegende Konstellation davon aus, dass ein Nachtragsliquidator gem. §§ 66 Abs. 5 GmbHG, 273 Abs. 4 AktG, besser geeignet ist als ein Pfleger gem. 1913 BGB.

\footnotetext{
${ }^{306}$ OLG Nürnberg vom 10.8.2007, in: GmbHR 2008, S. 41 ff. (43).

${ }^{307}$ Vgl. m. w. N. Mansel in: Krüger, H./Mansel, H. P. (Hrsg.) (2002), S. 122 f.; Mock, S./Schildt, D. in: Hirte H./Bücker T. (Hrsg.) (2006), § 17 Rn. 131; Süß, R. in: Wachter, T. (Hrsg.) (2007), Rn 240.

308 OLG Jena vom 22.8.2007, in: ZIP 2007, S. 1709 ff. (1711). Im Ergebnis ist die wohl auch die Auffassung des AG Charlottenburg vom 7.11.2008, in: GmbHR 2009, S. 321 ff. (323).

${ }^{309}$ Krömker, M./Otte, S. (2008), S. 964 ff. (965); Schmidt, J. (2008), S. 2400 ff. (2401); Bähr, R. M. in: Fritz, D. F./Herrmann O. (Hrsg.) (2008), Rn. 339; Leible, S./Lehmann, M. (2007), S. 1095 ff. (1098).
} 
Dies beruht zunächst schlicht darauf, dass die Bestellung eines Pflegers nicht mehr möglich ist, da die entsprechende Rechtsgrundlage im Zuständigkeitsänderungsgesetz ( 10 ZustErgG) mit Wirkung vom 25. April 2006 aufgehoben wurde. ${ }^{310}$ Vor allem aber ist die Bestellung eines Nachtragsliquidators die sachgerechteste Lösung, denn wie bei der Nachtragsliquidation einer GmbH oder Aktiengesellschaft geht es nach der hier vertretenen Meinung auch im Fall einer Rest-Limited, um die Herbeiführung der Vollbeendigung und diese ist der anerkannte Hauptfall der Nachtragsliquidation. ${ }^{311}$

Ferner ist ein deutsches Gericht für die Bestellung eines Nachtragsliquidators international zuständig. ${ }^{312}$ Dies folgt aus Art. 60 Abs. 1 EuGVVO. ${ }^{313}$ Im Übrigen ist an die Belegenheit des Hauptvermögens anzuknüpfen, was im vorliegenden Fall einer Rest-Limited mit Restvermögen in Deutschland unstrittig Deutschland ist. Innerhalb Deutschlands ist das Gericht zuständig, in dessen Bezirk die Zweigniederlassung der gelöschten Limited liegt bzw. lag. Falls keine Zweigniederlassung zum Handelsregister angemeldet wurde, kann analog an die Judikatur zu $§ 5$ Abs. 1 Satz 2 FGG, an die Belegenheit des Hauptvermögens angeknüpft werden.

Vor allem, ist wie oben bereits dargestellt, bei Bestellung eines Nachtragliquidators $\S \S$ 66 Abs. 5 GmbHG, 273 Abs. 4 AktG dem Gericht die Auswahl überlassen, wen es hierzu bestellt. Dabei muss zunächst der entsprechende Sachverhalt vom Gericht ermittelt werden und den ehemaligen Gesellschaftsorganen rechtliches Gehör verschafft werden, da die Bestellung eines Nachtragsliquidators deren Rechte berührt. ${ }^{314}$ Zudem ist der Beschluss zu begründen. Bei der in dieser Arbeit untersuchten Konstellation, also der Löschung der Limited aufgrund der Verletzung der englischen Publizitätspflichten durch die Direktoren, können und sollten diese aus dem Verfahren herausgehalten werden, da diese sonst weiter Misswirtschaften könnten. Ihre Ungeeignetheit zur Führung einer Limited haben diese bereits selbst bewiesen, da sie die Löschung und die damit verbundene Auflösung zu verschulden haben.

\footnotetext{
${ }^{310}$ Vgl. m. w. N. Schmidt, J. (2008), S. 2400 ff. (2401).

${ }^{311}$ M. w. N Krömker, M./Otte, S. (2008), S. 964 ff. (965 f.).

${ }^{312}$ Vgl. ausführlich hierzu OLG Jena vom 22.8.2007, in: ZIP 2007, S. 1709 ff. (1711); Schmidt, J. (2008), S. 2400 ff. (2401); Krömker, M./Otte, S. (2008), S. 964 ff. (965); Leible, S./Lehmann, M. (2007), S. 1095 ff. (1096).

${ }^{313}$ Vgl. ausführlich m. w. N. Schmidt, J. (2008), S. 2400 ff. (2401 f.).

${ }^{314}$ Vgl. hierzu ausführlich OLG Jena vom 22.8.2007, in: ZIP 2007, S. 1709 ff. (1711).
} 
Der so bestellte Nachtragsliquidator darf eine Rest-Limited gerichtlich als auch außergerichtlich vertreten, analog $§ 70$ Satz 1 Halbs. 2 GmbHG. ${ }^{315}$ Entsprechend dem Ziel der Abwicklung des in Deutschland belegenen Vermögens ist sein Wirkungskreis hierauf beschränkt. Der Liquidator ist ein unabhängiges Organ, ähnlich einem Insolvenzverwalter. ${ }^{316} \mathrm{Im}$ Besonderen sind ihm gegenüber weder die ehemaligen Direktoren noch die Gesellschafter weisungsbefugt.

\subsubsection{Die Liquidation der Rest-Limited}

Die Liquidation einer gelöschten Limited mit Restvermögen in Deutschland erfolgt so weit wie möglich und sachgerecht nach den Grundsätzen der Nachtragsliquidation einer $\mathrm{GmbH}$. Diese deutsche Gesellschaftsform ist der Limited am ähnlichsten und deren Nachtragsliquidation in der deutschen Literatur und Rechtsprechung ausführlich besprochen und geregelt. ${ }^{317}$ Dementsprechend kommen in den folgenden Ausführungen die bekannten einschlägigen Vorschriften der Nachtragsliquidation einer $\mathrm{GmbH}$ analog zur Anwendung. Es müssen also keine neuen Vorschriften zur Liquidation einer RestLimited geschaffen werden.

Zur Antragstellung auf Bestellung eines Nachtragsliquidators ist, wie bei der Nachtragsliquidation einer $\mathrm{GmbH}$, jeder Beteiligte befugt, der daran ein berechtigtes (unmittelbares) Interesse hat, also vor allem die Gesellschafter, die früheren Direktoren sowie die Gläubiger der gelöschten Limited. ${ }^{318}$ Dabei muss der Antragsteller seine Antragsberechtigung und die Notwendigkeit der Nachtragsliquidation glaubhaft machen, also die Löschung der Limited aus dem register of companies in England sowie das Vorhandensein eines Restvermögens in Deutschland. Hierbei kommt es nicht auf die Höhe des Vermögens an. Außerdem muss der Antragsteller die Gerichtsgebühren gem. § 121 KostO sowie ggf. auch einen Vorschuss zur Deckung des Vergütungs- und Auslagenersatzanspruchs des Nachtragsliquidators leisten.

\footnotetext{
${ }^{315}$ Schmidt, J. (2008), S. 2400 ff. (2403).

${ }^{316}$ Vgl. ausführlich hierzu Schmidt, J. (2008), S. 2400 ff. (2403).

${ }^{317}$ Vgl. Schmidt, J. (2008), S. 2400 ff. (2401 ff.).

${ }^{318}$ Vgl. m. w. N. Schmidt, J. (2008), S. 2400 ff. (2402).
} 
Es handelt sich bei der Rest-Limited, wie bereits dargelegt, um eine reine Liquidationsgesellschaft. Dementsprechend ist der einzige Zweck der Nachtragsliquidation die vollständige Abwicklung des in Deutschland belegenen Vermögens der Rest-Limited. ${ }^{319}$ Hieraus ergibt sich die funktionelle (Abwicklung) als auch gegenständliche (Vermögen in Deutschland) Beschränkung des Wirkungskreises des Nachtragsliquidators. Der Liquidator wird sich einen Überblick über die Vermögensverhältnisse der Limited verschaffen und die Gläubigerforderung gegen diese feststellen müssen. Hierzu muss ihm ein umfassendes Einsichtsrecht in die Geschäftsunterlagen gewährt werden.

Seine einzige Aufgabe ist dann die Verwertung des in Deutschland belegenen Vermögens. Davon werden dann zunächst, wie bei der Nachtragsliquidation einer $\mathrm{GmbH}$, die Gläubiger befriedigt und ein ggf. vorhandener Restbetrag wird an die Gesellschafter ausgeschüttet. ${ }^{320}$ Zur Maximierung des Erlöses und zur möglichst effektiven Verwertung des Vermögens der gelöschten Limited in Deutschland darf der Liquidator auch neue Verbindlichkeiten eingehen. Nach Beendigung der Nachtragsliquidation erstellt der Liquidator eine Schlussrechnung sowie eine Schlussbilanz. Der Abschluss der Liquidation ist ins Handelsregister einzutragen.

\subsubsection{Haftung der Vertreter der Rest-Limited}

Wie zuvor dargelegt, wird die Rest-Limited durch den Liquidator vertreten. Wie bereits erläutert ist die englische Limited mit der deutschen $\mathrm{GmbH}$,am nächsten verwandt“. Deswegen muss sich die Haftung ihres Liquidators in Deutschland nach der Haftung eines GmbH-Liquidators richten. Jedoch können hierbei spezifische GmbHliquidationsrechtliche Vorschriften nicht zur Anwendung kommen. Es ist nicht das Ziel der Liquidation die Rest-Limited so weit wie möglich an die $\mathrm{GmbH}$ anzunähern, sondern lediglich diese sachgerecht zu liquidieren. Dementsprechend kann für den Nachtragsliquidator nur die Haftung aus den Sorgfaltspflichten gem. §§ 43, 71 Abs. 4 GmbHG gelten ${ }^{321}$

\footnotetext{
${ }^{319}$ Zum allg. Zweck und zur Beschränkung der Nachtragsliquidation vgl. m. w. N. Schmidt, J. (2008), S. 2400 ff. (2402); Fn. 53.

${ }^{320}$ Vgl. m. w. N. Schmidt, J. (2008), S. 2400 ff. (2403).

${ }^{321}$ Krömker, M./Otte, S. (2008), S. 964 ff. (966).
} 


\subsubsection{Haftung der Gesellschafter der Rest-Limited}

Gemäß dem Gesellschaftsstatut einer englischen Limited ist die Haftung grundsätzlich auf das Gesellschaftsvermögen beschränkt. Ein Haftungsdurchgriff auf die Gesellschafter ist in der Praxis extrem selten. ${ }^{322} \mathrm{Da}$, wie oben gezeigt, für die Liquidation der Restgesellschaft das englische Gesellschaftsstatut aufrecht erhalten wird, richtet sich die Haftung der Gesellschafter grundsätzlich weiter nach englischem Recht. Dies gilt natürlich nur, solange die Gesellschaft nicht (wieder) in Deutschland werbend tätig wird. $\mathrm{Zu}$ den möglichen (Haftungs-) Folgen bei einer werbenden Tätigkeit der gelöschten Limited vgl. Kapitel 4.5.

\subsubsection{Insolvenzfähigkeit der Rest-Limited}

Eine Rest-Limited ist insolvenzfähig. Wenn der Liquidator oder die ehemaligen Gesellschafter bei Führungslosigkeit feststellen, dass ein Insolvenzeröffnungsgrund gegeben ist, müssen sie einen Insolvenzantrag stellen. Hier ist der durch das MoMiG neu geschaffene $\S 15 \mathrm{a}$ InsO einschlägig. Die internationale Zuständigkeit eines deutschen Insolvenzgerichts ergibt sich aus Art. 3 EuInsVO, da sich das COMI in Deutschland befindet, wenn hier der Hauptverwaltungssitz der Limited war. ${ }^{323}$

\subsection{Fortführung der Limited trotz Löschung}

Wenn die ehemaligen Direktoren oder Gesellschafter einer in England erloschenen Limited weiterhin in deren Namen auftreten, setzen sie sich der Gefahr einer persönlichen Haftung aus. ${ }^{324}$ Nach der Auflösung der Gesellschaft in England, welche gerade vom deutschen Recht als unumstößlich akzeptiert werden muss, kann nicht mehr in deren Namen gehandelt werden. ${ }^{325}$ Der ehemalige Direktor oder Gesellschafter handelt dann als falsus procurator, also als Vertreter ohne Vertretungsmacht, da er eine

\footnotetext{
${ }^{322}$ Vgl. m. w. N. Krömker, M./Otte, S. (2008), S. 964 ff. (966).

${ }^{323}$ Vgl. m. w. N. Schmidt, J. (2008), S. 2400 ff.. (2403). Ausführlich dazu Bähr, R. M. in: Fritz, D. F./Herrmann O. (Hrsg.) (2008), Rn. 340 ff.

${ }^{324}$ Vgl. Bähr, R. M. in: Fritz, D. F./Herrmann O. (Hrsg.) (2008), Rn. 336.

${ }^{325}$ Vgl. hierzu Borges, G. (2005), S. 134 ff. (141); Schmidt, J. (2007), S. 1712 ff. (1714); Römermann, V./Röver, N. in: Römermann, V. (Hrsg.) (2006), Private Limited Company in Deutschland. PraxisLeitfaden für Berater und Unternehmer, Bonn u. a., S. 136; Bähr, R. M. in: Fritz, D. F./Herrmann O. (Hrsg.) (2008), Rn. 336.
} 
nicht existente haftungsbeschränkte Gesellschaft vertritt und haftet somit persönlich. Diese Haftungsfigur gibt es sowohl im englischen, als auch im deutschen Recht. ${ }^{326}$ Für in Deutschland getätigte Geschäfte ergibt sie sich aus § 179 BGB (analog), da hierfür das Geschäftsstatut maßgeblich ist.

\subsection{Die Möglichkeit der Wiedereintragung im register of companies}

Ein weiteres Problem ergibt sich daraus, dass es im englischen Gesellschaftsrecht die Möglichkeit der Wiedereintragung einer gelöschten Limited gibt (restoration of dissolved companies). ${ }^{327}$ Wie bereits dargestellt, fällt das Vermögen einer gelöschten englischen Limited an die englische Krone. Es erfolgt keine Befriedigung der Gläubiger und Gesellschafter. Vielmehr können diese, auch noch Jahre nach der Löschung, die Wiedereintragung betreiben, um an die Vermögensgegenstände der gelöschten Limited zu gelangen. ${ }^{328}$

Im Falle einer erfolgreichen Wiedereintragung wird die Gesellschaft so behandelt, als ob sie nie gelöscht wurde. ${ }^{329}$ Die Krone muss das erlangte Vermögen wieder herausgeben. Wenn dies nicht möglich ist, muss sie Wertersatz leisten. ${ }^{330}$ Derjenige an den die Krone das Vermögen weiter veräußert hat, ist hiervon jedoch nicht betroffen. Er ist weder zum Wertersatz, noch zur Herausgabe des erlangten Eigentums verpflichtet. ${ }^{331}$

Die Wiedereintragung ist eine Ermessensentscheidung des Gerichts. Es ordnet die Wiedereintragung im Fall der Zwangslöschung nur an, wenn es der Auffassung ist, dass die Gesellschaft zum Zeitpunkt der Löschung noch aktiv war, oder wenn es die Wiedereintragung für billig und gerecht hält. Davon geht es vor allem in den Fällen aus,

\footnotetext{
326 Vgl. ausführlich hierzu m. w. N. Schmidt, J. (2008), S. 2400 ff. (2403 f.); zur Haftung nach englischem Recht s. Fn. 69.

${ }^{327}$ Krömker, M./Otte, S. (2008), S. 964 ff. (966 f.); Schmidt, J. (2008), S. 2400 ff. (2404). Ausführlich hierzu Zimmer, D./Naendrup, C. (2007), S. 789 ff. (813 ff.).

${ }^{328}$ Section 653 (2) CA 1985, ab 1.10. 2009 sections 1024 (4), 1030 (1), (4) CA 2006.

${ }^{329}$ Section 653 (3) CA 1985, ab 1.10.2009 sections 1028 (1), 1032 (1) CA 2006.

${ }^{330}$ Vgl. section 655 (2) CA 1985, ab 1.10.2009 section 1034 (2) CA 2006.

${ }^{331}$ Vgl. section 655 (1) CA 1985, ab 1.10.2009 section 1034 (1) CA 2006.
} 
in denen noch Vermögen vorhanden war. ${ }^{332}$ Bevor die Wiedereintragung vollzogen wird, müssen jedoch zuerst die versäumten Publizitätspflichten nachgeholt werden.

Ein großer Teil der deutschen Literatur geht davon aus, dass damit ebenfalls das in Deutschland belegene Vermögen an die wieder auflebende Limited zurückfalle. ${ }^{333}$ In der (Rechts-) Theorie ist dies eine $\mathrm{zu}$ bejahende Vorgehensweise. Jedoch fehlt ihr der Bezug zur wirtschaftlichen Realität. Vielmehr ist, zumindest im Ergebnis, der Auffassung von Schmidt zu folgen. ${ }^{334}$

Wenn man den ex-tunc Rückfall des in Deutschland belegenen Vermögens annehmen würde, dann wäre eine Nachtragsliquidation nicht möglich und es käme zu unerträglichen Schwebezuständen und Rechtsunsicherheit. Der Nachtragsliquidator könnte die Vermögensgegenstände nicht effektiv veräußern, da sich kaum Interessenten für diese finden würden, da diese zumindest bis zum Eigentumsübergang mit einem Rückfallrisiko behaftet sind.

Selbst wenn man weiter versucht nach dem Companies Act zu verfahren und die Erwerber von der Rückübertragung oder Entschädigung $\mathrm{zu}$ befreien, müsste der Liquidator auch entsprechend die Rolle der englischen Krone übernehmen. Er wäre dann wie diese zu stellen, und müsste der Limited ebenfalls Wertersatz für die veräußerten Vermögensgegenstände leisten. Da in Deutschland niemand zur Übernahme des Amtes eines Nachtragliquidators gezwungen werden kann, würde sich unter diesen Voraussetzungen kaum jemand finden, der dieses Amt übernimmt. Er müsste auch Jahre nach der Beendigung der Liquidation mit Schadensersatzansprüchen der Limited rechnen, selbst wenn der Erlös der Veräußerung bereits an die Gläubiger und Gesellschafter ausgekehrt wurde.

Schmidt begründet ihre Ablehnung mit dem Territorialitätsprinzip. Die Wiedereintragung der Limited in England führe daher nur zur „Wiederauferstehung“ des englischen Teils der Limited mit dem in England belegenen Vermögen. Dem ist gem. den Ausführungen in Kapitel 4.4. zuzustimmen. Der Heimfall des Vermögens an

\footnotetext{
${ }^{332}$ Krömker, M./Otte, S. (2008), S. 964 ff. (966). Ausführlich m. w. N. Zimmer, D./Naendrup, C. (2007), S. 789 ff. (813).

${ }^{333}$ Vgl. Schmidt, J. (2008), S. 2400 ff. (2400).

${ }^{334}$ Vgl. Schmidt, J. (2008), S. 2400 ff. (2404).
} 
die englische Krone als bona vacantia ist auf das Territorium Englands begrenzt. Dies entspricht der englischen Auffassung dieses Rechtsinstituts. Außerdem handelt es sich dabei, wie erläutert, nicht um eine Vorschrift des Gesellschaftsrechts, sondern um eine öffentlich-rechtliche Vorschrift. Diese muss dann ebenfalls für die Folgen aus der Verwertung des Vermögens durch die englische Krone gelten. Sie ist also nicht Teil des Gesellschaftsstatuts der Limited und damit nicht in Deutschland anwendbar.

Wenn die entsprechenden Vorschriften des Companies Act in Deutschland nicht angewandt werden, kann eine ordnungsgemäße und effektive Liquidation durchgeführt werden. Wenn die englische Limited während der Liquidationsphase wieder in das register of companies eingetragen wird, soll dies in Anerkennung der Grundsätze der Niederlassungsfreiheit dazu führen, dass diese an Stelle der Gesellschafter tritt und nach der Befriedigung der Gläubiger Letztbegünstigste ist. Damit fließt ihr ihr Vermögen auch auf diesem Wege wieder zu. Das Ergebnis ist ähnlich dem englischen, denn auch hier würde sie sich nach ihrer Wiedereintragung ihren alten Gläubigern gegenüber finden. Nur das diese hier schon vorab befriedigt wurden. 


\section{Fazit und Ausblick}

Die vorliegende Arbeit hat sich ausschließlich mit den Folgen der Löschung einer private company limited by shares mit Verwaltungssitz und Restvermögen in Deutschland beschäftigt. Die meisten der dargelegten Ausführungen sollten sich auch analog auf Limiteds übertragen lassen, die keinen Verwaltungssitz in Deutschland haben und hier wirtschaftlich tätig sind.

Als Ergebnis ist festzuhalten, dass in Folge der Rechtsprechung des EuGH zur Niederlassungsfreiheit zahlreiche Probleme im europäischen Wirtschaftsraum aufgetreten sind. Die Schaffung eines einheitlichen europäischen Binnenmarktes ist ein hehres Ziel, jedoch ist es bis dahin noch ein weiter Weg.

Die (gesellschaftsrechtlichen) Rechtssysteme der einzelnen Mitgliedstaaten sind zu verschieden, so dass dies nicht problemlos möglich ist. Ein gutes Beispiel dafür sind die Gründungs- und die Sitztheorie, die in ihren Grundannahmen zu verschieden sind, um harmonisch nebeneinander zu existieren. Ebenso brauchen die Bürger und Unternehmer Zeit, sich mit den neuen Möglichkeiten und Risiken vertraut zu machen. Eigentlich sollte sich in Deutschland mittlerweile jeder bewusst sein, mit welcher Unternehmensform er es zu tun hat, wenn er mit einer (haftungsbeschränkten) Limited Geschäfte macht. Bei ihr ergibt sich der Schutz der Gläubiger gerade nicht aus dem Vorhandensein eines Mindestkapitals, sondern daher, dass diese zur umfassenden Publizität gegenüber dem Companies House und damit der Öffentlichkeit verpflichtet ist. Dies muss beachtet werden, bei Geschäftsbeziehung bei einer solchen Gesellschaft. Ein Blick auf die Internetseite des Companies House sollte daher, gerade bei Aufnahme einer Geschäftsbeziehung mit einer „unbekannten“ Limited, unverzichtbar sein.

Das das englische System der Veröffentlichung von Informationen mit den daran angeknüpften Folgen für die Gesellschaft, Direktoren, Sekretäre bei Nichtbeachtung funktioniert beweist die Quote der „rein englischen“ Gesellschaften, die sich daran halten, diese lag in den vergangenen Jahren immer bei ca. $95 \%$. $^{335}$

\footnotetext{
${ }^{335}$ Vgl. m. w. N. Davies, P. L. (2008) S. 749.
} 
Befriedigende Lösungen können nur durch Regelungen auf europäischer Ebene geschaffen werden. Bis dahin darf es nicht Ziel der nationalen Gesetzgebung, Rechtsprechung und Literatur sein $\mathrm{zu}$ versuchen, die grundsätzlich verschiedenen Systeme krampfhaft aneinander anzupassen. Dadurch entstehen immer nur neue Schutzlücken. Speziell für diese Arbeit bedeutet das, dass Deutschland zuziehende Auslandsgesellschaften aus Gründungstheoriestaaten nicht problemlos in sein Gesellschaftsrechtssystem integrieren kann, da dieses auf der Sitztheorie basiert.

Vielmehr muss es darum gehen, bis zur Schaffung einer einheitlichen europäischen Vorschrift für ein bestimmtes Problem auf nationaler Ebene, eine sachgerechte Lösung zu finden. Nach diesem Grundsatz wurde in der vorliegenden Arbeit bei Betrachtung einer gelöschten Limited mit Restvermögen in Deutschland verfahren. Dies wurde durch die Qualifikation der Rest-Limited als reine Liquidationsgesellschaft erreicht. Nach Meinung des Autors können so unter Beachtung der Niederlassungsfreiheit und des Gesellschaftsstatuts der Limited die Interessen aller Beteiligten am besten werden. 


\section{Literaturverzeichnis}

Bachner, T. (2007),

Die Limited in der Insolvenz, Wien

Becht, M. u. a. (2008),

Where do firms incorporate? Deregulation and the cost of entry, in: Journal of Corporate Finance, S. 241 ff.

Behrens, P. (Hrsg.) (1997),

Die Gesellschaft mit beschränkter Haftung im internationalen und europäischen Recht, 2. Aufl., Berlin

(zitiert: Bearbeiter in Behrens, P. (Hrsg.) (1997))

Borges, G. (2004),

Gläubigerschutz bei ausländischen Gesellschaften mit inländischem Sitz, in: ZIP, S. 733 ff.

Borges, G. (2005),

Der rechtliche Status einer im Registerstaat erloschenen Gesellschaft, in: IPRax, S. 134 ff.

Buchmann, T. (2007),

Die Insolvenz der englischen Limited in Deutschland. De lege lata sowie im Gefüge der Modernisierung des europäischen Gesellschaftsrechts, Baden-Baden

Davies, P. L. (2008),

Gower and Davies’ Principles of Modern Company Law, 8. Aufl., London

Department of Trade and Industry (Hrsg.) (2006),

Companies in 2005-2006. Report for the year ended 31 March 2006, London

Eidenmüller, H. (Hrsg.) (2004),

Ausländische Kapitalgesellschaften im deutschen Recht, München (zitiert: Bearbeiter in: Eidenmüller, H. (Hrsg.) (2004)) 
Fritz, D. F./Herrmann O. (Hrsg.) (2008),

Die Private Limited Company in Deutschland, Münster

(zitiert: Bearbeiten in: Fritz, D. F./Herrmann O. (Hrsg.) (2008))

Goode, R. (2005),

Principles of Corporate Insolvency Law, 3. Aufl., London

Graf von Bernstorff, C. (2006),

Einführung in das englische Recht, 3. Aufl., München

Heckel, M. (2006),

Das Fiskuserbrecht im Internationalen Privatrecht. Eine rechtsvergleichende Untersuchung im Hinblick auf ein künftiges europäisches Erbkollisionsrecht, Tübingen

Herdegen, M. (2005),

Internationales Wirtschaftsrecht, 5. Aufl., München

Hirte H./Bücker T. (Hrsg.) (2006),

Grenzüberschreitende Gesellschaften - Praxishandbuch für ausländische Kapitalgesellschaften mit Sitz im Inland, 2. Aufl., Köln (zitiert: Bearbeiter in: Hirte H./Bücker T. (Hrsg.) (2006))

Hoffmann, B. von/Thorn, K. (2005),

Internationales Privatrecht, 8. Aufl., München

Höfling, B. S. (2002),

Das englische internationale Gesellschaftsrecht, Heidelberg

Ing, N. D. (1971),

Bona Vacantia, London

Job, A. (2007),

Besteuerung und Rechnungslegung ausländischer Kapitalgesellschaften mit inländischem Verwaltungssitz. Dargestellt am Beispiel einer englischen private limited company, Frankfurt am Main 
Just, C. (2005),

Die englische Limited in der Praxis, München

Just, C. (2008a),

Die englische Limited in der Praxis, 3. Aufl., München

Just, C. (Hrsg.) (2008b),

Englisches Gesellschaftsrecht. Companies Act 2006, Limited Liability Partnerships Act 2000, München

Kienzl, F. (2008),

Gläubigerschutz bei zuziehenden EU-Auslandsgesellschaften am Beispiel der englischen private company Limited by shares, Augsburg

Krömker, M./Otte, S. (2008),

Die gelöschte Limited mit Restvermögen in Deutschland: Stehen Gläubiger und Gesellschafter im Regen?, in: BB, S. 964 ff.

Krüger, H./Mansel, H. P. (Hrsg.) (2002),

Liber amicorum Gerhard Kegel, München

(zitiert: Bearbeiter in: Krüger, H./Mansel, H. P. (Hrsg.) (2002))

Leible, S./Lehmann, M. (2007),

Auswirkung der Löschung einer Private Limited Company auf ihr in Deutschland belegenes Vermögen, in: GmbHR, S. 1095 ff.

Lembeck, E. D. (2003),

UK Company Law Reform - Ein Überblick, in: NZG, S. 956 ff.

Lyall, F. (2002),

An Introduction to British Law, 2. Aufl., Baden-Baden

Münchener Kommentar zum Bürgerlichen Gesetzbuch (2006),

Band 11. EGBGB (Art 50-245). Internationales Handels- und Gesellschaftsrecht, 4. Aufl., München

(zitiert: Bearbeiter in: MünchKomm (2006), IntGesR) 
Neuhaus, P. H. (1976),

Die Grundbegriffe des internationalen Privatrechts, 2. Aufl., Tübingen

Niemeier, W. (2006),

GmbH und Limited im Markt der Unternehmensrechtsträger, in: ZIP, S. 2237 ff.

Niemeier, W. (2007),

Die "Mini-GmbH" (UG) trotz Marktwende bei der Limited?, in: ZIP, S. 1794 ff.

Palandt, O. (2007),

Bürgerliches Gesetzbuch, 66. Aufl, München

(zitiert: Bearbeiter in Palandt, O. (2007))

Redmond, P. W. D./Shears, P. (1990),

General Principles of English Law, 6. Aufl., London

Römermann, V. (Hrsg.) (2006),

Private Limited Company in Deutschland. Praxis-Leitfaden für Berater und Unternehmer, Bonn u. a.

(zitiert: Bearbeiter in: Römermann, V. (Hrsg.) (2006))

Schmidt, J. (2007),

Kommentar zu OLG Jena 2007-08-22 6 W, in ZIP, S. 1712 ff.

Schmidt, J. (2008),

Verfahren und Gefahren bei der Liquidation einer „Rest-Limited“, in: ZIP, S. 2400 ff.

Schmittmann, J. M. (2007),

Die scheinausländische Gesellschaft, in: NZI, S. V. ff.

Segner, K./Matuszok, T. (2009),

Limited oder Mini-GmbH?, München. 
Staudinger, J. von (1998),

Kommentar zum Bürgerlichen Gesetzbuch mit Einführungsgesetz und Nebengesetzen. EGBGB/IPR, Internationales Gesellschaftsrecht, Berlin (zitiert: Bearbeiter in: Staudinger, J. von (1998); IntGesR)

Staudinger, J. von (2003),

Kommentar zum Bürgerlichen Gesetzbuch mit Einführungsgesetz und Nebengesetzen. EGBGB/IPR, Einleitung zum IPR, Art. 3-6 EGBGB, 13 Aufl., Berlin (zitiert: Bearbeiter in: Staudinger, J. von (2003), Einl. IPR)

Vallender, H. (2006),

Die Insolvenz von Scheinauslandsgesellschaften, in: ZGR, S. 425 ff.

Wachter, T. (Hrsg.) (2007),

Handbuch das Fachanwalts für Handels- und Gesellschaftsrecht, Münster (zitiert: Bearbeiter in: Wachter, T. (Hrsg.) (2007))

Westhoff, O. (2007),

Die Verbreitung der englischen Limited mit Verwaltungssitz in Deutschland, in: GmbHR, S. 474 ff.

Wilms, T. (2006),

Die englische Limited in deutscher Insolvenz. Nach Centros, Überseering und Inspire Art, Baden-Baden

Zessel, M. (2008),

Durchgriffshaftung gegenüber einer in Deutschland ansässigen Limited?,

Baden-Baden

Zimmer, D./Naendrup, C. (2007),

For Whom the Bell Tolls - Folgen einer Nichtbeachtung englischer Publizitätsgebote durch in Deutschland aktive Limited Companies, in: ZGR, S. 789 ff. 


\section{Internetquellenverzeichnis}

Department for Business, Enterprise and Regulatory Reform, www.berr.gov.uk

Companies House,

www.companieshouse.gov.uk

Bundesministerium der Justiz, www.bmj.de

L4You Ltd., www.limited4you.de

Statistisches Bundesamt, www.destatis.de 


\section{Anhang}

\section{Anhang 1: Table of Commencement Dates ${ }^{336}$}

The attached table is intended to provide guidance on the commencement timetable for the Companies Act 2006. It cannot, however, provide a definitive guide: you may therefore also wish to refer to the relevant commencement order. (The eight commencement orders are published on the OPSI_website, with direct links from BERR's Companies Act website.)

The colour shading reflects the main commencement date for each part.

Provisions relating to accounts and reports were generally commenced for financial years beginning on or after the relevant date (e. g. paragraph 43 in Schedule 3 to the Third Commencement Order provides that "Section 417 of the Companies Act 2006 (contents of directors' report: business review) applies to directors' reports for financial years beginning on or after 1 October 2007”).

The commencement of powers to make orders or regulations by statutory instrument does not necessarily mean that the Government intends to use the powers as part of its implementation of the Act.

Some provisions (e. g. definitions) were progressively brought into force for the purposes of each tranche of provisions commenced, and have been finally commenced completely from 1 October 2009.

Following the final commencement on 1 October 2009, four provisions will not have been commenced. These are:

- section $327(2)(c)$

- section 330(6)(c)

- section 1175 as it applies in Northern Ireland

- Part 2 of Schedule 9

\begin{tabular}{|l|l|l|}
\hline 1 & $\begin{array}{l}\text { General introductory provisions (1-6) } \\
\text { Section 2: 6 April 2007 }\end{array}$ & 1 October 2009 \\
\hline 2 & Company formation (7-16) & 1 October 2009 \\
\hline 3 & $\begin{array}{l}\text { A company's constitution (17-38) } \\
\text { Sections 29 \& 30: 1 October 2007 }\end{array}$ & 1 October 2009 \\
\hline 4 & $\begin{array}{l}\text { A company's capacity and related matters (39-52) } \\
\text { Section 44: 6 April 2008 }\end{array}$ & 1 October 2009 \\
\hline 5 & $\begin{array}{l}\text { A company's name (53-85) } \\
\text { Sections 69 to 74: 1 October 2008 } \\
\text { Sections 82 to 85: } 1 \text { October 2008 }\end{array}$ & 1 October 2009 \\
\hline
\end{tabular}

336 Quelle: BERR (Hrsg.) (2008), Companies Act 2006: table of commencement dates, http://www.berr.gov.uk/files/file48793.pdf, 18.04.2009. 


\begin{tabular}{|c|c|c|}
\hline 6 & A company's registered office (86-88) & 1 October 2009 \\
\hline 7 & Re-registration as a means of altering a company's status (89-111) & 1 October 2009 \\
\hline 8 & $\begin{array}{l}\text { A company's members }(112-144) \\
\text { Sections } 116 \text { to } 119: 1 \text { October } 2007 \\
\text { Sections } 121 \& 128: 6 \text { April } 2008\end{array}$ & 1 October 2009 \\
\hline 9 & Exercise of members' rights (145-153) & 1 October 2007 \\
\hline 10 & $\begin{array}{l}\text { A company's directors (154-259) } \\
\text { Sections } 155 \text { to } 159: 1 \text { October } 2008 \\
\text { Sections } 162 \text { to } 167: 1 \text { October } 2009 \\
\text { Sections } 175 \text { to } 177: 1 \text { October } 2008 \\
\text { Sections } 180(1),(2)(\text { in part), \& (4)(b), and } 181(2) \&(3): 1 \text { October } \\
2008 \\
\text { Sections } 182 \text { to } 187: 1 \text { October } 2008 \\
\text { Sections } 240 \text { to } 247: 1 \text { October } 2009\end{array}$ & 1 October 2007 \\
\hline 11 & Derivative claims and proceedings by members $(260-269)$ & 1 October 2007 \\
\hline 12 & $\begin{array}{l}\text { Company secretaries }(270-280) \\
\text { Section 270(3)(b)(ii): } 1 \text { October } 2009 \\
\text { Sections } 275 \text { to } 279: 1 \text { October } 2009\end{array}$ & 6 April 2008 \\
\hline 13 & $\begin{array}{l}\text { Resolutions and meetings (281-361) } \\
\text { Sections 308 \& 309: } 20 \text { January } 2007 \\
\text { Section 333: } 20 \text { January } 2007 \\
\text { Sections 327(2)(c) \& 330(6)(c) are not being commenced. }\end{array}$ & 1 October 2007 \\
\hline 14 & $\begin{array}{l}\text { Control of political donations and expenditure (362-379) } \\
\text { Provisions relating to independent election candidates: } 1 \text { October } \\
2008 \\
\text { Part } 14 \text { came into force in Northern Ireland on } 1 \text { November } 2007 \text {, } \\
\text { except for provisions relating to independent election candidates. }\end{array}$ & 1 October 2007 \\
\hline 15 & $\begin{array}{l}\text { Accounts and reports (380-474) } \\
\text { Section 417: } 1 \text { October } 2007 \\
\text { Section 463: } 20 \text { January } 2007 \text { for reports and statements first sent } \\
\text { to members and others after that date }\end{array}$ & 6 April 2008 \\
\hline 16 & $\begin{array}{l}\text { Audit }(475-539) \\
\text { Sections } 485 \text { to } 488: 1 \text { October } 2007\end{array}$ & 6 April 2008 \\
\hline 17 & $\begin{array}{l}\text { A company's share capital (540-657) } \\
\text { Section 544: } 6 \text { April } 2008 \\
\text { Sections 641(1)(a) \& (2)-(6), 642-644, 652(1) and (3) \& 654: } 1 \\
\text { October } 2008\end{array}$ & 1 October 2009 \\
\hline 18 & $\begin{array}{l}\text { Acquisition by limited company of its own shares (658-737) } \\
\text { Repeal of the restrictions under the Companies Act } 1985 \text { on } \\
\text { financial assistance for acquisition of shares in private companies, } \\
\text { including the "whitewash" procedure: } 1 \text { October } 2008\end{array}$ & 1 October 2009 \\
\hline 19 & Debentures $(738-754)$ & 6 April 2008 \\
\hline 20 & Private and public companies (755-767) & 6 April 2008 \\
\hline 21 & Certification and transfer of securities (768-790) & 6 April 2008 \\
\hline 22 & $\begin{array}{l}\text { Information about interests in a company's shares (791-828) } \\
\text { Sections } 811(4), 812,814: 6 \text { April } 2008\end{array}$ & 20 January 2007 \\
\hline 23 & Distributions (829-853) & 6 April 2008 \\
\hline 24 & A company's annual return (854-859) & 1 October 2009 \\
\hline 25 & Company charges (860-894) & 1 October 2009 \\
\hline 26 & Arrangements and reconstructions (895-901) & 6 April 2008 \\
\hline 27 & Mergers and divisions of public companies (902-941) & 6 April 2008 \\
\hline 28 & Takeovers etc (942-992) & 6 April 2007 \\
\hline
\end{tabular}




\begin{tabular}{|c|c|c|}
\hline 29 & Fraudulent trading (993) & 1 October 2007 \\
\hline 30 & Protection of members against unfair prejudice (994-999) & 1 October 2007 \\
\hline 31 & Dissolution and restoration to the register (1000-1034) & 1 October 2009 \\
\hline 32 & Company investigations: amendments (1035-1039) & 1 October 2007 \\
\hline 33 & $\begin{array}{l}\text { UK companies not formed under the Companies Acts (1040-1043) } \\
\text { Section 1043: } 6 \text { April } 2007\end{array}$ & 1 October 2009 \\
\hline 34 & Overseas companies (1044-1059) & 1 October 2009 \\
\hline 35 & $\begin{array}{l}\text { The registrar of companies (1060-1120) } \\
\text { Section } 1063 \text { (in respect of England, Wales and Scotland): } 6 \text { April } \\
2007 \\
\text { Section } 1068(5): 1 \text { January } 2007 \\
\text { Sections } 1077 \text { to } 1080: 1 \text { January } 2007 \\
\text { Sections } 1085 \text { to } 1092: 1 \text { January } 2007 \\
\text { Sections } 1102 \text { to } 1107: \text { I January } 2007 \\
\text { Section } 111: 1 \text { January } 2007\end{array}$ & 1 October 2009 \\
\hline 36 & $\begin{array}{l}\text { Offences under the Companies Acts (1121-1133) } \\
\text { Section 1124: } 1 \text { October } 2007 \\
\text { Section 1126: } 6 \text { April } 2008\end{array}$ & $\begin{array}{l}\text { With relevant } \\
\text { provisions }\end{array}$ \\
\hline 37 & $\begin{array}{l}\text { Companies: supplementary provisions (1134-1157) } \\
\text { Section } 1137(1),(4),(5)(\text { b) and (6): } 30 \text { September } 2007 \\
\text { Sections } 1143 \text { to } 1148: 20 \text { January } 2007 \\
\text { Section } 1157: 1 \text { October } 2008\end{array}$ & $\begin{array}{l}\text { With relevant } \\
\text { provisions }\end{array}$ \\
\hline 38 & $\begin{array}{l}\text { Companies: interpretation (1158-1174) } \\
\text { Sections 1161, 1162, 1164, 1165, } 1169 \text { and } 1172: 6 \text { April } 2008 \\
\text { Section 1167: } 30 \text { September } 2007 \\
\text { Section 1170: } 6 \text { April } 2007\end{array}$ & $\begin{array}{l}\text { With relevant } \\
\text { provisions }\end{array}$ \\
\hline 39 & $\begin{array}{l}\text { Companies: minor amendments (1175-1181) } \\
\text { Section } 1175 \text { (in relation to England \& Wales and Scotland): } 1 \\
\text { April 2008 } \\
\text { Sections 1180: } 1 \text { October } 2009 \\
\text { Section 1181: } 1 \text { October } 2009\end{array}$ & 6 April 2007 \\
\hline 40 & Company directors: foreign disqualification etc (1182-1191) & 1 October 2009 \\
\hline 41 & Business names (1192-1208) & 1 October 2009 \\
\hline 42 & $\begin{array}{l}\text { Statutory auditors (1209-1264) } \\
\text { Sections } 1242 \text { to } 1244: 29 \text { June } 2008 \\
\end{array}$ & 6 April 2008 \\
\hline 43 & Transparency obligations and related matters (1265-1273) & Royal Assent \\
\hline 44 & $\begin{array}{l}\text { Miscellaneous provisions (1274-1283) } \\
\text { Sections 1274 and 1276: Royal Assent } \\
\text { Section 1275: } 1 \text { October 2009 } \\
\text { Sections 1277 to 1280: } 1 \text { October } 2008 \\
\text { Section 1281: } 6 \text { April 2007 } \\
\text { Section 1282: } 6 \text { April 2008 } \\
\text { Section 1283: } 1 \text { October 2009 }\end{array}$ & \\
\hline 45 & Northern Ireland (1284-1287) & $\begin{array}{l}\text { With relevant } \\
\text { provisions }\end{array}$ \\
\hline 46 & $\begin{array}{l}\text { General supplementary provisions (1288-1297) } \\
\text { Section 1295: With relevant provisions }\end{array}$ & Royal Assent \\
\hline 47 & Final provisions $(1298-1300)$ & Royal Assent \\
\hline
\end{tabular}




\section{Selbständigkeitserklärung}

Ich erkläre hiermit, dass ich die vorliegende Diplomarbeit selbständig angefertigt und nur die angegebenen Quellen und Hilfsmittel verwendet habe.

Berlin, 29.04.2009

Kay Müller 